\title{
Acceleration and Volumetric Strain generated by the Parkfield 2004 Earthquake on the GEOS Strong-Motion Array near Parkfield, CA
}

\author{
By \\ Roger D. Borcherdt, Malcolm J.S. Johnston, Christopher Dietel, Gary \\ Glassmoyer, Doug Myren, and Christopher Stephens \\ U.S. Geological Survey \\ Open-File Report 2004-1376
}

October 11,2004

Any use of trade, product, or firm names is for descriptive purposes only and does not imply endorsement by the U. S. Government. 


\title{
Acceleration and Volumetric Strain generated by the Parkfield 2004 Earthquake on the GEOS Strong-Motion Array near Parkfield, CA
}

\author{
Roger D. Borcherdt, Malcolm J.S. Johnston, Christopher Dietel, Gary Glassmoyer, Doug \\ Myren, and Christopher Stephens
}

U.S. Geological Survey (MS 977), 345 Middlefield Road, Menlo Park, CA 94025

\begin{abstract}
An integrated array of 11 General Earthquake Observation System (GEOS) stations installed near Parkfield, CA provided on scale broad-band, wide-dynamic measurements of acceleration and volumetric strain of the Parkfield earthquake (M 6.0) of September 28, 2004. Three component measurements of acceleration were obtained at each of the stations. Measurements of collocated acceleration and volumetric strain were obtained at four of the stations. Measurements of velocity at most sites were on scale only for the initial P-wave arrival. When considered in the context of the extensive set of strong-motion recordings obtained on more than 40 analog stations by the California Strong-Motion Instrumentation Program (Shakal, et al., 2004 http://www.quake.ca.gov/cisn-edc) and those on the dense array of Spudich, et al, (1988), these recordings provide an unprecedented document of the nature of the near source strong motion generated by a M 6.0 earthquake. The data set reported herein provides the most extensive set of near field broad band wide dynamic range measurements of acceleration and volumetric strain for an earthquake as large as M 6 of which the authors are aware. As a result considerable interest has been expressed in these data. This report is intended to describe the data and facilitate its use to resolve a number of scientific and engineering questions concerning earthquake rupture processes and resultant near field motions and strains. This report provides a description of the array, its scientific objectives and the strong-motion recordings obtained of the main shock. The report provides copies of the uncorrected and corrected data. Copies of the inferred velocities, displacements, and Psuedo velocity response spectra are provided. Digital versions of these recordings are accessible with information available through the internet at several locations: the National Strong-Motion Program web site (http://agram.wr.usgs.gov/), the COSMOS Virtual Data Center Web site (http://www.cosmos-eq.org), and the CISN Engineering and Berkeley data centers (http://www.quake.ca.gov/cisn-edc). They are also accessible together with recordings on the GEOS Strong-motion Array near Parkfield, CA since its installation in 1987 through the USGS GEOS web site ( http://nsmp.wr.usgs.gov/GEOS).
\end{abstract}

\section{INTRODUCTION}

The suggested occurrence of a repeat moderate $M \sim 6.0$ earthquake on the San Andreas Fault near Parkfield, CA (Bakun and McEvilly, 1984) triggered the design of many near source experiments focused on understanding the nature of the crustal failure processes and resultant seismic radiation fields associated with moderate earthquakes. This segment of the San Andreas ruptured during the 1966 Parkfield earthquake and was initially anticipated to rupture by 1993 
(Bakun and Lindh, 1985). The GEOS strong-motion array was installed along this segment of the San Andreas Fault (Borcherdt and Johnston, 1988) to provide on-scale broad-band, high resolution, near-source measurements of acceleration, velocity, and volumetric strain at high sampling rates. The array was designed to provide strong-motion and wide dynamic range signals to address a variety of near source scientific and engineering issues. The array has been in operation since completion of its installation in 1987.

The occurrence of the Parkfield earthquake of September 28, 2004 along the same segment of the San Andreas Fault that ruptured during the 1966 Parkfield earthquake has provided a unique set of measurements on an array designed for the purpose of recording this particular earthquake. This report provides a detailed description of the array and the resultant strongmotion measurements of the main shock.

\section{ARRAY DESIGN}

The GEOS strong-motion array was designed to provide on-scale broad-band- high resolution measurements of earthquakes occurring along the segment of the San Andreas fault that ruptured during the 1966 Parkfield earthquake (Borcherdt and Johnston, 1988). In conjunction with long period strain measurement efforts conducted by Johnston (Johnston, et al., 1982) the GEOS array is designed to provide short period measurements from collocated accelerometers, velocity transducers, and volumetric strain meters in order to obtain high resolution on-scale measurements of seismic radiation fields in the near source region over a wide range in earthquake magnitude. The array is designed to provide on-scale measurements of ground motions ranging in amplitude from near seismic background noise level to $2 \mathrm{~g}$ in acceleration using collocated velocity transducers and accelerometers. In addition, the array is designed to provide collocated measurements of volumetric strain at some of the sites with measurable signal levels ranging in amplitude from levels as low as $10^{-11}$ to levels exceeding $10^{-6}$ strain.

The use of volumetric strain sensors, also termed dilatometers (Sacks, et al., 1971) in the array extends the bandwidth for observation of near source motions to periods longer than those detectable by accelerometers or seismometers. The bandwidth afforded by the dilatometers allows pre-, co-, and post- seismic strain changes to be observed over time intervals ranging from several months to about 0.02 seconds. The wide dynamic range of the sensors allows the sensors to measure on-scale strong-motion signals as generated in the near source region as well as small strain variations, including changes in DC level that are more than 5 orders of magnitude less at earth strain noise levels.

Stations in the array are distributed within and along both sides of the fault zone out to distances of about $10 \mathrm{~km}$. The locations of the stations, the San Andreas Fault and epicenters for the main shock and the largest aftershocks in the first 40 hours are shown in Figure 1. Station identification, coordinates, and distances, and azimuth are tabulated in Table 1.

The array as presently configured comprises 12 stations. All of the stations are equipped with collocated three-component accelerometers (FBA 13, natural frequency $100 \mathrm{~Hz}, \pm 2 \mathrm{~g}$ full scale; Kinemetrics, Inc.) and velocity transducers. Four of the stations are also equipped with borehole volumetric strain meters.

The signals from the sensors at each site are recorded on a six channel General Earthquake Observation System (GEOS) recorder (Borcherdt et al., 1985). The systems permit the recording 
of \pm 10 volt input signals in either AC or DC coupled modes with up to $84 \mathrm{~dB}$ gain in $6 \mathrm{~dB}$ steps at 16 bit $(96 \mathrm{~dB})$ resolution to provide a maximum dynamic range near $180 \mathrm{~dB}$ at 1 second.

Event and instrument parameters are transmitted via GOES satellite at 10-minute intervals. Parameters such as trigger time, peak amplitude, time of peak amplitude and duration together with a variety of instrument status parameters are transmitted. The satellite transmissions permit the retrieval of critical event and instrument status information in near real time (Mueller, et al. 1995). Sensor and recording system calibrations are recorded before and after each storage media change.

The signals from the three-component accelerometers and three component velocity transducers are recorded at each of the sites not collocated with a dilatometer. At the dilatometer sites the signal from the volumetric strain meters is recorded in both AC and DC coupled modes with the AC signal recorded at two gain levels differing by $30 \mathrm{~dB}$. The dilatometer signal is recorded in both $\mathrm{AC}$ and $\mathrm{DC}$ modes to permit accurate measurement of co-seismic strain changes as well as resolution of high frequency strain variations. In addition, the signals from the dilatometers are recorded continuously via GOES satellite telemetry to Menlo Park at a lower sampling rate of 1 sample per 10 minutes.

Remoteness of the sites required that low-power recording systems (GEOS is less than about 2 watts quiescence) be used with solar cells providing power to commercially available car batteries. For long term deployment purposes, power consumption is further reduced by programming the systems to record in event-detect mode. At the time of the earthquake the systems were programmed to trigger on relatively strong events to minimize maintenance visits. The vertical component of velocity recorded at each site was used as the trigger channel.

For the sites equipped with accelerometers and velocity transducers, gains were programmed for the recorders so that signals over a dynamic range exceeding $130 \mathrm{~dB}$ could be detected over a bandwidth of about 15 to 0.02 seconds $(0.06$ to $50 \mathrm{~Hz})$ with this bandwidth varying some depending on the strength of the input signal. For sites equipped with accelerometers and dilatometers, the lower limit of resolution for acceleration is near $6 \times 10^{-6} \mathrm{~g}$ and that for volumetric strain near $10^{-11}$ strain.

The period bandwidth for detection of volumetric strain with the signals recorded on both GEOS and continuously via satellite telemetry is greater than $10^{8}$ to 0.05 seconds at earth-strain noise levels (Johnston and Borcherdt, 1984). An average estimate of earth-strain noise is shown in Figure 2. This spectrum derived earlier for a site in the eastern Mojave Desert, California illustrates the bandwidth and detection levels for the volumetric strain meters. This spectrum is nearly the same as a similar spectrum of average earth strain noise derived from dilatometer recordings at the Gold Hill site in the mid 1980's (Johnston and Linde, 2002). The spectrum shows local maxima due to microseisms near 4 and 8 seconds and earth tides near 12 and 24 hours and a decrease in noise with period of about $10 \mathrm{~dB}$ per decade. The spectrum shows a detection bandwidth of more than 8 orders of magnitude at earth-noise levels. Maximum strain detection limits of $10^{-6}$ strain for the dilatometers located at depths of 150-200 m suggests a dynamic range for strain detection of $145-150 \mathrm{~dB}$.

The theory and interpretation of collocated temporal derivatives of the displacement field as inferred from accelerometers or velocity transducers and divergence of the displacement field as inferred from volumetric strain meters are provided by Borcherdt, (1988), Borcherdt and 
Johnston, (1988), Johnston et al, (1986), Borcherdt, Johnston and Glassmoyer (1989), Borcherdt and Glassmoyer (1989).

\section{UNPROCESSED STRONG-MOTION MEASUREMENTS OF ACCELERATION AND VOLUMETRIC STRAIN OF THE PARKFIELD 2004 EARTHQUAKE}

Plots of the original uncorrected acceleration time histories and the corresponding volumetric strain time histories are shown in Figures 3-18 for 17 seconds commencing about 2 seconds before the arrival of the first $\mathrm{P}$ wave signal. Plots of only 17 seconds of the recordings are provided to illustrate the signal resolution recorded from the two types of sensors. The plots are arranged in order of epicentral distance of the corresponding recording site. Plots of only 9 seconds of the acceleration time history are provided for the Work Ranch recording, because infrequent servicing intervals had lead to the recording media at this site being near maximum capacity at the time of the earthquake. No recordings of the main shock were obtained at the Chalome station (PG-CFU), because washed-out roads had prevented this site from being serviced for logistic difficulties for a 12-month period prior to the earthquake. The recording capacity of the recorder at this site was exceeded at the time of the main shock, but the system was still operational. Rapid changes in strain observed at Vineyard Canyon via satellite suggest that further calibration and evaluation of the signal recorded at this station are warranted. Users are advised to treat the recording at this site as preliminary. Similarly, the recording of vertical acceleration at the Stockdale Mountain site is being further evaluated and should be considered as preliminary.

\section{PROCESSED STRONG-MOTION MEASUREMENTS OF ACCELERATION OF THE PARKFIELD 2004 EARTHQUAKE}

Plots of processed acceleration time histories are provided in Figures 19-29. These plots show acceleration, velocity and displacement time histories inferred using standard procedures developed to process strong-motion records (Stephens and Boore, 2004). The time histories are plotted for a time interval of 45 seconds. The actual time histories are generally significantly longer than 45 seconds, with the exception of those from the Work Ranch site. The length of the original triggered recordings in some cases exceeds 400 seconds. The digital time histories are being archived at their maximum length, but generally not longer than 180 seconds.

The long period corner selected for the low cut filter to provide the processed acceleration time history was determined individually for each recording from visual examination of the corresponding Fourier amplitude spectra. The corners were chosen at the period where the spectra indicated the long period noise levels were greater than earthquake generated signal levels. The corners chosen for each of the acceleration time histories are shown on the corresponding trace. Non-casual, second-order, Butterworth low-cut filters with a $6 \mathrm{~dB}$ per octave decay were applied to padded acceleration time histories to infer the corresponding velocity and displacement time histories. Filter parameters for each of the time histories are indicated on the corresponding trace and available in the Meta data being archived with each of the time histories. 


\section{COLLOCATED MEASUREMENTS OF ACCELERATION AND VOLUMETRIC STRAIN}

To better illustrate the broad bandwidth of the signals detected by the volumetric strain meters, plots of the signals recorded at the dilatometer sites are superimposed in Figures 30 - 34 . Plots of the volumetric strain signals as recorded via satellite telemetry over a 72 hour period centered on the time of occurrence of the main shock are shown as the first trace in each figure. Plots of the volumetric strain signals as recorded at 200 sps on GEOS for a 17 second interval are shown as the second trace in each figure. The corresponding acceleration time histories plotted for the same time interval are shown as traces 3-5.

Strain variations are evident at each of the sites (Figures 29-33) due to earth tides atmospheric pressure, and the co-seismic strain offset associated with the main shock. The coseismic offset associated with a magnitude 5 aftershock slightly more than one day later also is clearly evident at Froelich and Jack Canyon (Figures 30 and 31). The volumetric strain time histories recorded at high sampling rates (trace 2) emphasize the longer period response capabilities of the dilatometer in comparison to that for the accelerometer. Further discussion of the response capabilities of the dilatometer in comparison to seismometers can be found in Borcherdt, Johnston, and Glassmoyer (1989).

\section{PSEUDO VELOCITY RESPONSE SPECTRA}

Response spectra computed from the corrected three-component acceleration time histories are shown in Figures 34-65. The spectra suggest a wide variation in energy content as a function of period for each site and component of motion. The spectra suggest that the motions recorded to the north of the epicenter are relatively richer in long period energy than those recorded south of the epicenter. This observation is consistent with the major rupture propagation in a northwesterly direction from the epicenter.

\section{DIGITAL DATA ARCHIVES}

Digital versions of these recordings are available from the internet at several locations. They are available from the web site maintained by the National Strong-Motion Program in COSMOS format at http://agram.wr.usgs.gov/ which is linked to the COSMOS Virtual Data Center Web site at http://www.cosmos-eq.org and to the CISN Engineering data center at http://www.quake.ca.gov/cisn-edc. The digital recordings also are archived together with the other recordings from the GEOS Strong-Motion Array at the USGS GEOS web site http://nsmp.wr.usgs.gov/GEOS.

\section{ACKNOWLEDGEMENTS}

Conscientious reviews by Janise Rodgers and Stan Silverman were helpful.

\section{REFERENCES}

Bakun, W.H., and A.G. Lindh, 1985, The Parkfield, California earthquake prediction experiment, Science, 229, 619-624. 
Borcherdt, R.D., Fletcher, J.B., Jensen, E.G., Maxwell, G.L., Van Schaack, J.R., Warrick, R.E., Cranswick, E., Johnston, M.J.S., and McClearn, R., 1985, A general earthquake observation system (GEOS): Bulletin of the Seismological Society of America, 75, p. 1783-1825.

Evertson, D. W., 1977, Borehole strain meters for seismology, Rep. ARL-TR-77-62, Appl. Research

Johnston, M.J.S., Borcherdt, R.D., and Linde, A.T., 1986, Short-period strain (0.1-105s): Near source strain field for an earthquake (ML 3.2) near San Juan Bautista, California: Journal of Geophysical Research, v. 91, p. 11,497-11,502.

Borcherdt, R.D., and Johnston, M.J.S., 1988, A broadband, wide dynamic range, strong-motion network near Parkfield, California USA for measurement of acceleration and volumetric strain: Ninth World Conference on Earthquake Engineering, Proceedings VIII, p. 125-130.

Borcherdt, R.D., 1988, Volumetric strain and particle displacements for body and surface waves in a general viscoelastic half-space: Geophysical Journal of the Royal Astronomical Society, v. 93, p. $215-228$.

Borcherdt, R.D., 1988, Recording strong motion-new methods and instrumentation in the U.S.: Jour. Int'l. Council Bldg. Res. (CIB), v. 16, p. 87-92.

Borcherdt, R.D., Johnston, M.J.S., and Glassmoyer, G., 1989, On the use of volumetric strain meters to infer additional characteristics of short-period seismic radiation: Bulletin of the Seismological Society of America, v. 79, p. 1006-1023.

Borcherdt, R.D., and Glassmoyer, G., 1989, An exact anelastic model for the free-surface reflection of P and S-I waves: Bulletin of the Seismological Society of America, v. 79, p. 842-859.

Mueller, R. J., M. Lee, M. J. S. Johnston, R. D. Borcherdt, G. Glassmoyer, and S. Silverman, 1995, Near-real time monitoring of seismic events and status of portable digital recorders using satellite telemetry, Bull. Seismol. Soc. Am., 85, 640-645.

Johnston, M. J. S. and R. D. Borcherdt, 1984, Earth strain in the period range 0.1-10,000 seconds at six borehole sites within the San Andreas fault system, EOS 65, 1015.

Johnston, M. J. S., Borcherdt, R. D., Gladwin, M. T., Glassmoyer, G., and Linde, A. T., 1987b, Static and dynamic strain during the ML5.9 Banning, Ca, earthquake on July 8, 1986, EOS 68, 1244.

Johnston, M. J. S., R. D. Borcherdt, and A. T. Linde, 1986, Short-period strain (0.1-105 s): nearsource strain field for an earthquake (ML 3.2) near San Juan Bautista, California, J. Geophys. Res. 91, 11,497-11,502.

Johnston, M. J. S., A. T. Linde, M. T. Gladwin, and R. D. Borcherdt, 1987, Fault failure with moderate earthquakes, Tectonophysics 144, 189-206.

Johnston, M. J. S., A. T. Linde, I. Sacks, and D. Myren, 1982, Borehole dilatometer strain array -Installation and preliminary results from the Mojave desert, EOS 63, 430.

Johnston, M. J. S. and A. T. Linde, 2002, Implications of crustal strain during conventional, slow, and silent earthquakes, Internat. Handbook of Earthq. and Engin. Seismology, 81 A, 589-605

Sacks, I.S., S. Suyehiro, D. W. Evertson,, and Y. Yamgishi, 1971, Sacks-Evertson strain meter, its installation in Japan and some preliminary results concerning strain steps, Papers meterrol. Geophys. 22, 195-207.

Silverman, S., C. Mortensen, and M. J. S. Johnston, 1989, A satellite-based digital data system for low-frequency geophysical data, Bull. Seis. Soc. Am., 79, 189-198.

Stephens, C. and D. M. Boore, 2004, ANSS/NSMP strong-motion processing procedures, Proc., COSMOS Invited Workshop on Record Processing Guidelines, COSMOS, Richmond, CA.

Spudich, P., Baker, L., and Fletcher, J., 1988, The USGS dense seismic array at Parkfield, California: Instrumentation and data analysis, in Yeh, Y.T., and Chiu, H.C., eds., International Workshop on Strong Motion Arrays, 2nd, Taipai, Taiwan, 16-19 Jan. 1988, Proceedings: Taipai, Taiwan, Institute of Earth Sciences, Academic Sinica, p. 123-134. 
Table 1. Coordinates of stations in the General Earthquake Observation System (GEOS)strong-motion array near Parkfield, CA operated by the U.S. Geological Survey.

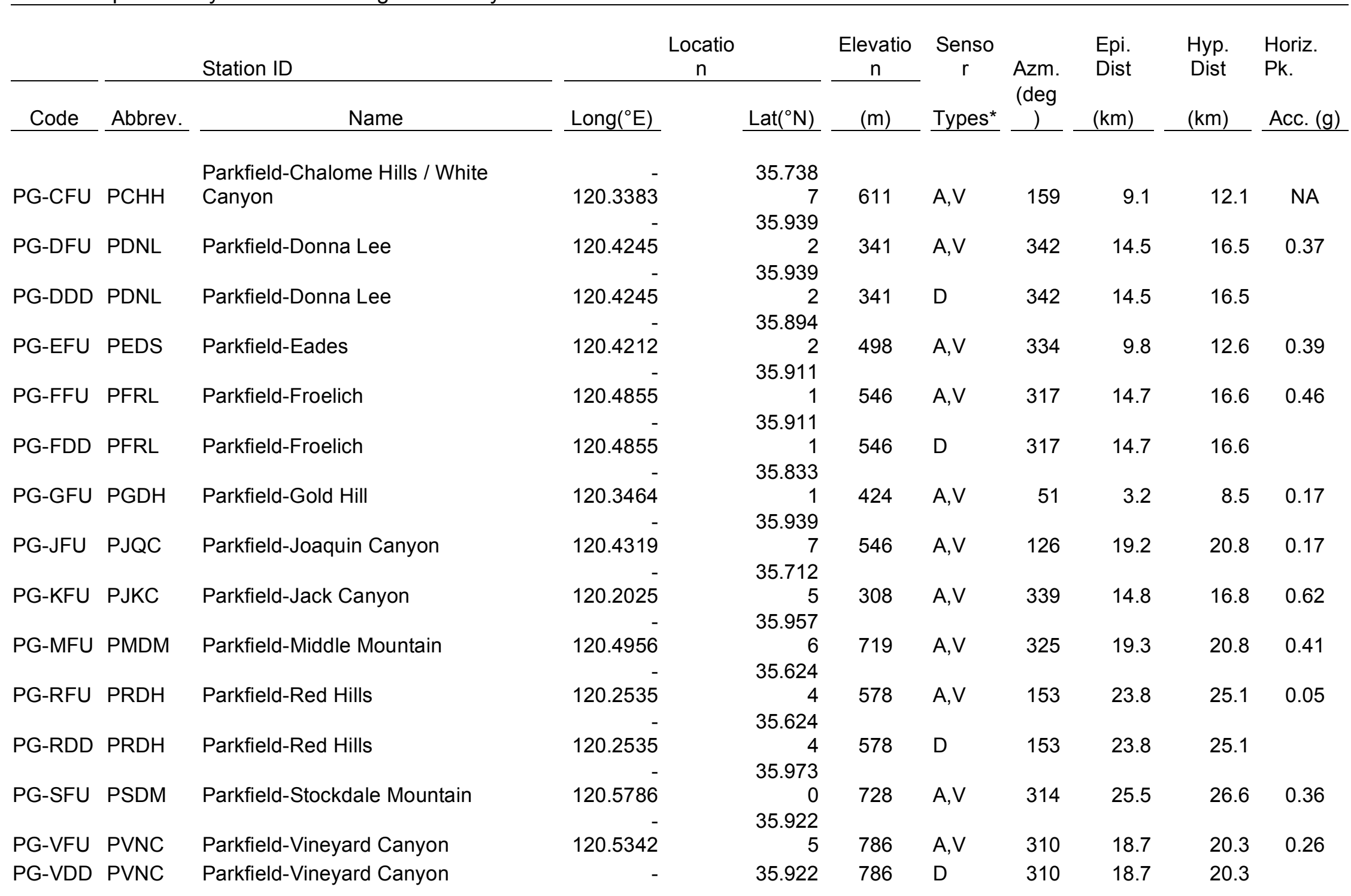


PG-

120.5342

WFU

PWKR Parkfield-Work Ranch

120.5111

${ }^{*} \mathrm{~A}=$ Accelerometer $; \mathrm{V}=$ Velocity Transducer $; \mathrm{D}=$ Dilatometer 
Table 2. Peak horizontal acceleration, velocity and Psudeo Spectral Acceleration at 0.3, 1.0, and

3.0 seconds as inferred from the GEOS acceleration recordings of the Parkfield, CA earthquake of September 28, 2004.

\begin{tabular}{|c|c|c|c|c|c|c|c|c|}
\hline & & Station ID & Orient & $\mathrm{Pk}$ Acc & $\mathrm{Pk}$ Vel & & PSA & \\
\hline Code & Abbrev. & Name & & $\mathrm{cm} / \mathrm{s} / \mathrm{s}$ & $\mathrm{cm} / \mathrm{s}$ & $0.3 \mathrm{~s}$ & $1.0 \mathrm{~s}$ & $3.0 \mathrm{~s}$ \\
\hline PG-DFU & PDNL & Parkfield-Donna Lee & UP & 171.0 & 9.0 & 20.3 & 4.41 & 0.832 \\
\hline & & & $\mathrm{N}$ & 366.0 & -13.9 & 42.3 & 10.20 & 1.540 \\
\hline & & & $E$ & 289.0 & -15.1 & 31.4 & 12.70 & 2.350 \\
\hline PG-EFU & PEDS & Parkfield-Eades & UP & -192.0 & 7.4 & 18.5 & 9.70 & 0.991 \\
\hline & & & $\mathrm{N}$ & -384.0 & -25.8 & 46.1 & 39.80 & 3.220 \\
\hline & & & $E$ & 312.0 & -26.7 & 37.5 & 37.30 & 4.210 \\
\hline PG-FFU & PFRL & Parkfield-Froelich & UP & -215.0 & -6.7 & 14.1 & 10.50 & 1.100 \\
\hline & & & $\mathrm{N}$ & 378.0 & -11.1 & 23.5 & 15.40 & 2.590 \\
\hline & & & E & 448.0 & -17.5 & 54.2 & 9.81 & 1.760 \\
\hline PG-GFU & PGDH & Parkfield-Gold Hill & UP & -116.0 & -2.1 & 7.1 & 1.83 & 0.569 \\
\hline & & & $\mathrm{N}$ & 137.0 & -5.7 & 13.8 & 2.99 & 1.040 \\
\hline & & & E & -168.0 & 6.0 & 15.0 & 3.67 & 0.575 \\
\hline PG-JFU & PJQC & Parkfield-Joaquin Canyon & UP & -302.0 & 9.6 & 55.9 & 4.91 & 0.682 \\
\hline & & & $\mathrm{N}$ & -609.0 & 25.5 & 122.0 & 18.30 & 1.900 \\
\hline & & & $E$ & 487.0 & -30.3 & 73.9 & 21.30 & 3.720 \\
\hline PG-KFU & PJKC & Parkfield-Jack Canyon & UP & -159.0 & 4.4 & 9.9 & 2.54 & 0.381 \\
\hline & & & $\mathrm{N}$ & -167.0 & 10.7 & 23.4 & 7.36 & 0.730 \\
\hline & & & $\mathrm{E}$ & -144.0 & -6.1 & 18.7 & 7.16 & 0.509 \\
\hline PG-MFU & PMDM & Parkfield-Middle Mountain & UP & -108.0 & 8.4 & 33.6 & 7.29 & 1.600 \\
\hline & & & $\mathrm{N}$ & -402.0 & 29.4 & 108.0 & 16.10 & 6.190 \\
\hline & & & $E$ & 181.0 & -26.0 & 50.5 & 22.40 & 6.900 \\
\hline PG-RFU & PRDH & Parkfield-Red Hills & UP & 53.0 & 1.7 & 5.2 & 2.85 & 0.225 \\
\hline & & & $\mathrm{N}$ & -46.7 & -3.1 & 9.3 & 3.78 & 0.265 \\
\hline & & & $E$ & -44.5 & 1.8 & 6.0 & 1.59 & 0.111 \\
\hline PG-SFU & PSDM & Parkfield-Stockdale Mtn. & $S$ & -229.1 & 6.8 & 26.6 & 3.75 & 0.601 \\
\hline & & & W & -347 & 8.1 & 27.3 & 4.41 & 0.789 \\
\hline PG-VFU & PVNC & Parkfield-Vineyard Cyn. & UP & 145.0 & 6.3 & 23.4 & 8.82 & 1.510 \\
\hline & & & $\mathrm{N}$ & 256.0 & 22.4 & 71.6 & 17.70 & 3.570 \\
\hline & & & $E$ & 184.0 & -16.9 & 40.7 & 30.60 & 2.630 \\
\hline PG-WFU & PWKR & Parkfield-Work Ranch & UP & 167.0 & 4.4 & 12.4 & 3.55 & 0.327 \\
\hline & & & $\mathrm{N}$ & 183.0 & 5.6 & 14.8 & 5.28 & 0.809 \\
\hline & & & $E$ & 335.0 & 9.9 & 23.4 & 3.85 & 0.831 \\
\hline
\end{tabular}

${ }^{*} \mathrm{~A}=$ Accelerometer; $\mathrm{V}=$ Velocity Transducer $; \mathrm{D}=$ Dilatometer 


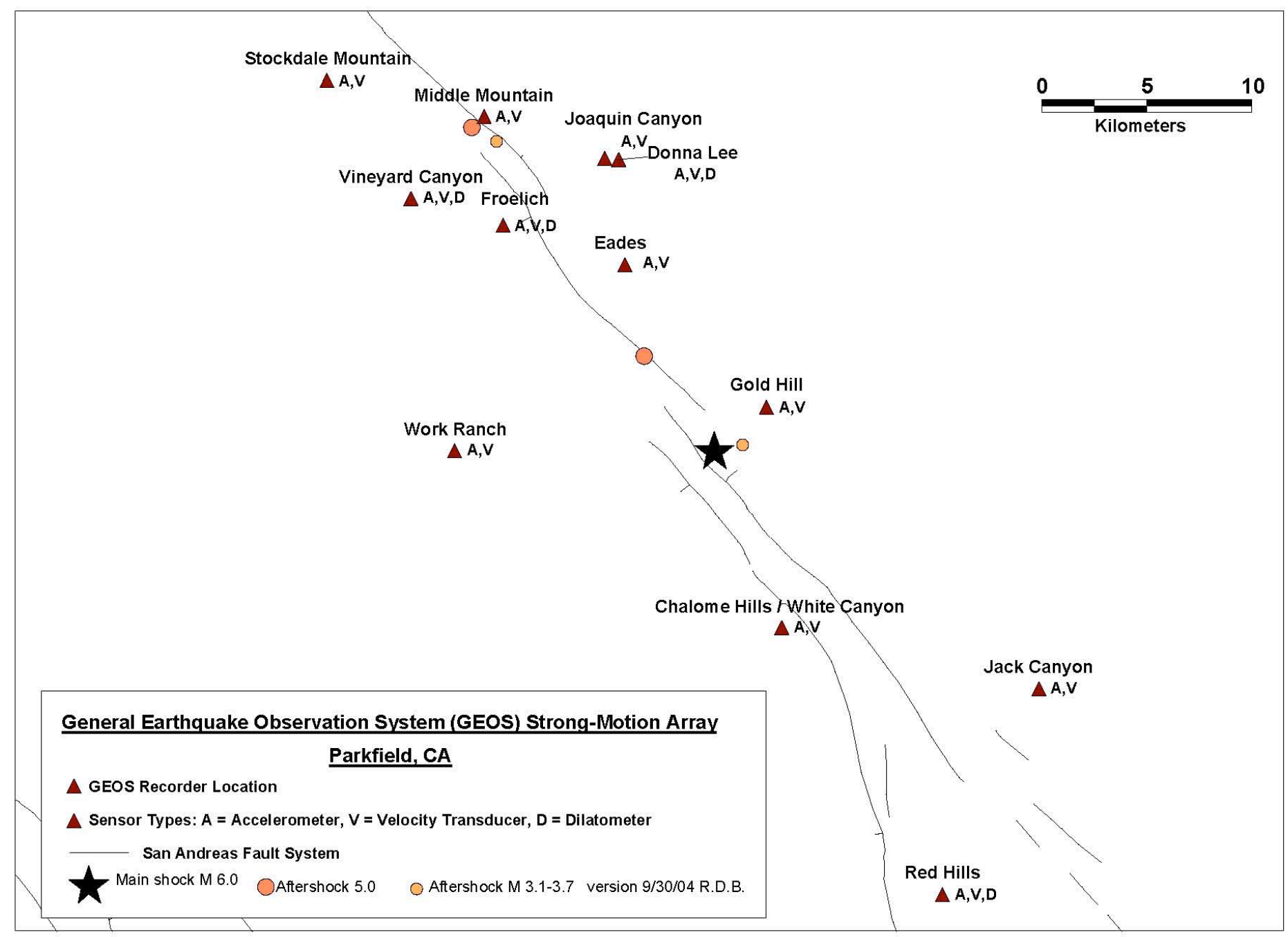

Figure 1. Map showing location of accelerometers (A), velocity transducers (V), dilatometers (D) and GEOS recorders that provided on-scale recordings of the motions generated by the Parkfield earthquake of September 28, 2004. 


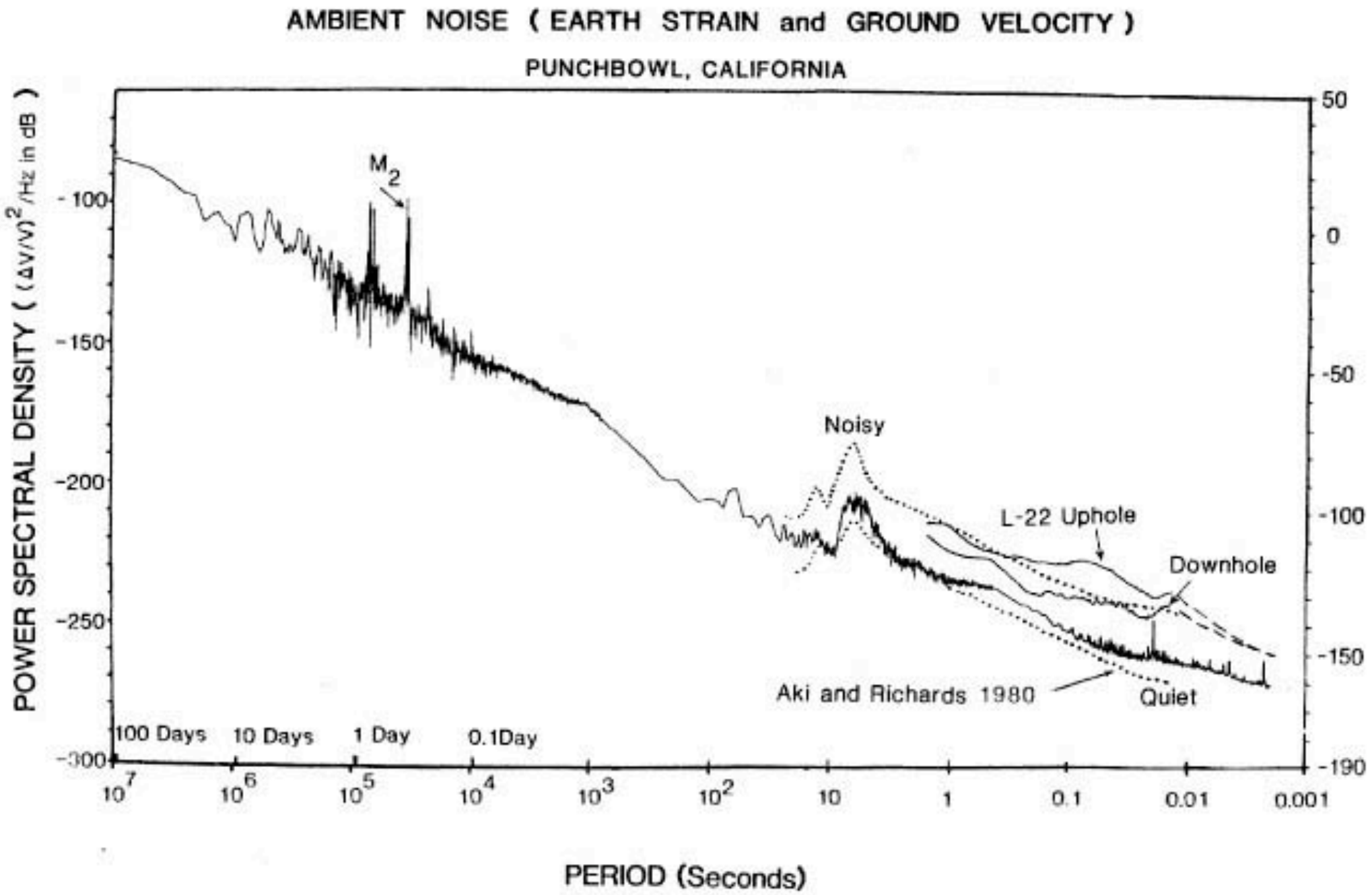

告

Figure 2. Average seismic noise spectra derived from volumetric strain meter at a site in Mojave Desert, CA (PUBS) for the period band $10^{7}$ to $1.7 \times 10^{-2}$ seconds (from Borcherdt et al., 1989) showing the detection bandwidth and thresholds for the volumetric strain meters. Similar spectra are available for the Gold Hill site in Johnston and Linde, (2002). 


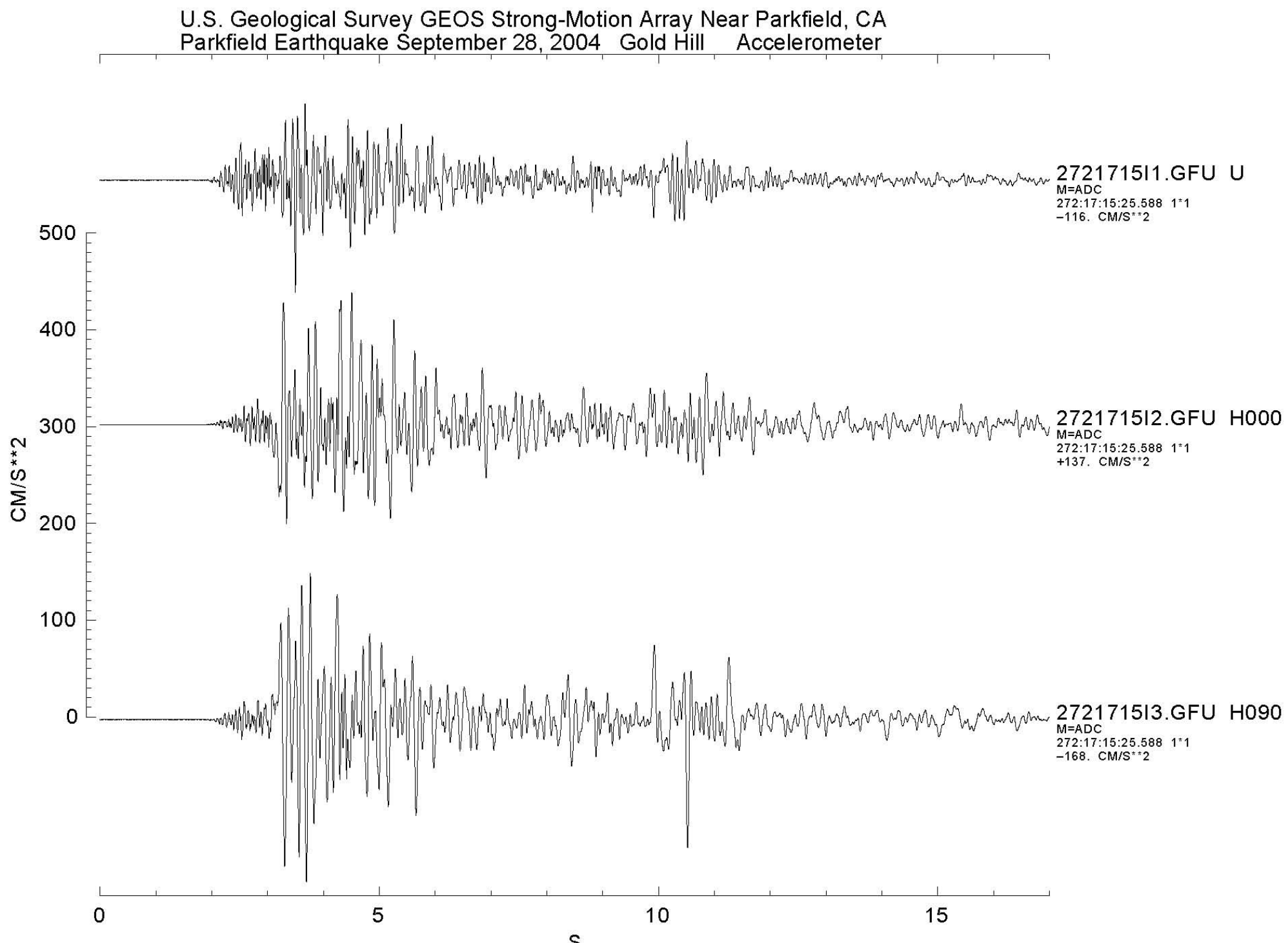

Figure 3. Vertical and horizontal acceleration time histories generated by the Parkfield earthquake of September 28, 2004 as recorded on the GEOS Strong-motion array near Parkfield, CA at the Gold Hill site (see Figure 1 and Table 1). 


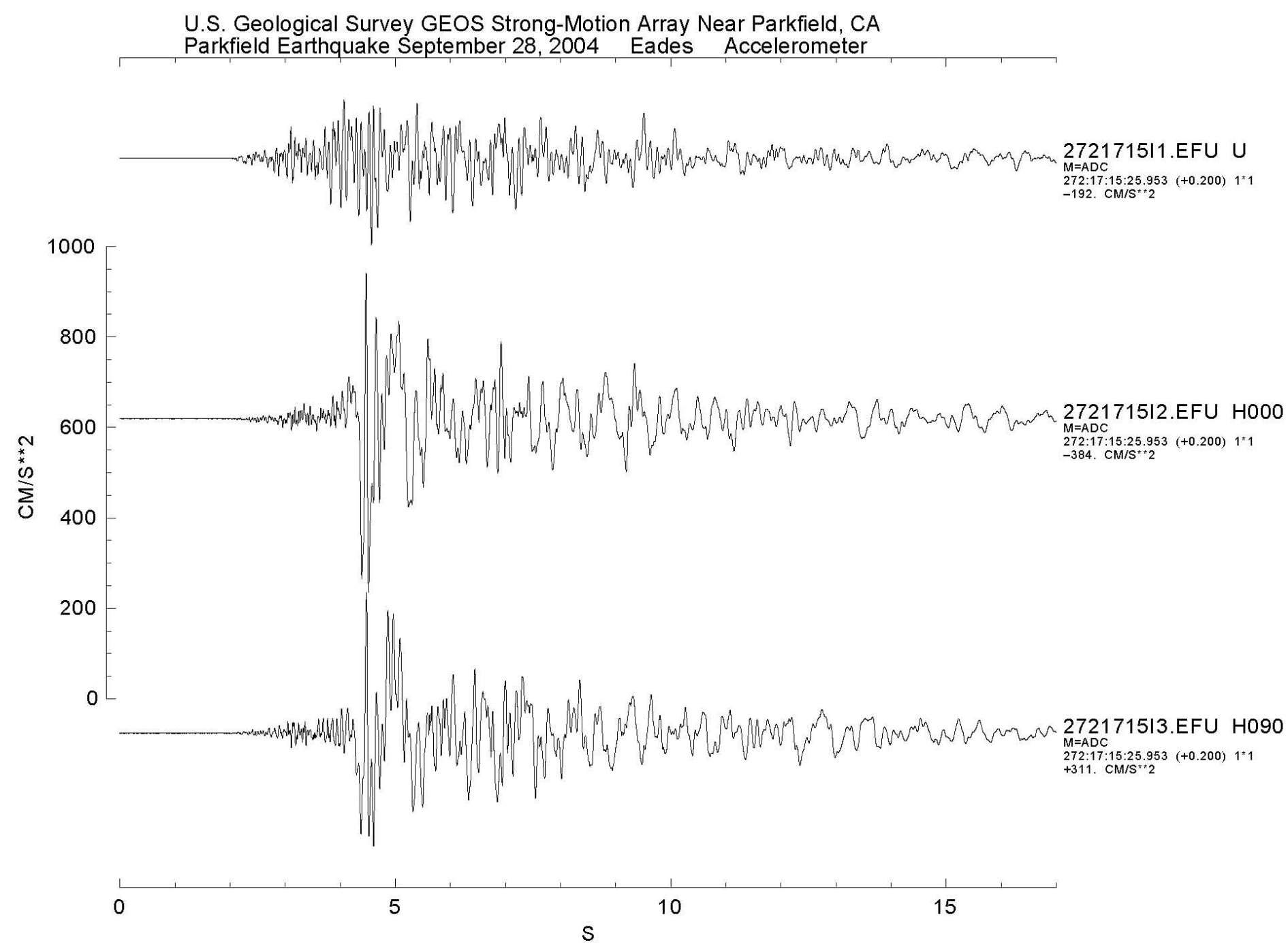

Figure 4. Vertical and horizontal acceleration time histories generated by the Parkfield earthquake of September 28, 2004 as recorded on the GEOS Strong-motion array near Parkfield, CA at the Eades site (see Figure 1 and Table 1). 


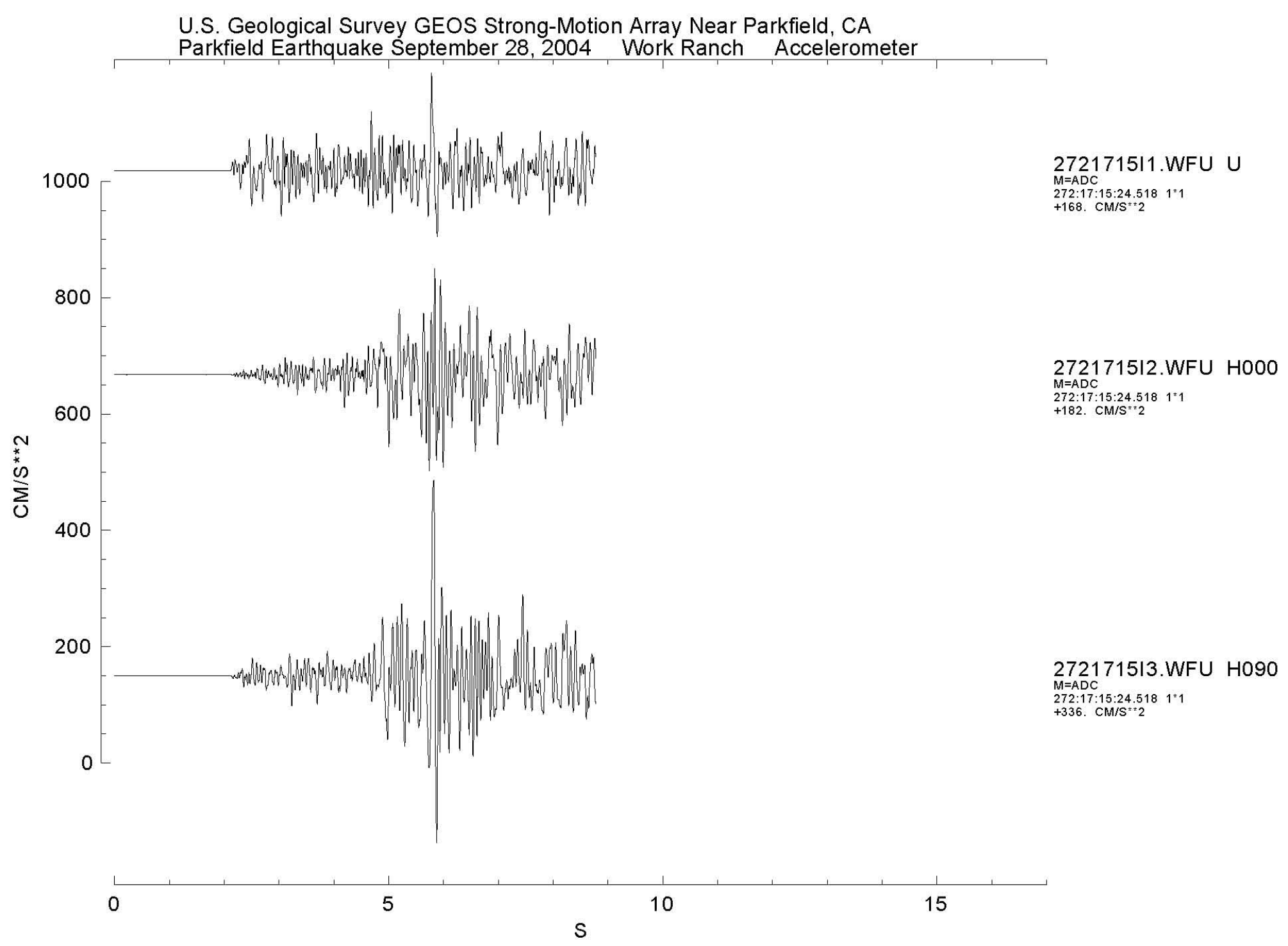

Figure 5. Vertical and horizontal acceleration time histories generated by the Parkfield earthquake of September 28,2004 as recorded on the GEOS Strong-motion array near Parkfield, CA at the Work Ranch site (see Figure 1 and Table 1). 
U.S. Geological Survey GEOS Strong-Motion Array Near Parkfield, CA

Parkfield Earthquake September 28, 2004 Donna Lee Accelerometer
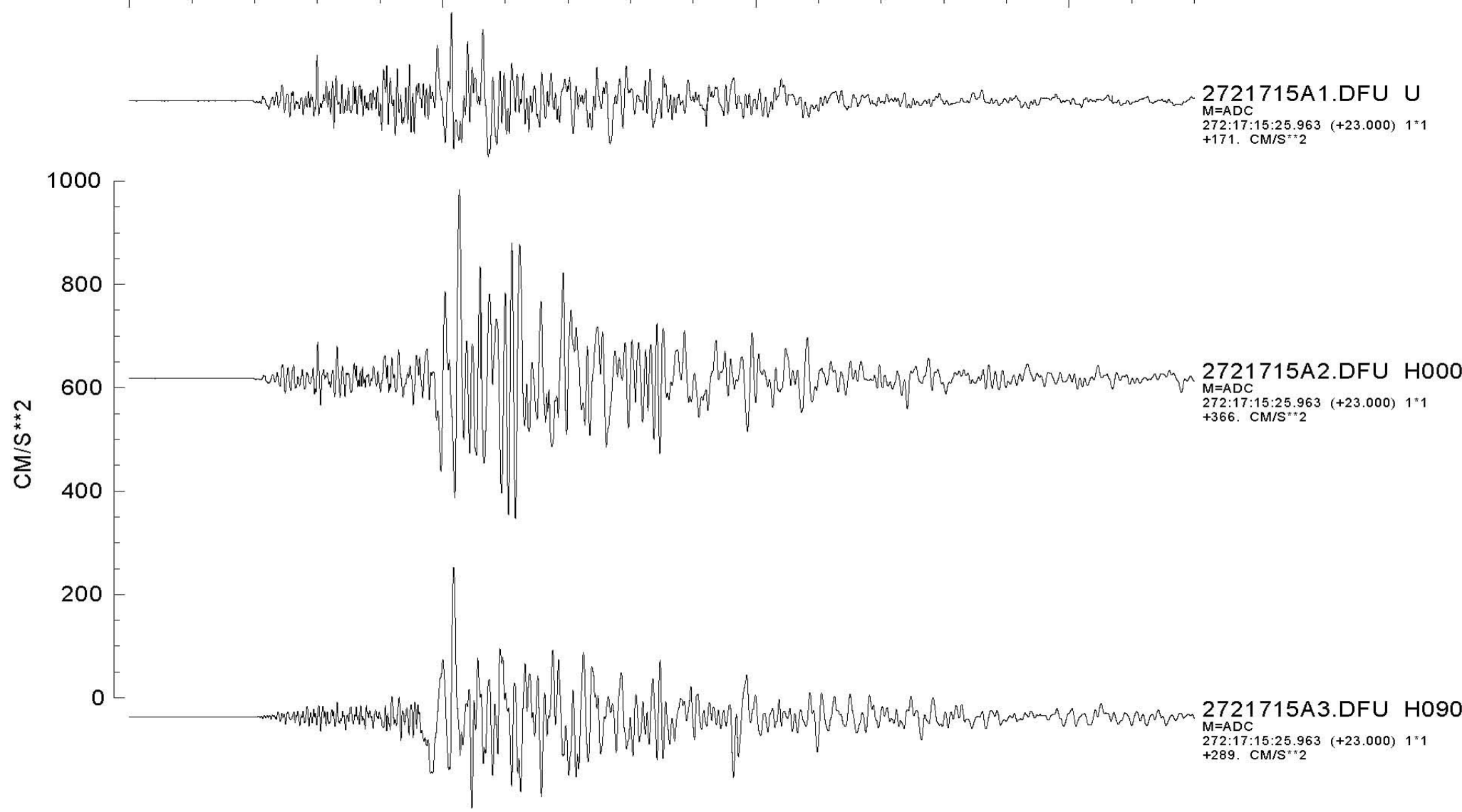

0

5

10

15

Figure 6. Vertical and horizontal acceleration time histories generated by the Parkfield earthquake of September 28, 2004 as recorded on the GEOS Strong-motion array near Parkfield, CA at the Donna Lee site (see Figure 1 and Table 1). 


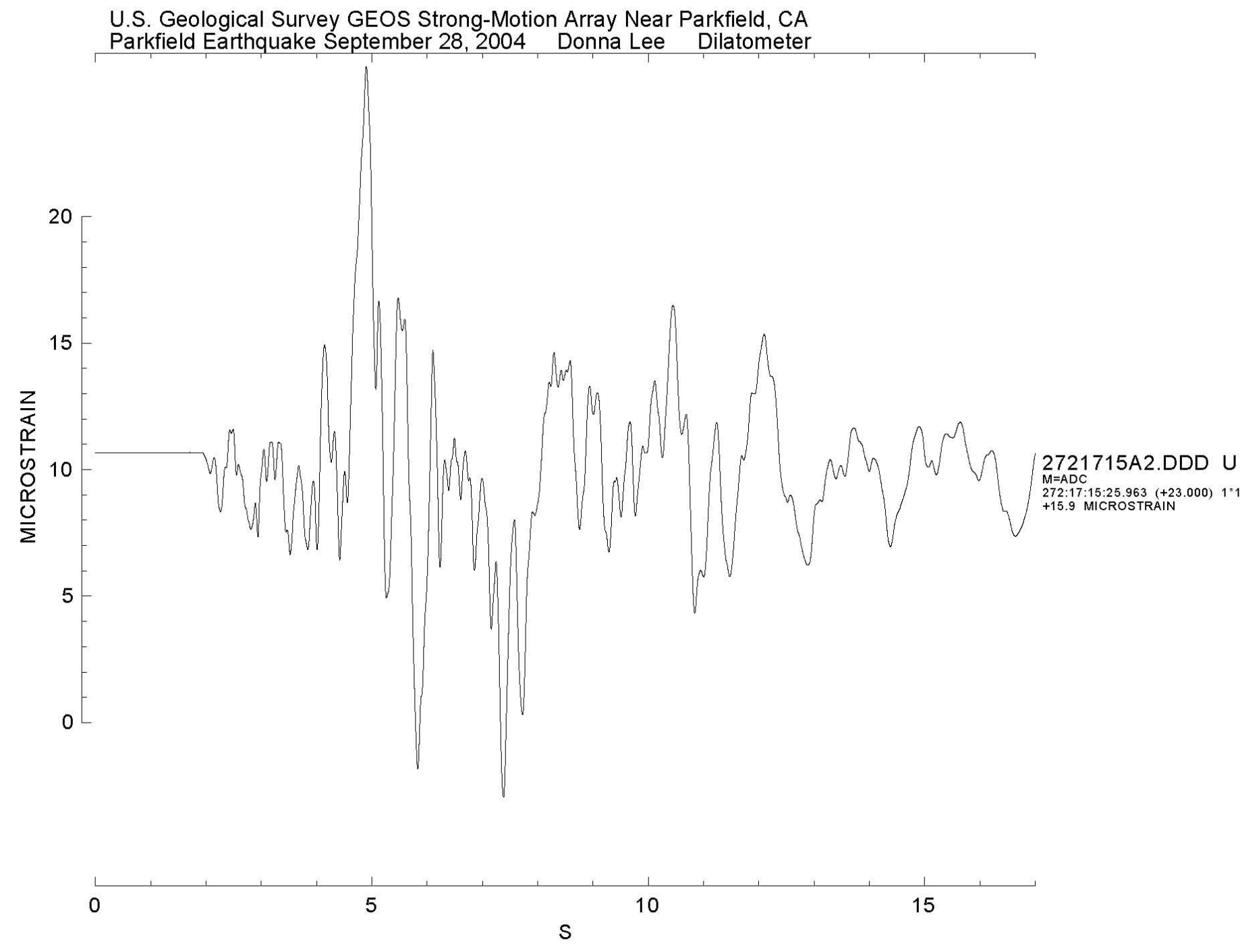

Figure 7. Volumetric strain generated by the Parkfield earthquake of September 28, 2004 as recorded on the GEOS Strong-motion array near Parkfield, CA at the Donna Lee site (see Figure 1 and Table 1). 


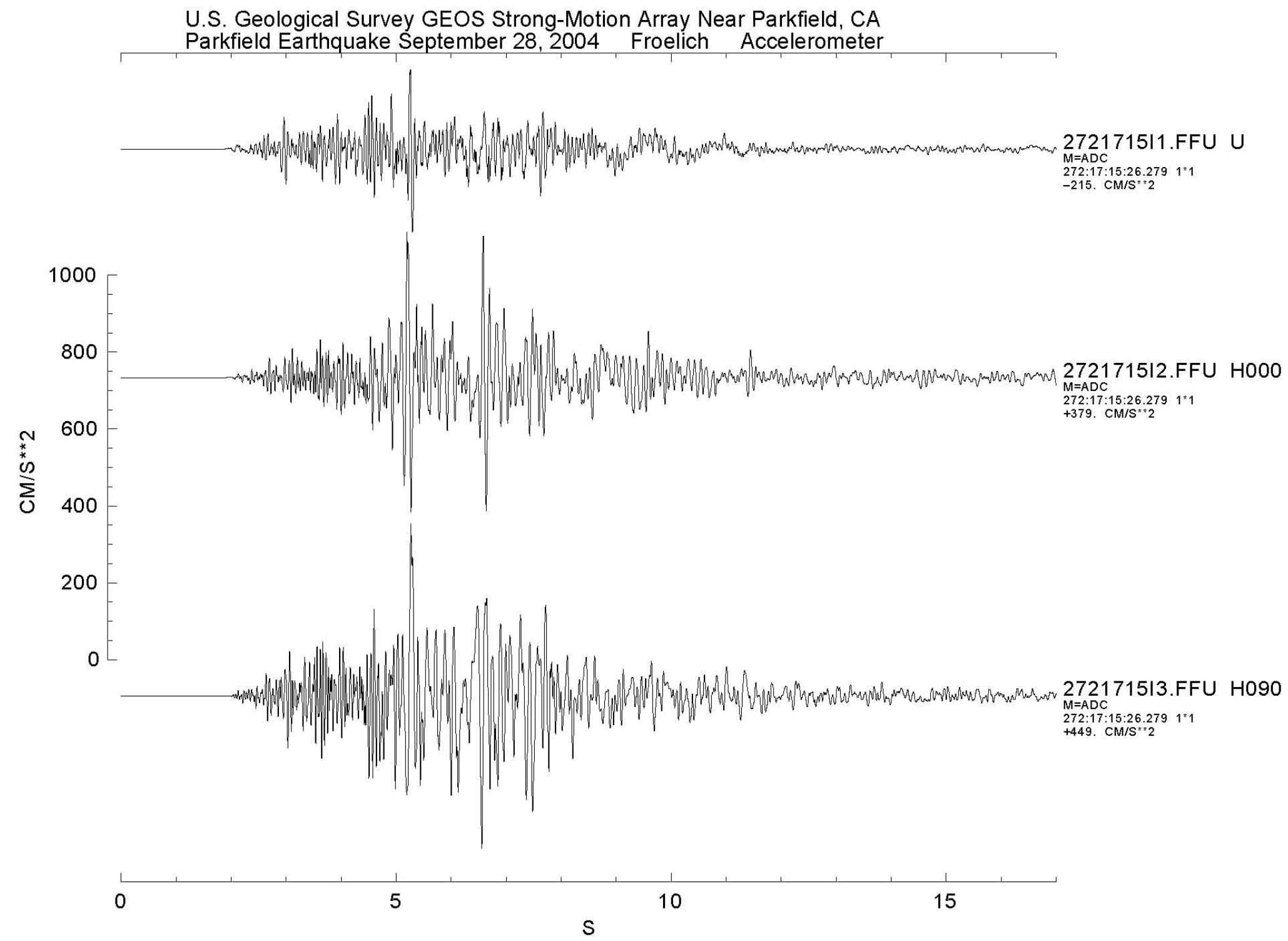

Figure 8. Vertical and horizontal acceleration time histories generated by the Parkfield earthquake of September 28, 2004 as recorded on the GEOS Strong-motion array near Parkfield, CA at the Froelich site (see Figure 1 and Table 1). 


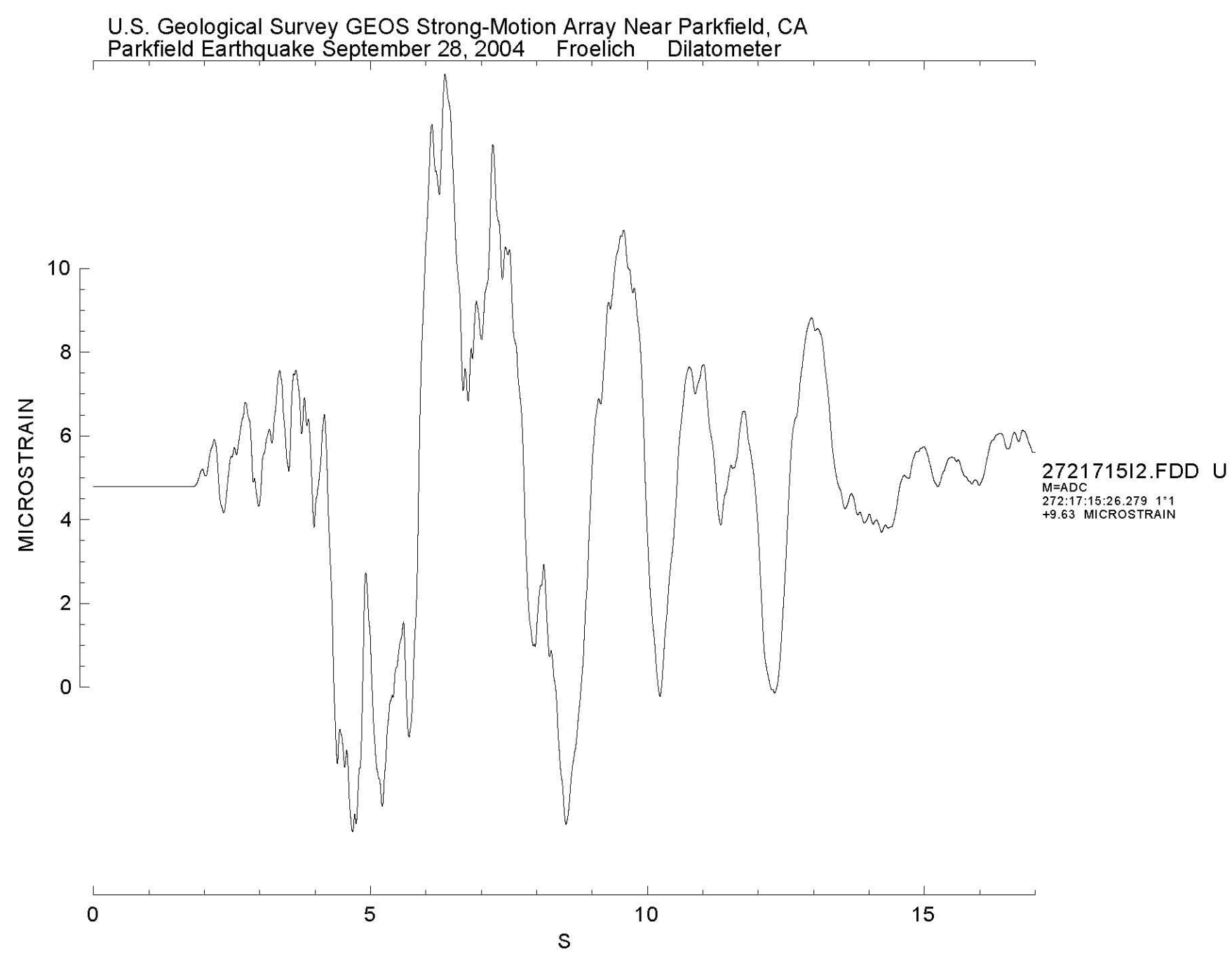

Figure 9. Volumetric strain generated by the Parkfield earthquake of September 28, 2004 as recorded on the GEOS Strong-motion array near Parkfield, CA at the Froelich site (see Figure 1 and Table 1). 


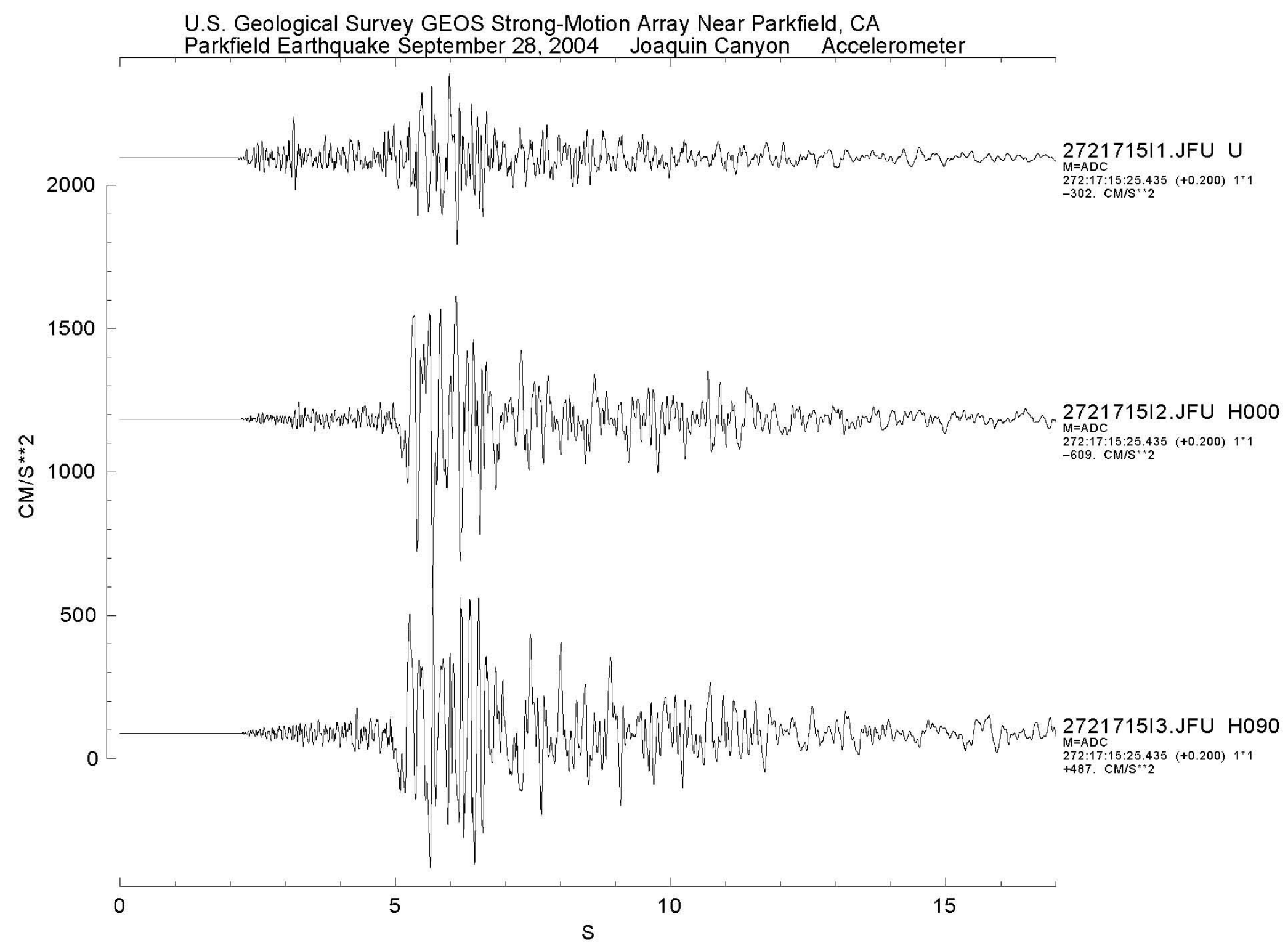

Figure 10. Vertical and horizontal acceleration time histories generated by the Parkfield earthquake of September 28,2004 as recorded on the GEOS Strong-motion array near Parkfield, CA at the Joaquin Canyon site (see Figure 1 and Table 1). 


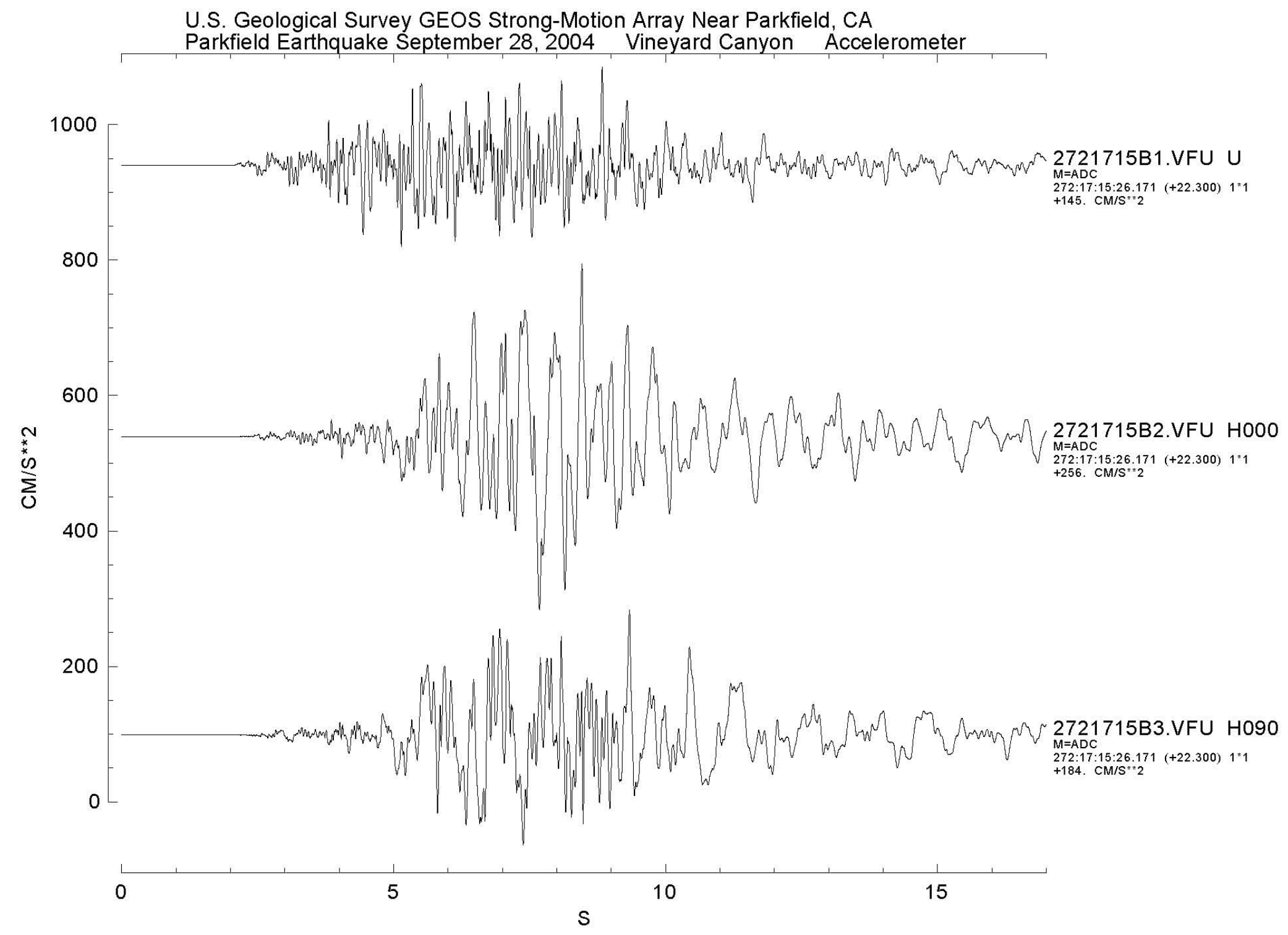

Figure 11. Vertical and horizontal acceleration time histories generated by the Parkfield earthquake of September 28,2004 as recorded on the GEOS Strong-motion array near Parkfield, CA at the Vineyard Canyon site (see Figure 1 and Table 1). 


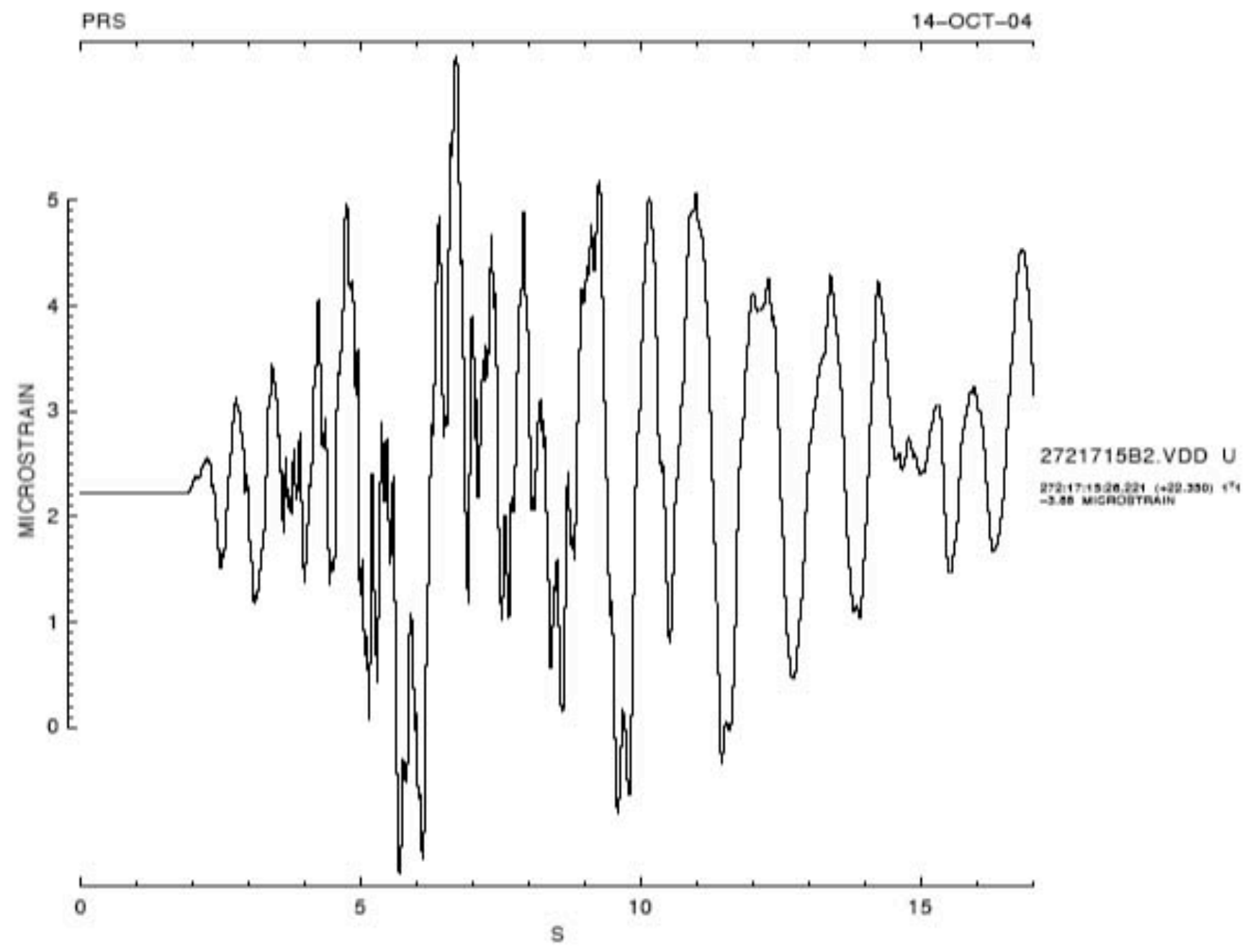

Figure 12. Volumetric strain generated by the Parkfield earthquake of September 28, 2004 as recorded on the GEOS Strong-motion array near Parkfield, CA at the Vineyard Canyon site (see Figure 1 and Table 1). 
U.S. Geological Survey GEOS Strong-Motion Array Near Parkfield, CA

Parkfield Earthquake September 28, 2004 Jack Canyon Accelerometer

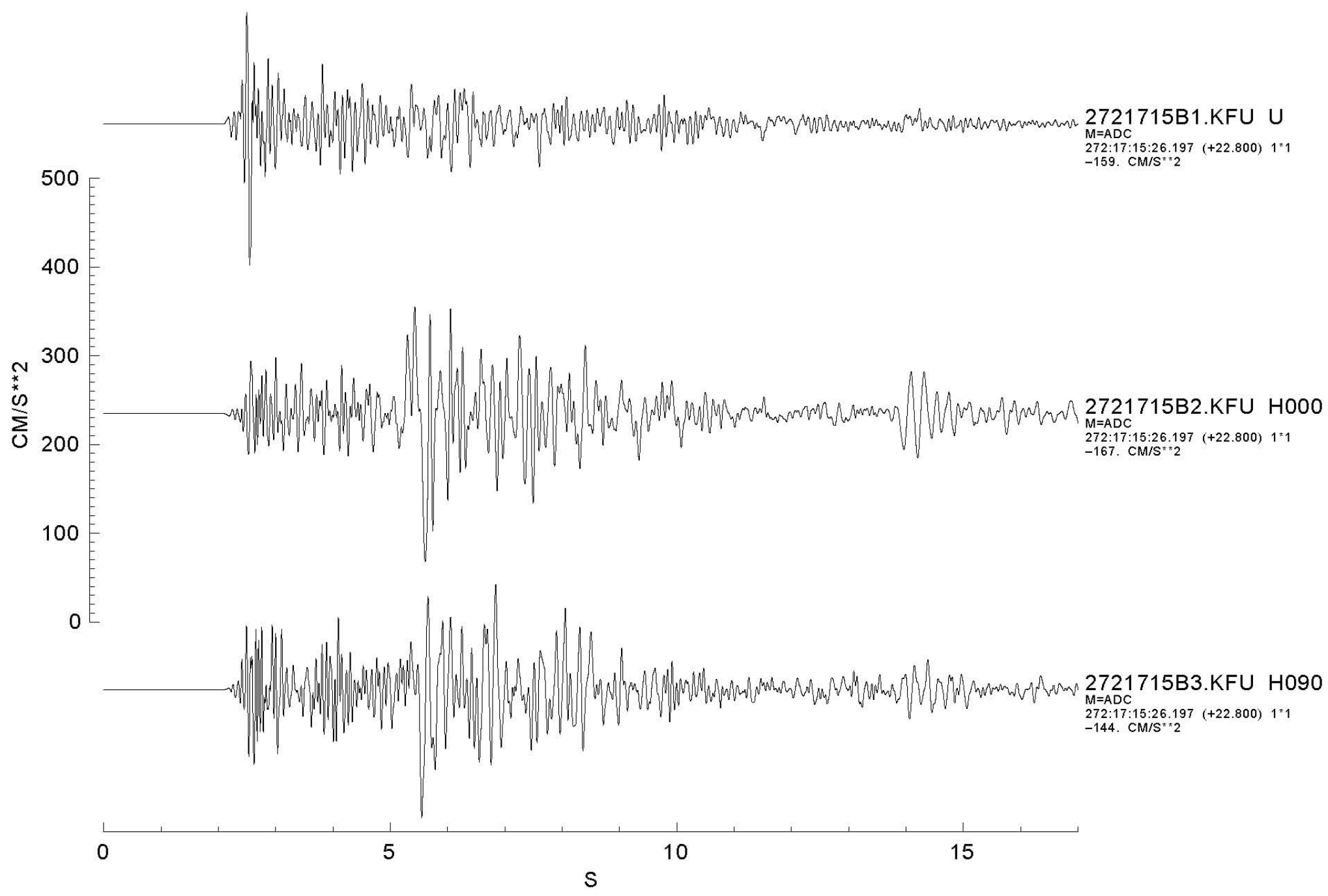

Figure 13. Vertical and horizontal acceleration time histories generated by the Parkfield earthquake of September 28, 2004 as recorded on the GEOS Strong-motion array near Parkfield, CA at the Jack Canyon site (see Figure 1 and Table 1). 


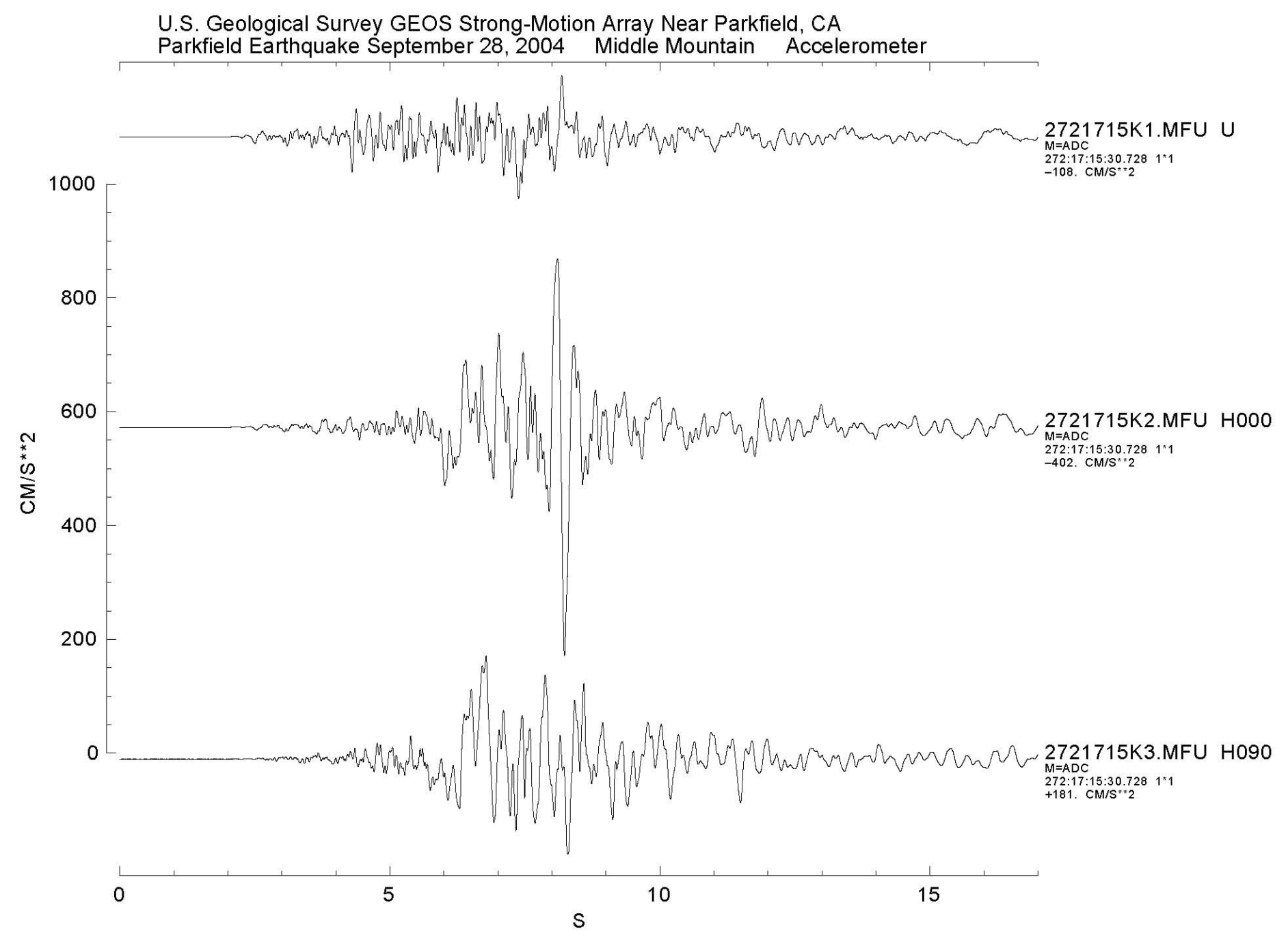

Figure 14. Vertical and horizontal acceleration time histories generated by the Parkfield earthquake of September 28,2004 as recorded on the GEOS Strong-motion array near Parkfield, CA at the Middle Mountain site (see Figure 1 and Table 1). 


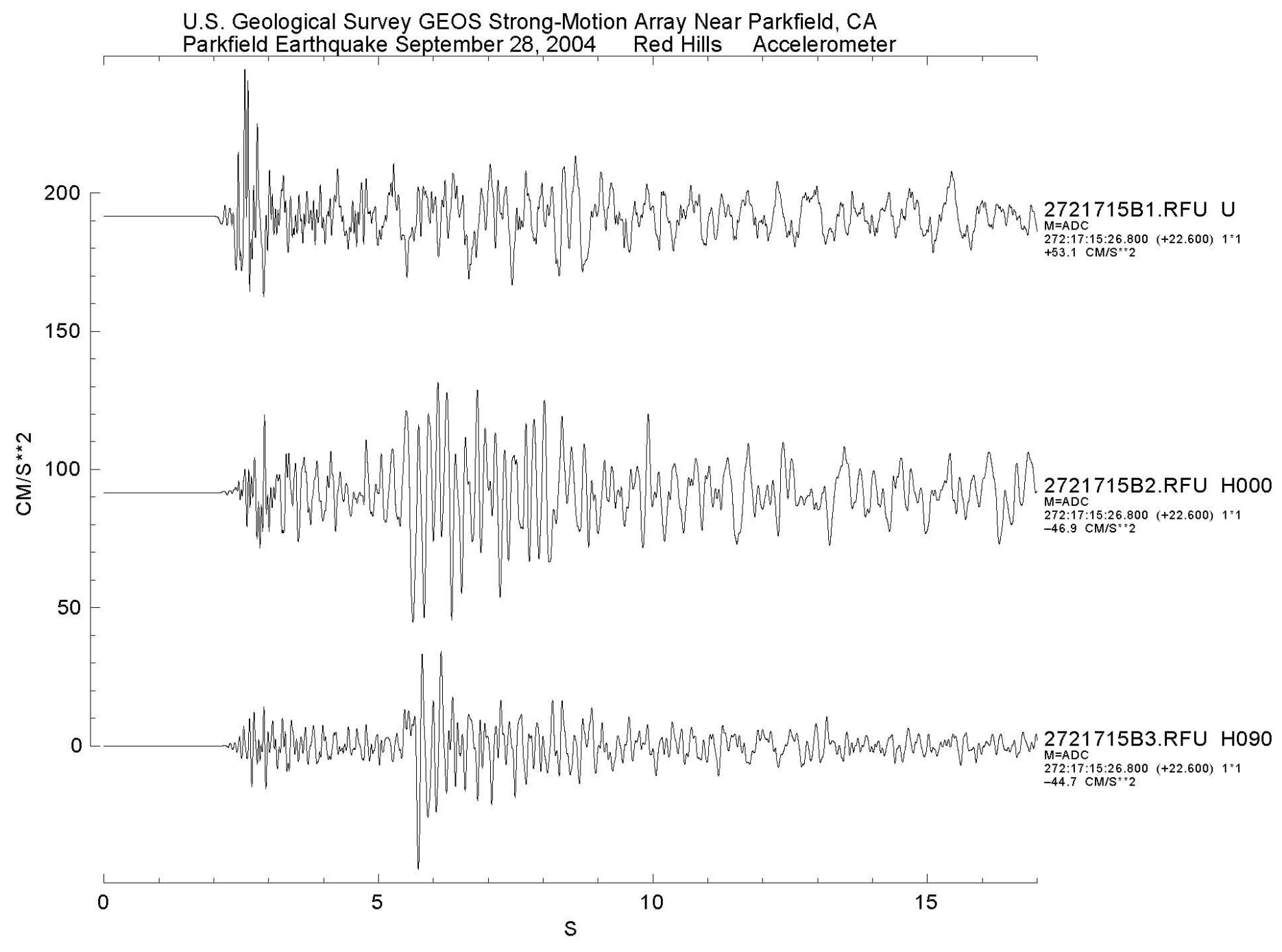

Figure 15. Vertical and horizontal acceleration time histories generated by the Parkfield earthquake of September 28, 2004 as recorded on the GEOS Strong-motion array near Parkfield, CA at the Red Hills site (see Figure 1 and Table 1). 


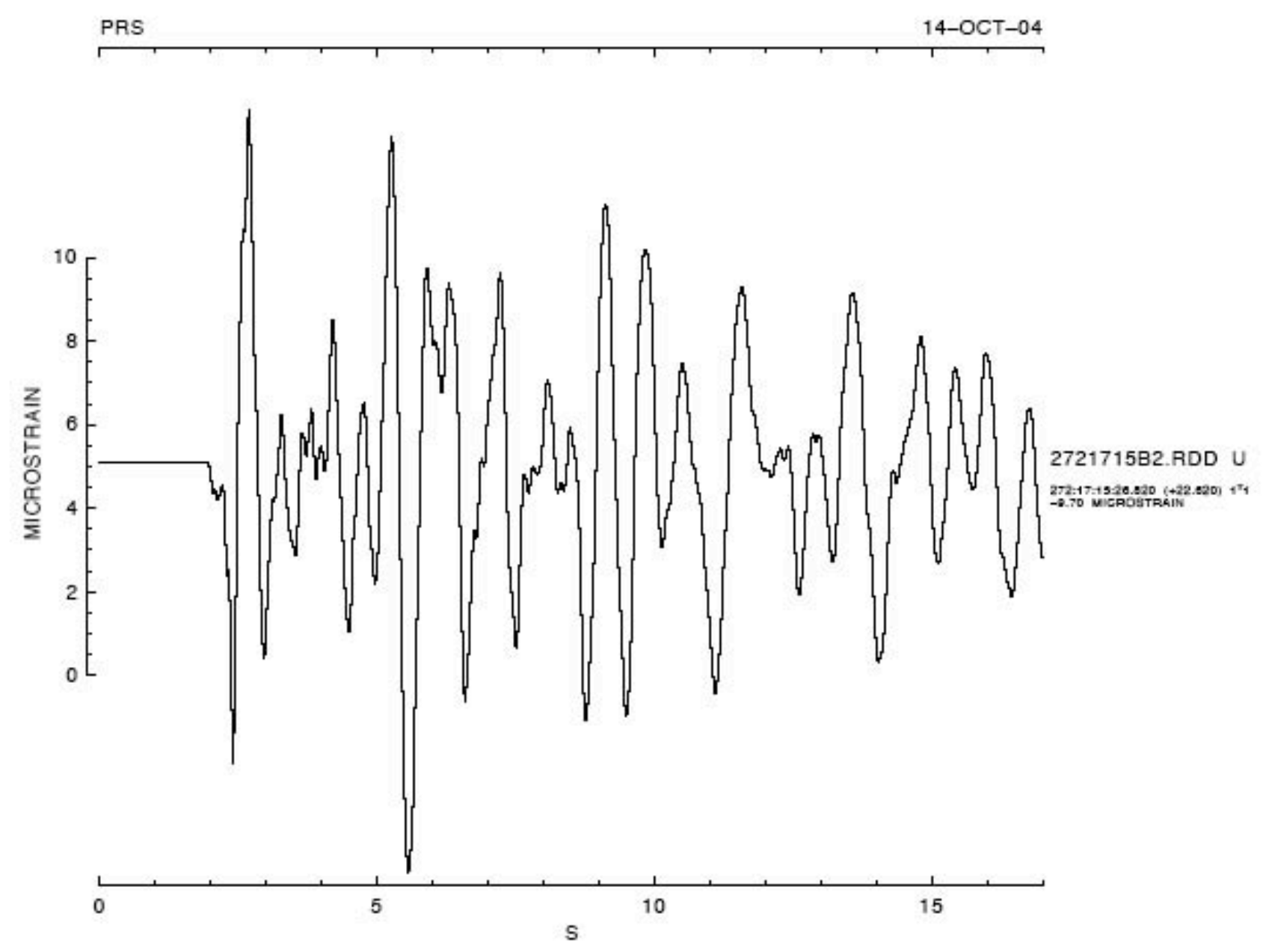

Figure 16. Volumetric strain generated by the Parkfield earthquake of September 28, 2004 as recorded on the GEOS Strong-motion array near Parkfield, CA at the Red Hills site (see Figure 1 and Table 1). 


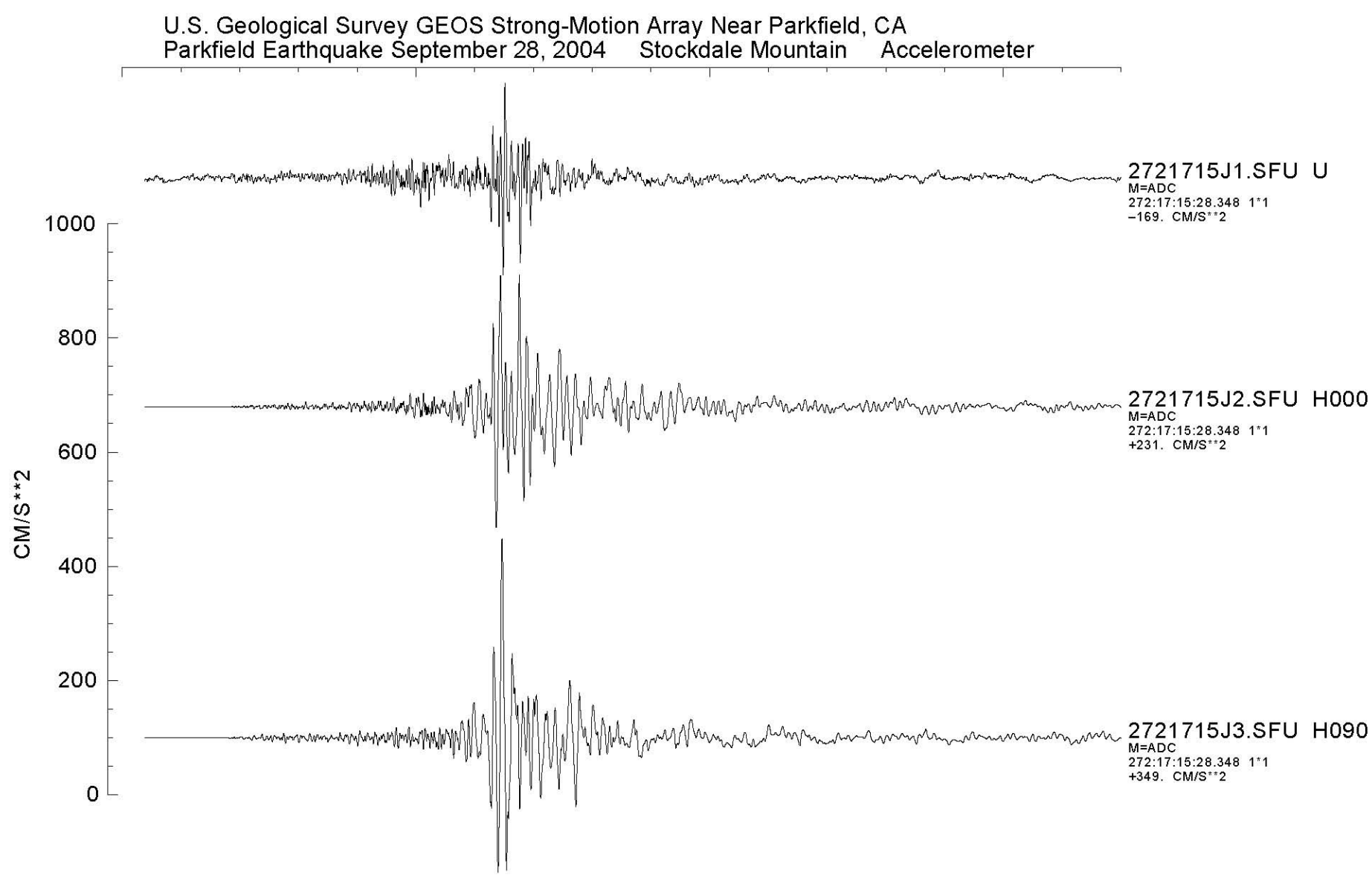

0

10

15

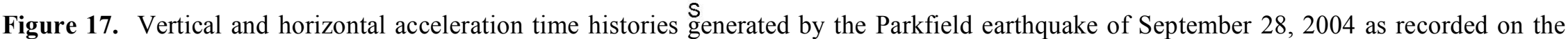
GEOS Strong-motion array near Parkfield, CA at the Stockdale Mountain site (see Figure 1 and Table 1). 
2004/09/28 17:15 PARKFIELD, CA EARTHQUAKE

STA: DFU_CA:Parkfield; Donna Lee, Dist: $14.5 \mathrm{~km}$, Az: 342

GEOS S/N: 7 Source: USGS
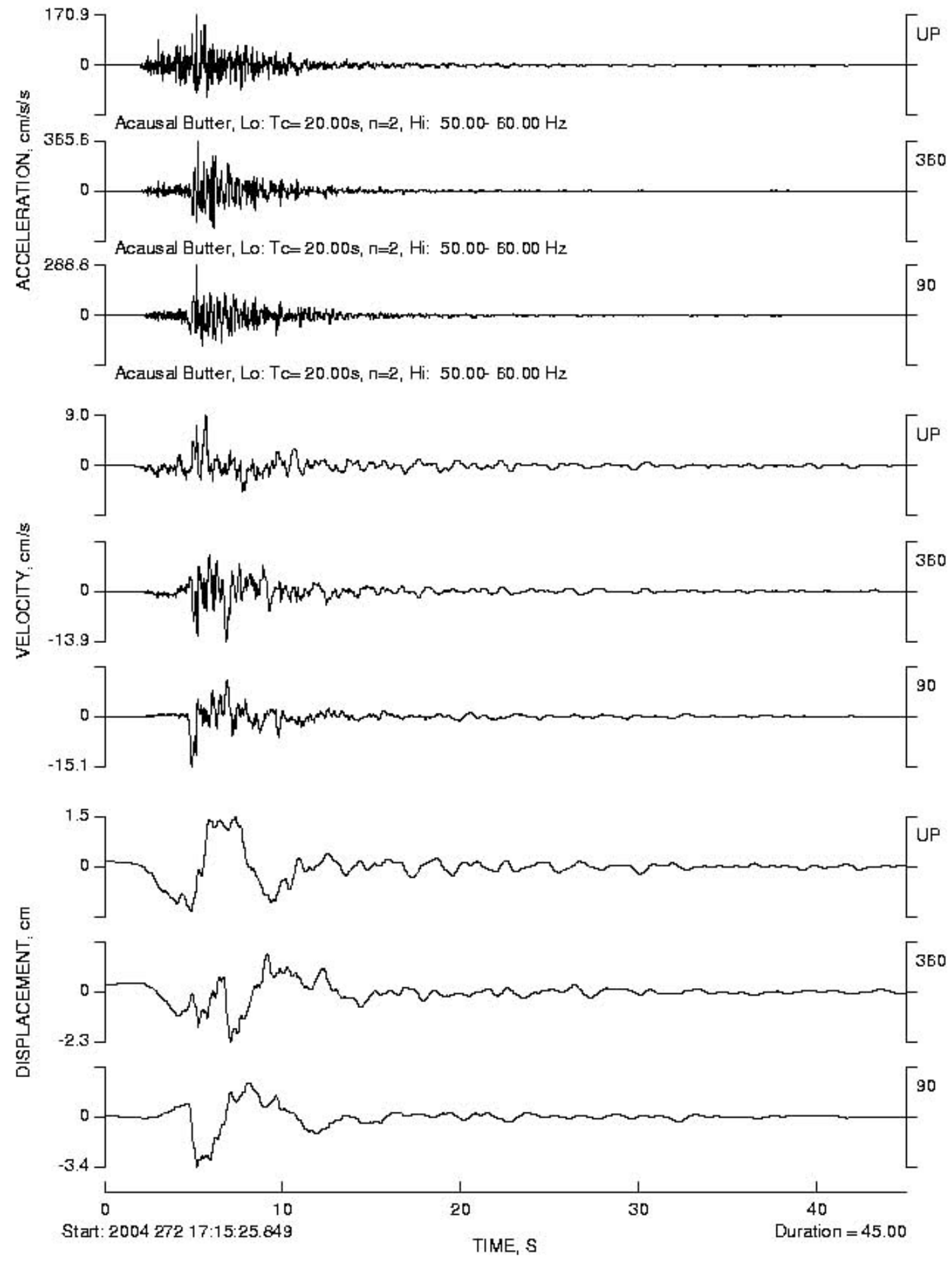

Figure 18. Corrected acceleration, velocity, and displacement inferred for the Parkfield earthquake of September 28, 2004 as recorded on the GEOS Strong-motion array near Parkfield, CA at the Donna Lee site (see Figure 1 and Table 1). 

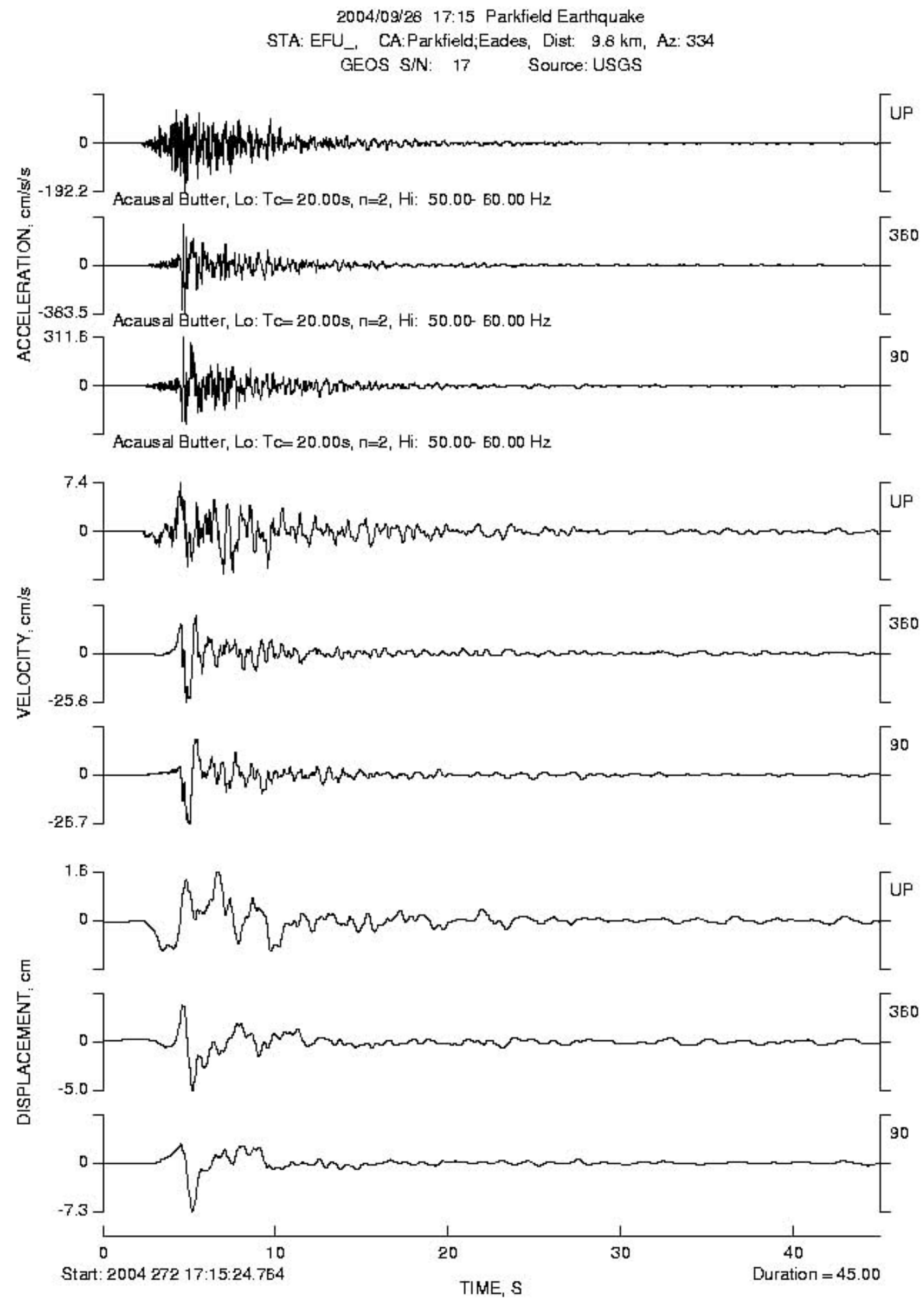

Figure 19. Corrected acceleration, velocity, and displacement inferred for the Parkfield earthquake of September 28, 2004 as recorded on the GEOS Strong-motion array near Parkfield, CA at the Eades site (see Figure 1 and Table 1). 

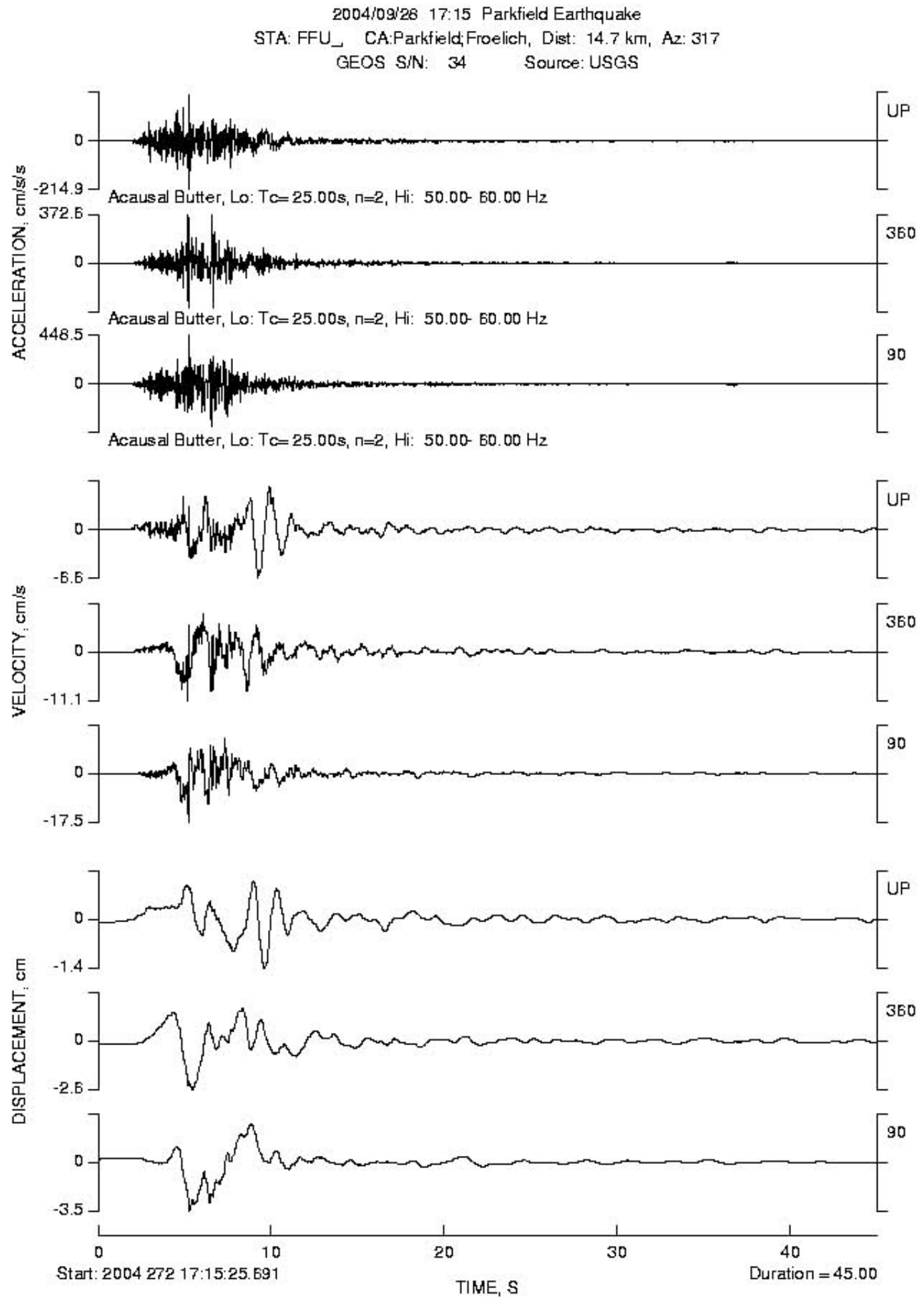

Figure 20. Corrected acceleration, velocity, and displacement inferred for the Parkfield earthquake of September 28, 2004 as recorded on the GEOS Strong-motion array near Parkfield, CA at the Froelich site (see Figure 1 and Table 1). 

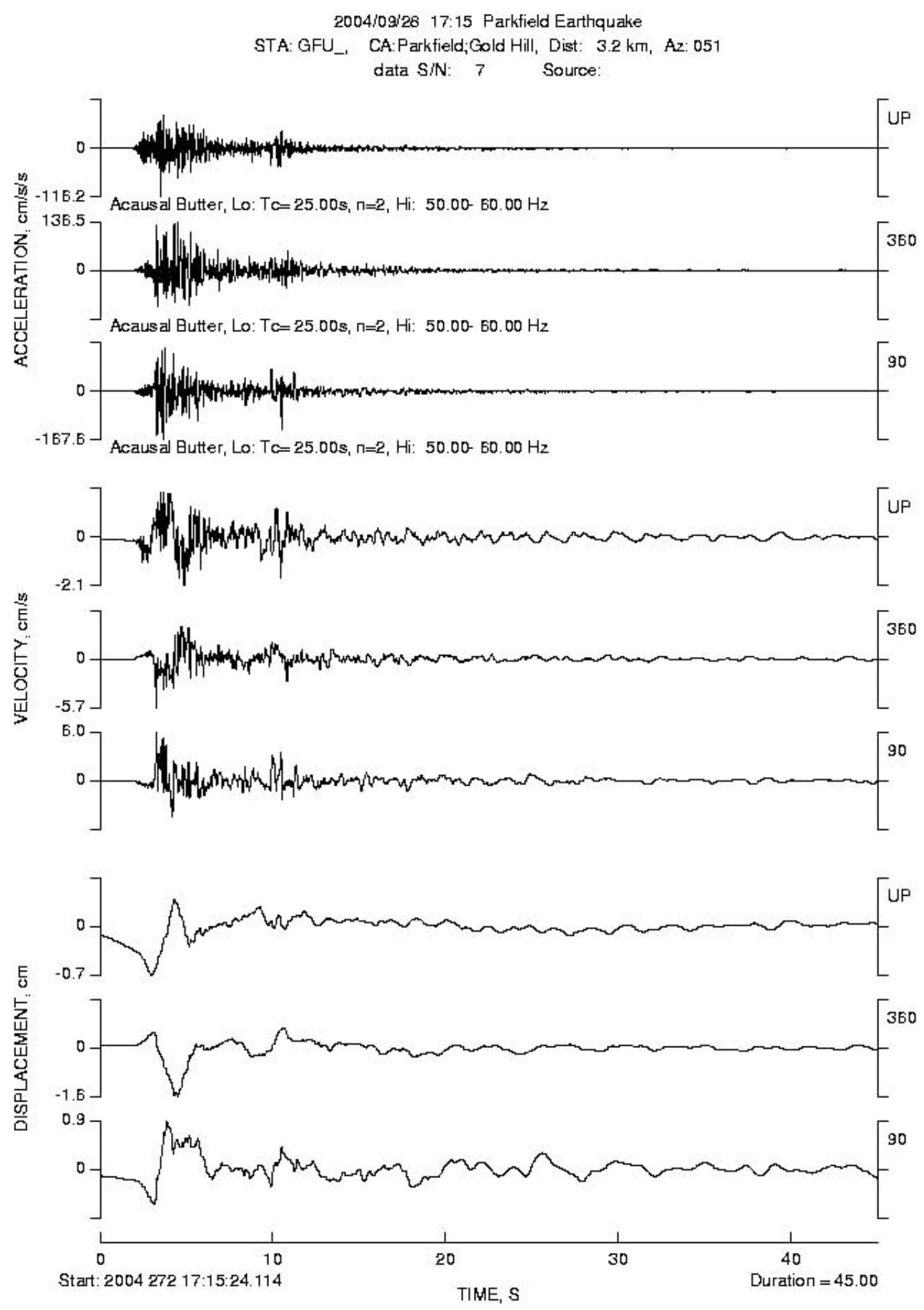

Figure 21. Corrected acceleration, velocity, and displacement inferred for the Parkfield earthquake of September 28, 2004 as recorded on the GEOS Strong-motion array near Parkfield, CA at the Gold Hill site (see Figure 1 and Table 1). 


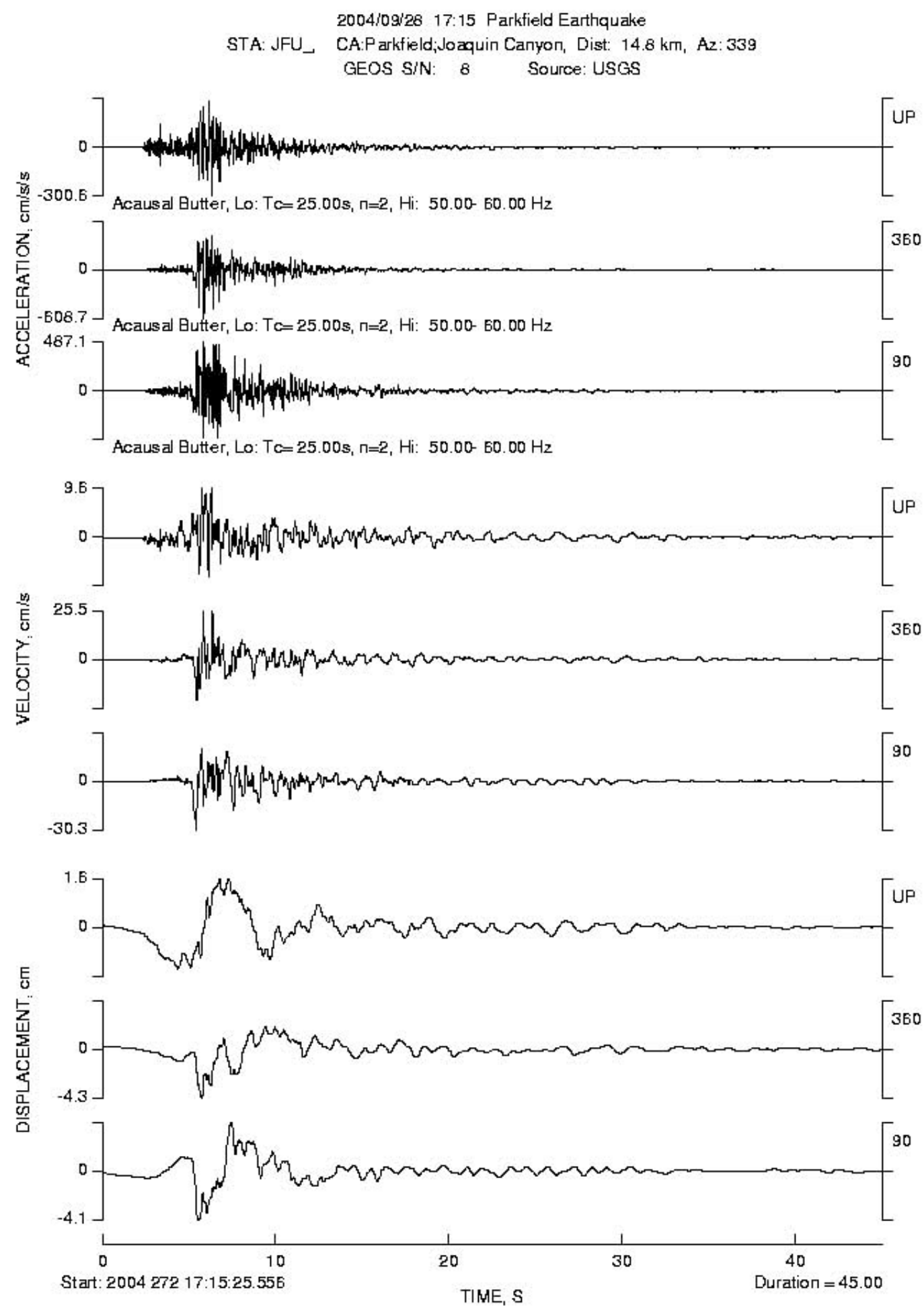

Figure 22. Corrected acceleration, velocity, and displacement inferred for the Parkfield earthquake of September 28, 2004 as recorded on the GEOS Strong-motion array near Parkfield, CA at the Joaquin Canyon site (see Figure 1 and Table 1). 

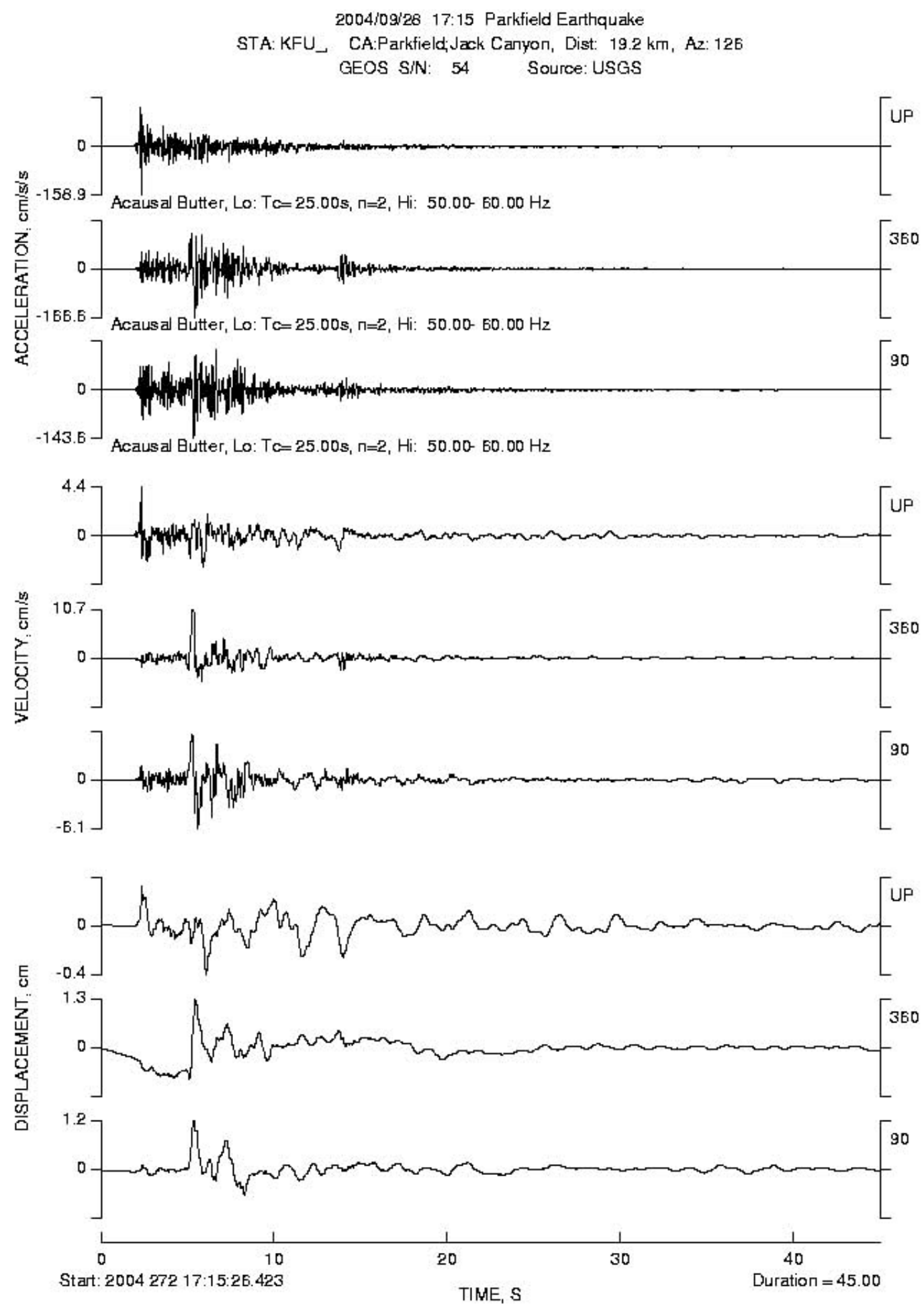

Figure 23. Corrected acceleration, velocity, and displacement inferred for the Parkfield earthquake of September 28, 2004 as recorded on the GEOS Strong-motion array near Parkfield, CA at the Jack Canyon site (see Figure 1 and Table 1). 


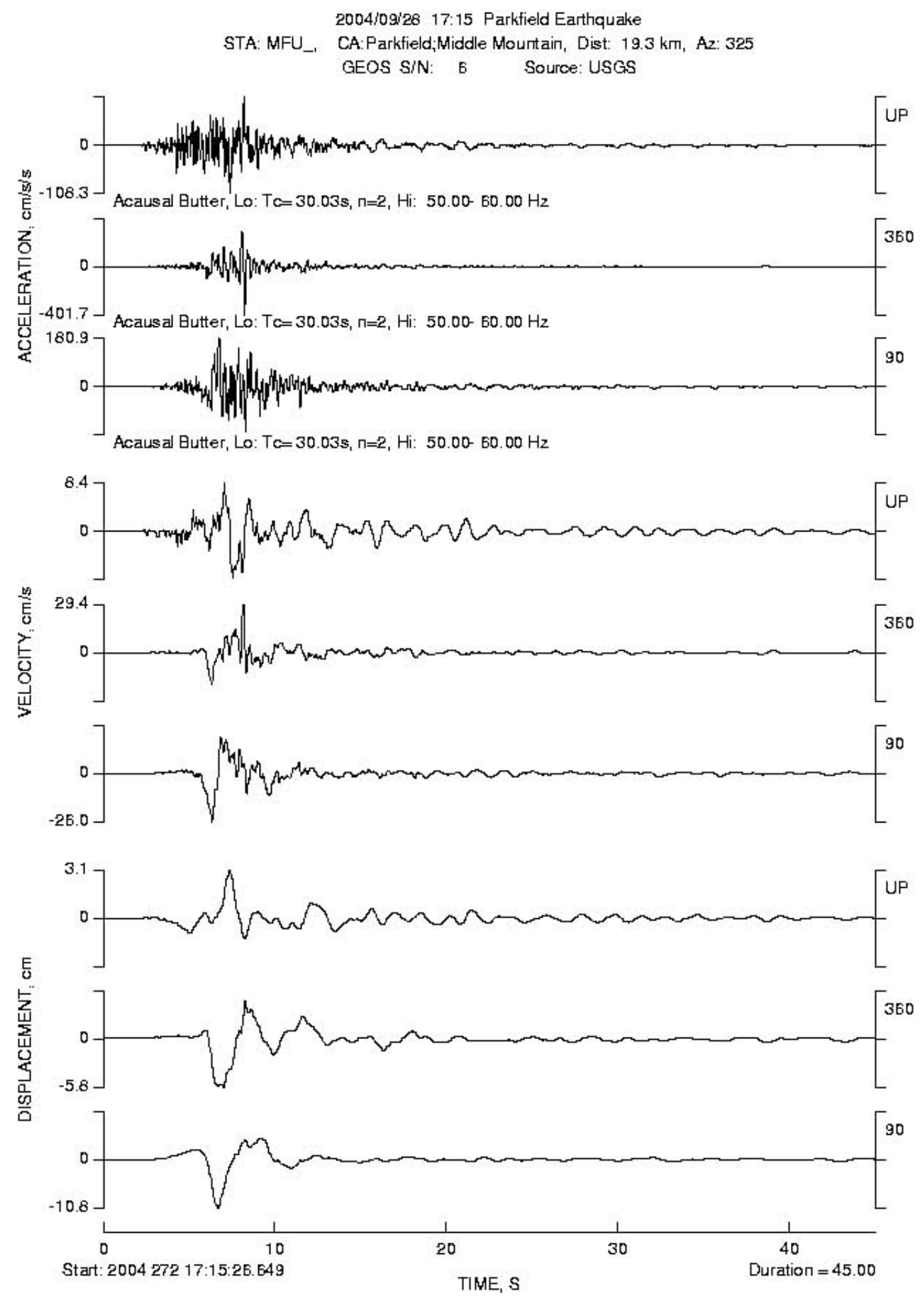

Figure 24. Corrected acceleration, velocity, and displacement inferred for the Parkfield earthquake of September 28, 2004 as recorded on the GEOS Strong-motion array near Parkfield, CA at the Middle Mountain site (see Figure 1 and Table 1). 

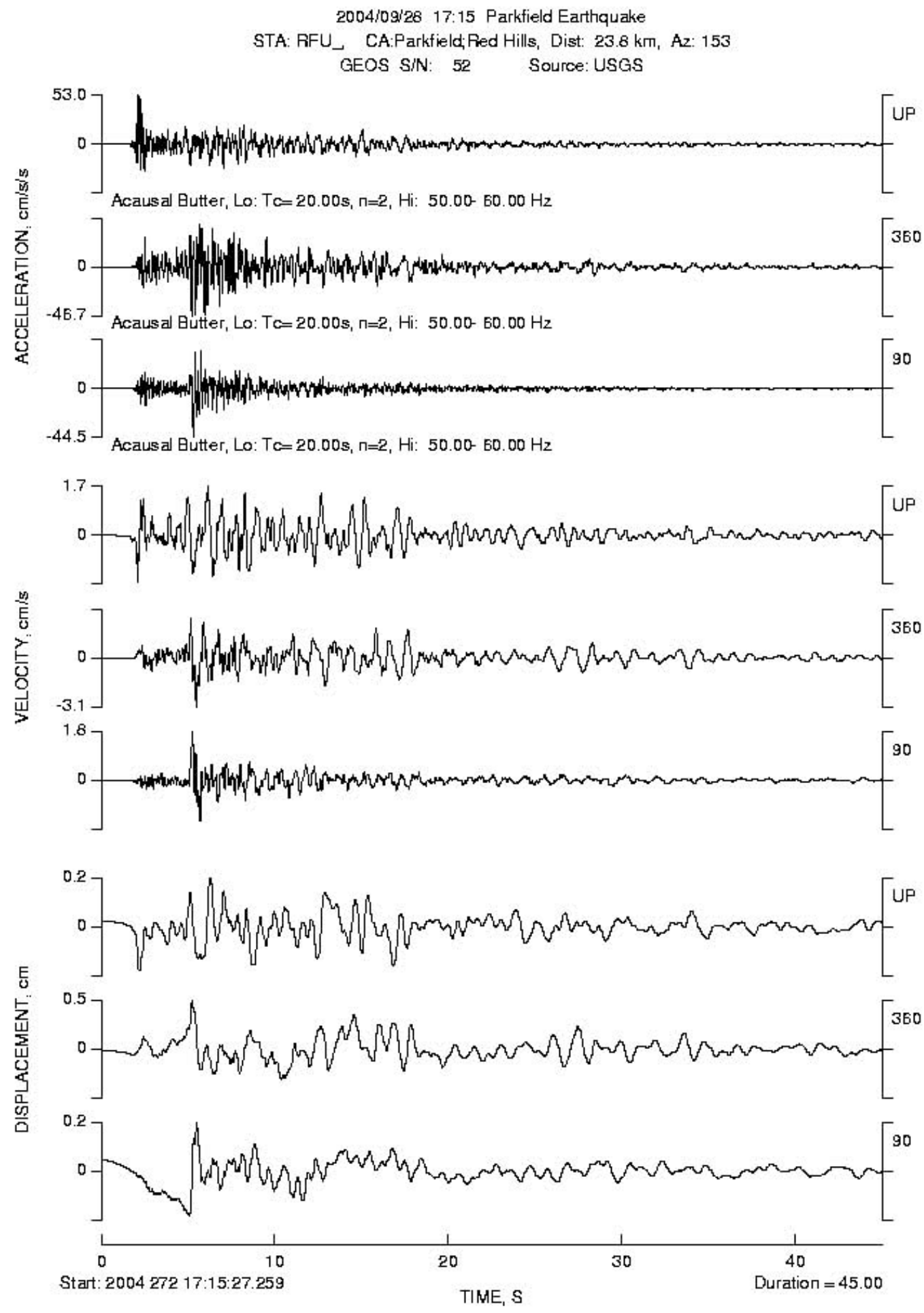

Figure 25. Corrected acceleration, velocity, and displacement inferred for the Parkfield earthquake of September 28, 2004 as recorded on the GEOS Strong-motion array near Parkfield, CA at the Red Hills site (see Figure 1 and Table 1). 

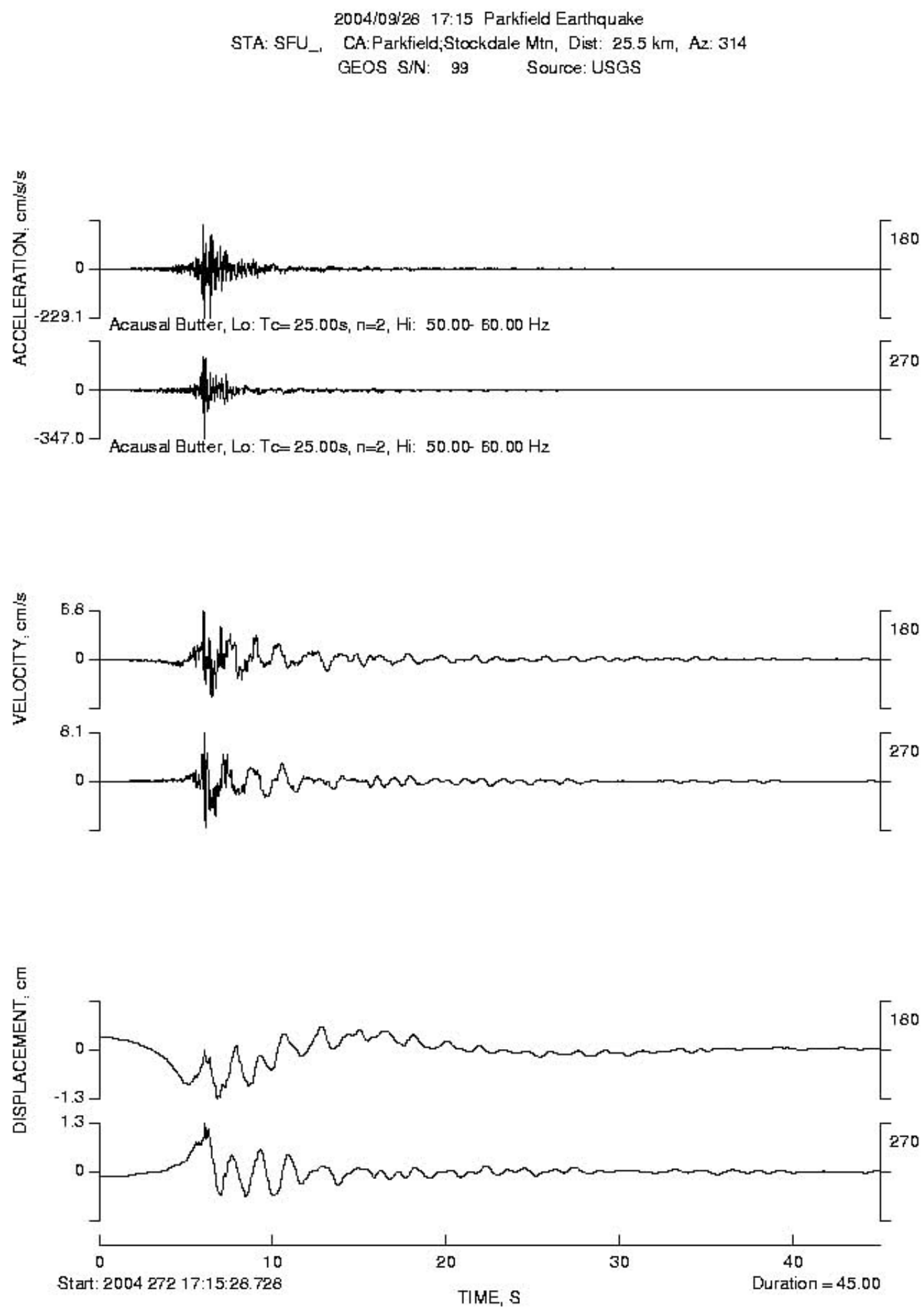

Figure 26. Corrected acceleration, velocity, and displacement inferred for the Parkfield earthquake of September 28, 2004 as recorded on the GEOS Strong-motion array near Parkfield, CA at the Stockdale Mountain site (see Figure 1 and Table 1). 


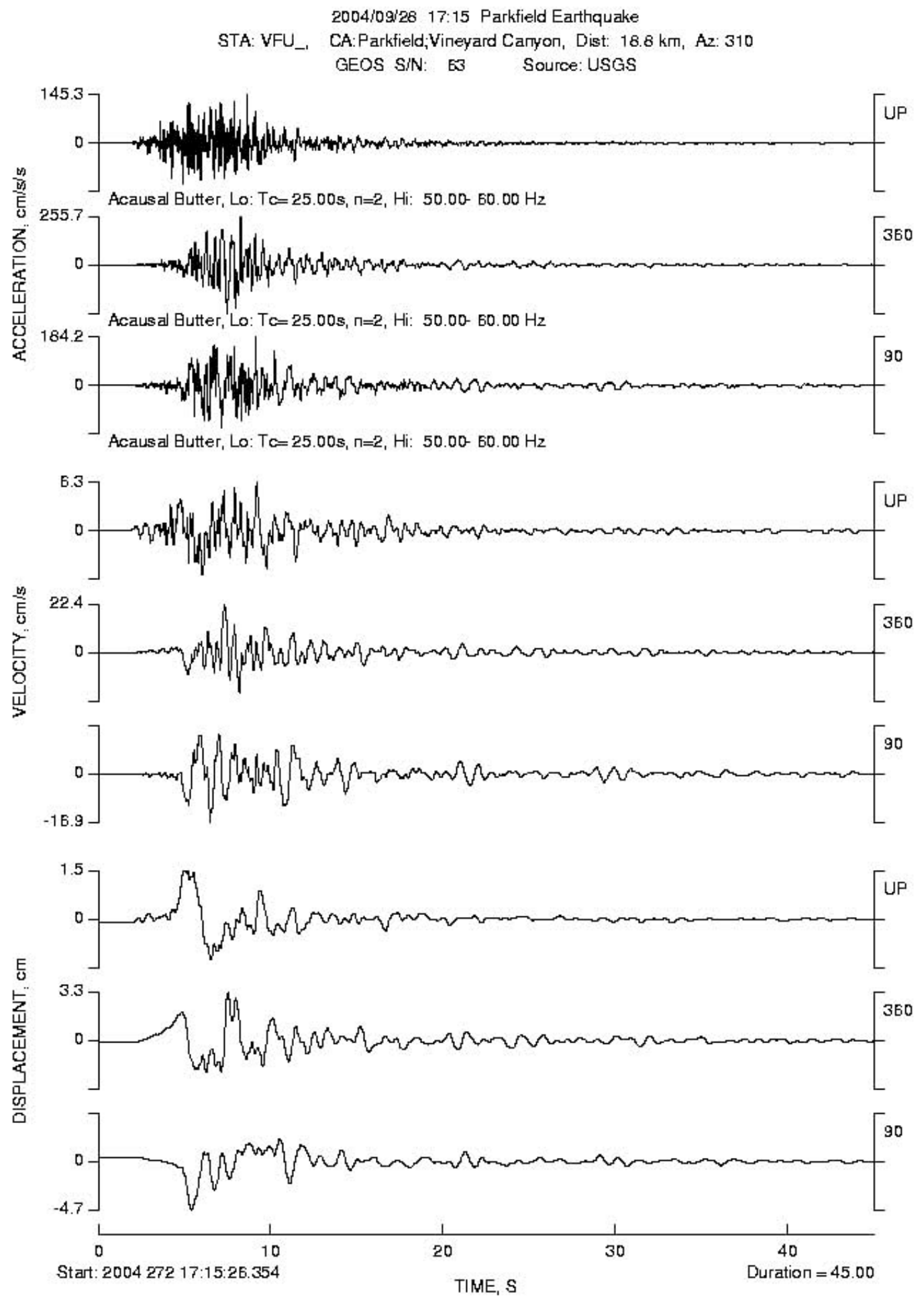

Figure 27. Corrected acceleration, velocity, and displacement inferred for the Parkfield earthquake of September 28, 2004 as recorded on the GEOS Strong-motion array near Parkfield, CA at the Vineyard Canyon site (see Figure 1 and Table 1). 

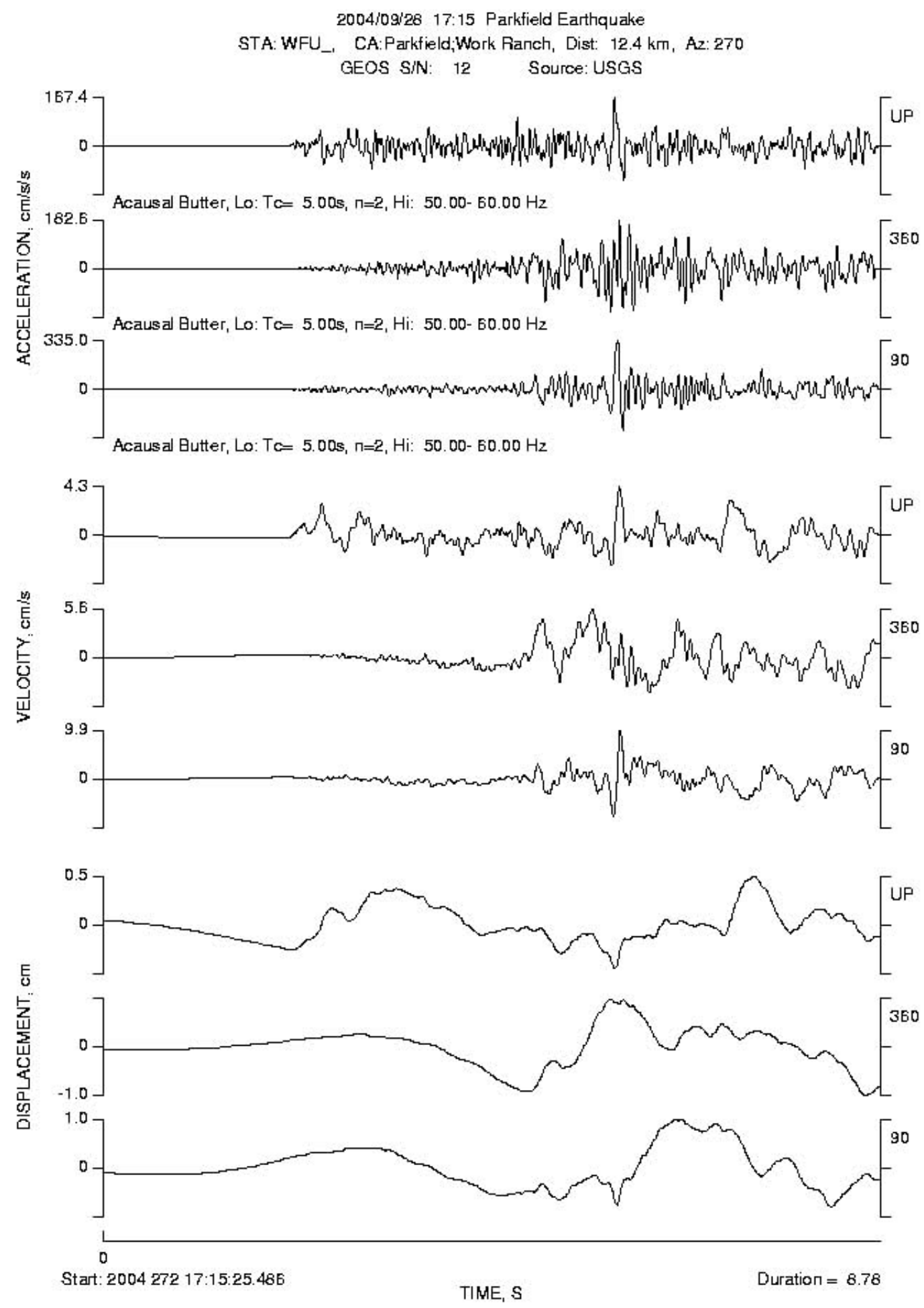

Figure 28. Corrected acceleration, velocity, and displacement inferred for the Parkfield earthquake of September 28, 2004 as recorded on the GEOS Strong-motion array near Parkfield, CA at the Work Ranch site (see Figure 1 and Table 1). 


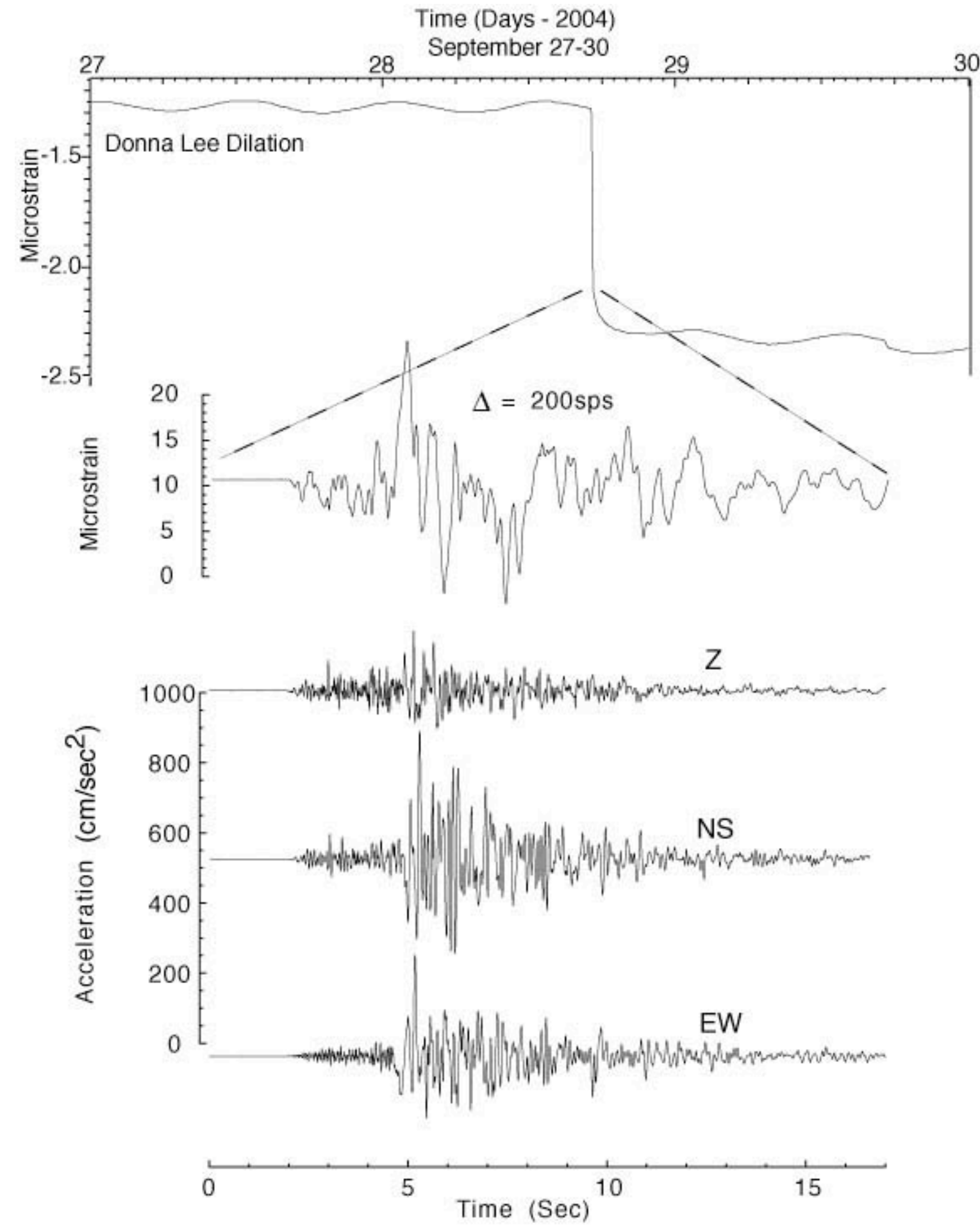

Figure 29. Volumetric-strain time histories at two sampling rates (1 sp 10 mins., trace 1; 200 sps, trace 2) and 3 component acceleration time histories (200 sps, traces 3, 4, and 5) generated by the Parkfield earthquake of September 28, 2004 at the Donna Lee site (see Figure 1 and Table 1). Trace 1 was recorded continuously via GOES satellite (Silverman et al., 1989). Traces 2-5 were recorded on the GEOS Strong-motion array near Parkfield, CA. 


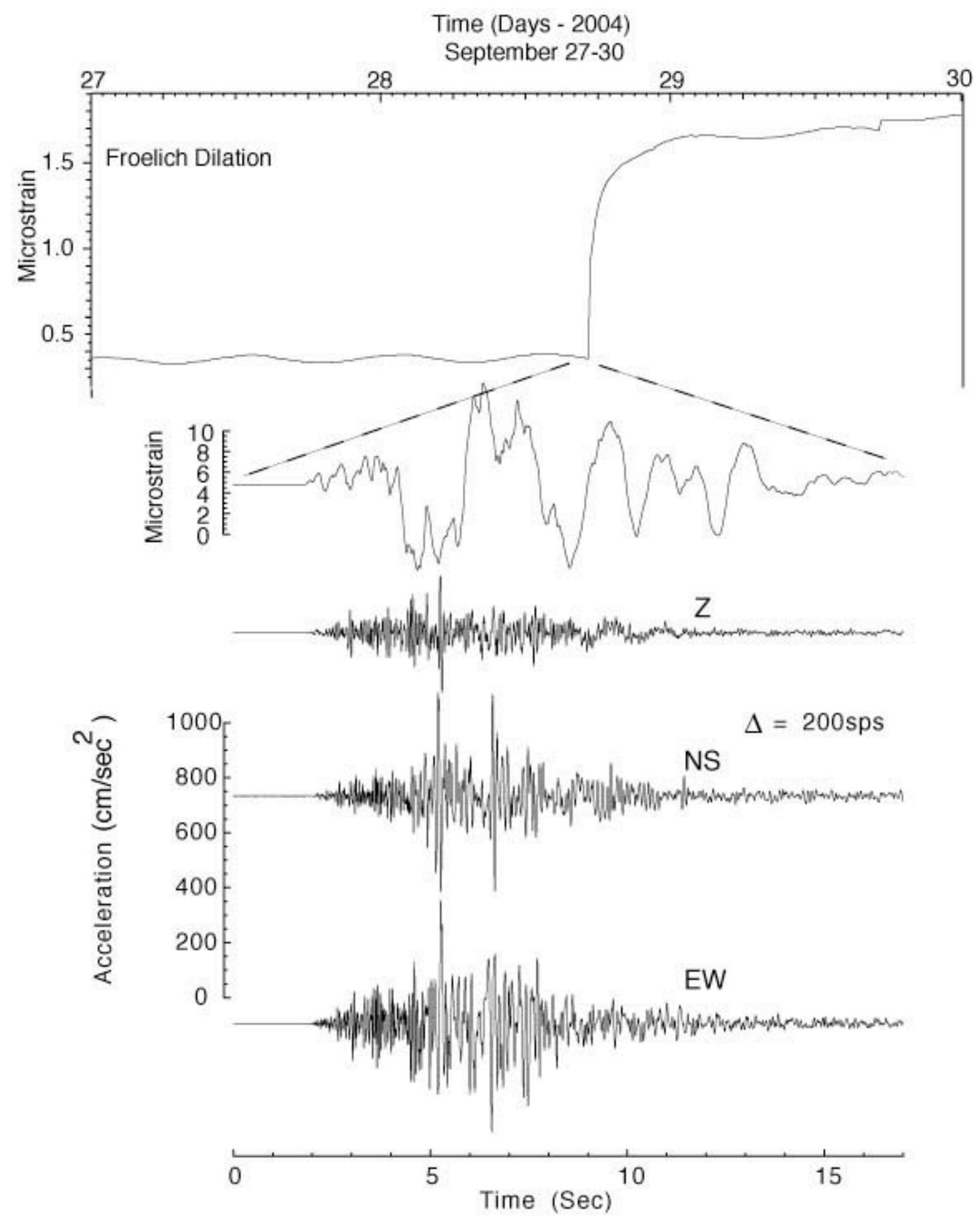

Figure 30. Volumetric-strain time histories at two sampling rates ( $1 \mathrm{sp} 10$ mins., trace 1; $200 \mathrm{sps}$, trace 2) and 3 component acceleration time histories (200 sps, traces 3, 4, and 5)) generated by the Parkfield earthquake of September 28, 2004 at the Froelich site (see Figure 1 and Table 1). Trace 1 was recorded continuously via GOES satellite (Silverman et al., 1989). Traces 2-5 were recorded on the GEOS Strongmotion array near Parkfield, CA. 

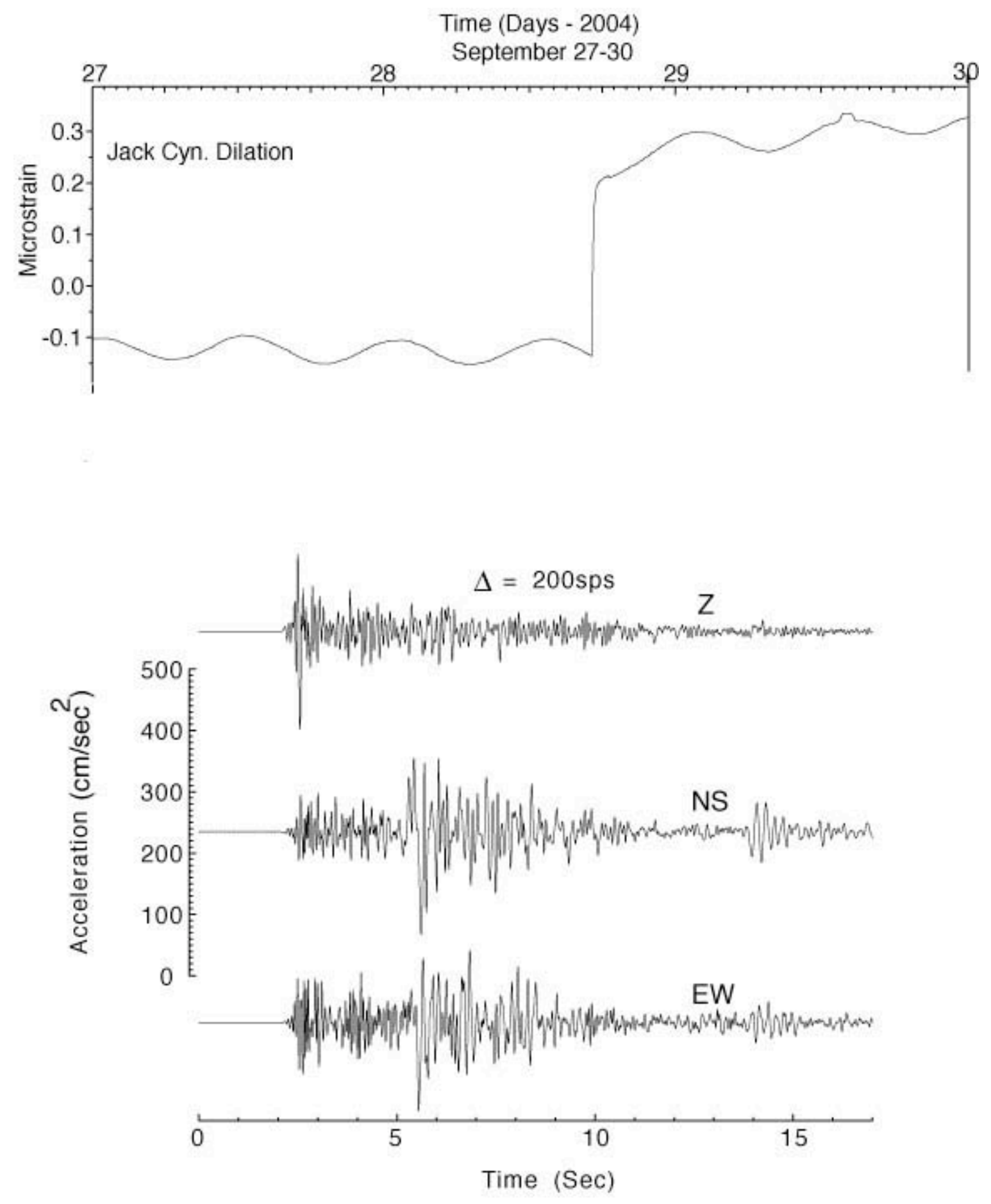

Figure 31. Volumetric-strain time histories atone sampling rates $(1 \mathrm{sp} 10$ mins., trace 1 and component acceleration time histories (200 sps, traces 2, 3, and 4)) generated by the Parkfield earthquake of September 28, 2004 at the Jack Canyon site (see Figure 1 and Table 1). Trace 1 was recorded continuously via GOES satellite (Silverman et al., 1989). Traces 2-4 were recorded on the GEOS Strong-motion array near Parkfield, CA. 
Time (Days)

September 27-30, 2004

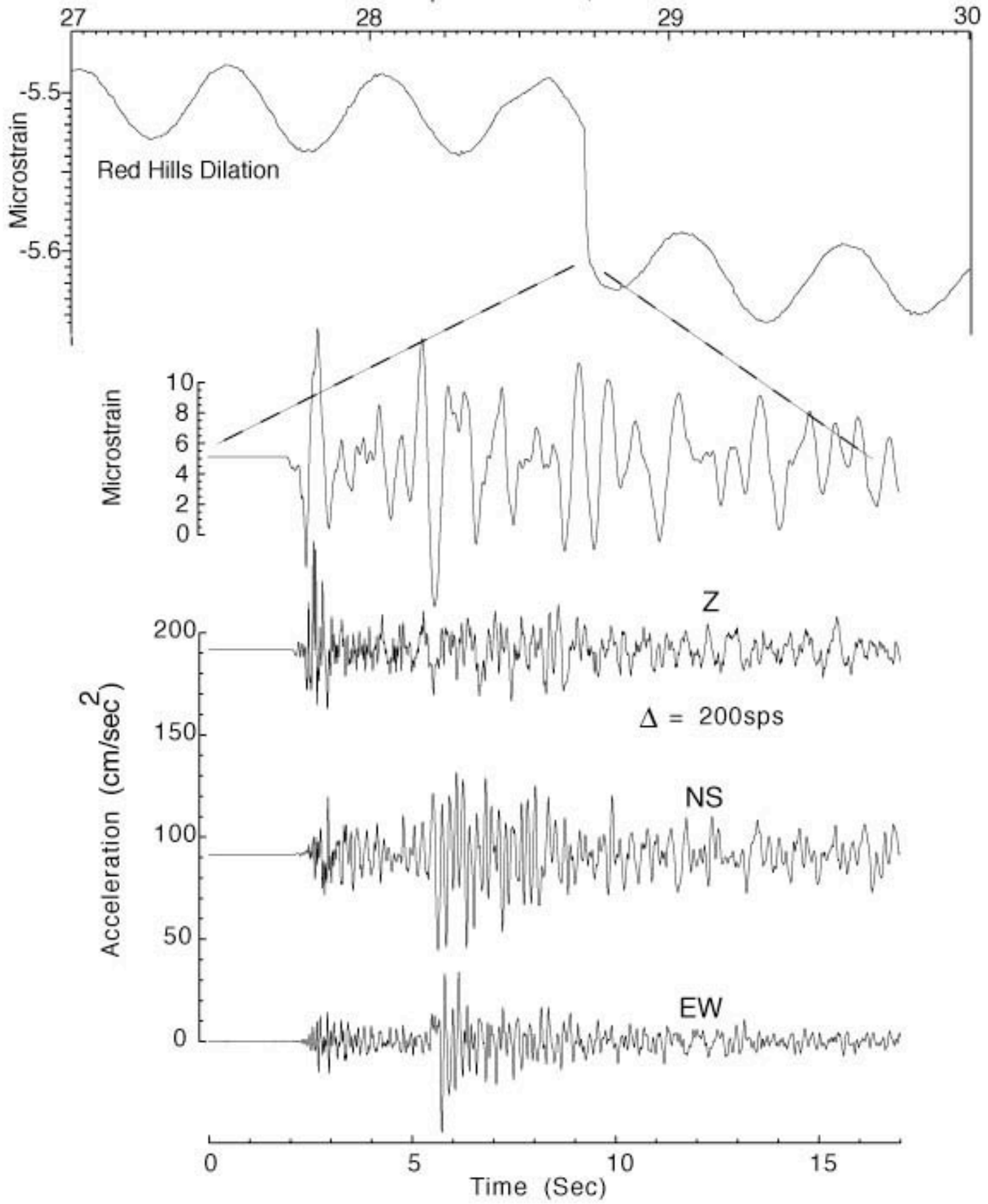

Figure 32. Volumetric-strain time histories at two sampling rates ( $1 \mathrm{sp} 10$ mins., trace $1 ; 200 \mathrm{sps}$, trace 2 ) and 3 component acceleration time histories (200 sps, traces 3, 4, and 5)) generated by the Parkfield earthquake of September 28, 2004 at the Red Hills site (see Figure 1 and Table 1). Trace 1 was recorded continuously via GOES satellite (Silverman et al., 1989). Traces 2-5 were recorded on the GEOS Strongmotion array near Parkfield, CA. 


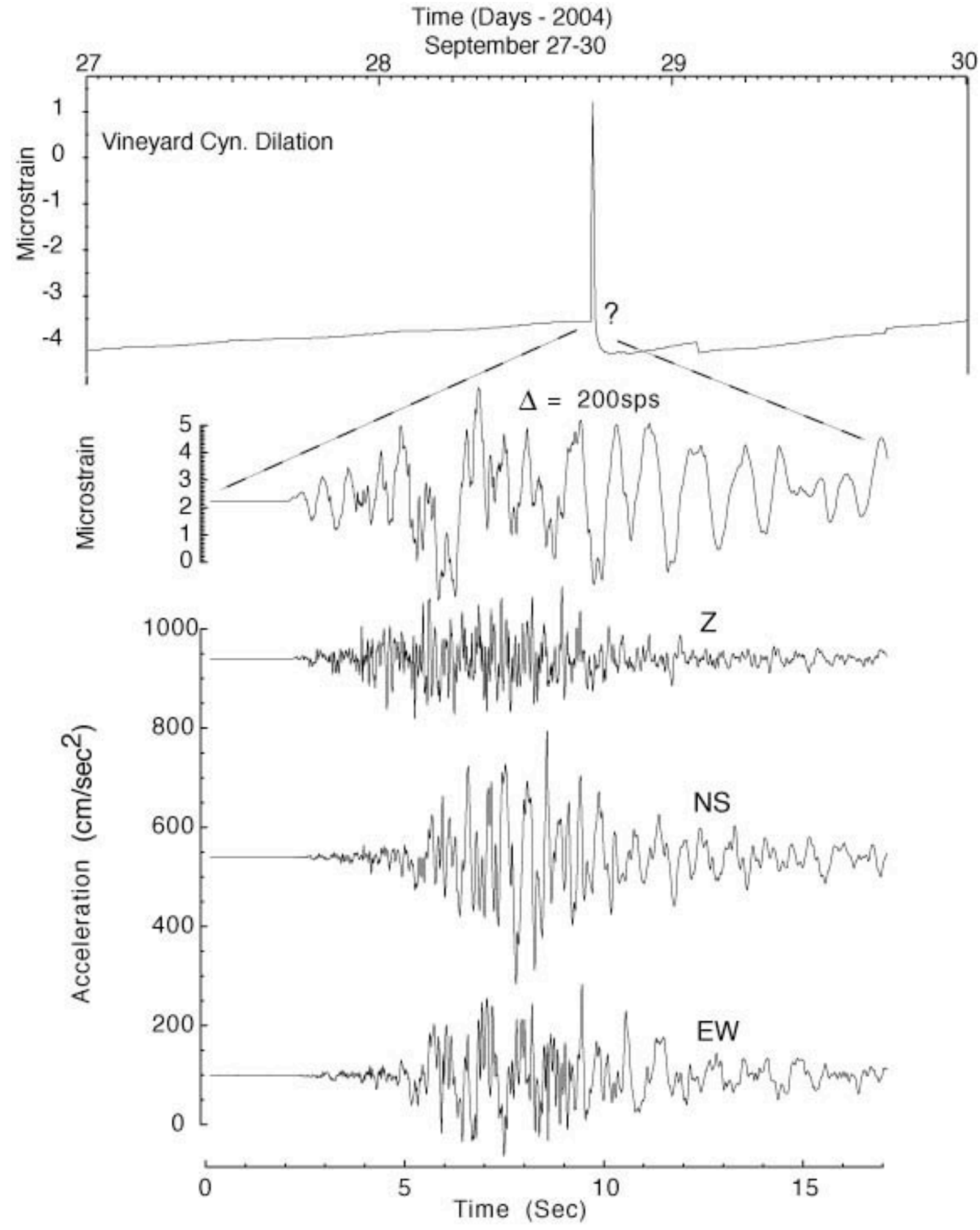

Figure 33. Volumetric-strain time histories at two sampling rates ( $1 \mathrm{sp} 10$ mins., trace 1; $200 \mathrm{sps}$, trace 2) and 3 component acceleration time histories (200 sps, traces 3, 4, and 5)) generated by the Parkfield earthquake of September 28, 2004 at the Vineyard Canyon site (see Figure 1 and Table 1). Trace 1 was recorded continuously via GOES satellite (Silverman et al., 1989). Traces 2-5 were recorded on the GEOS 


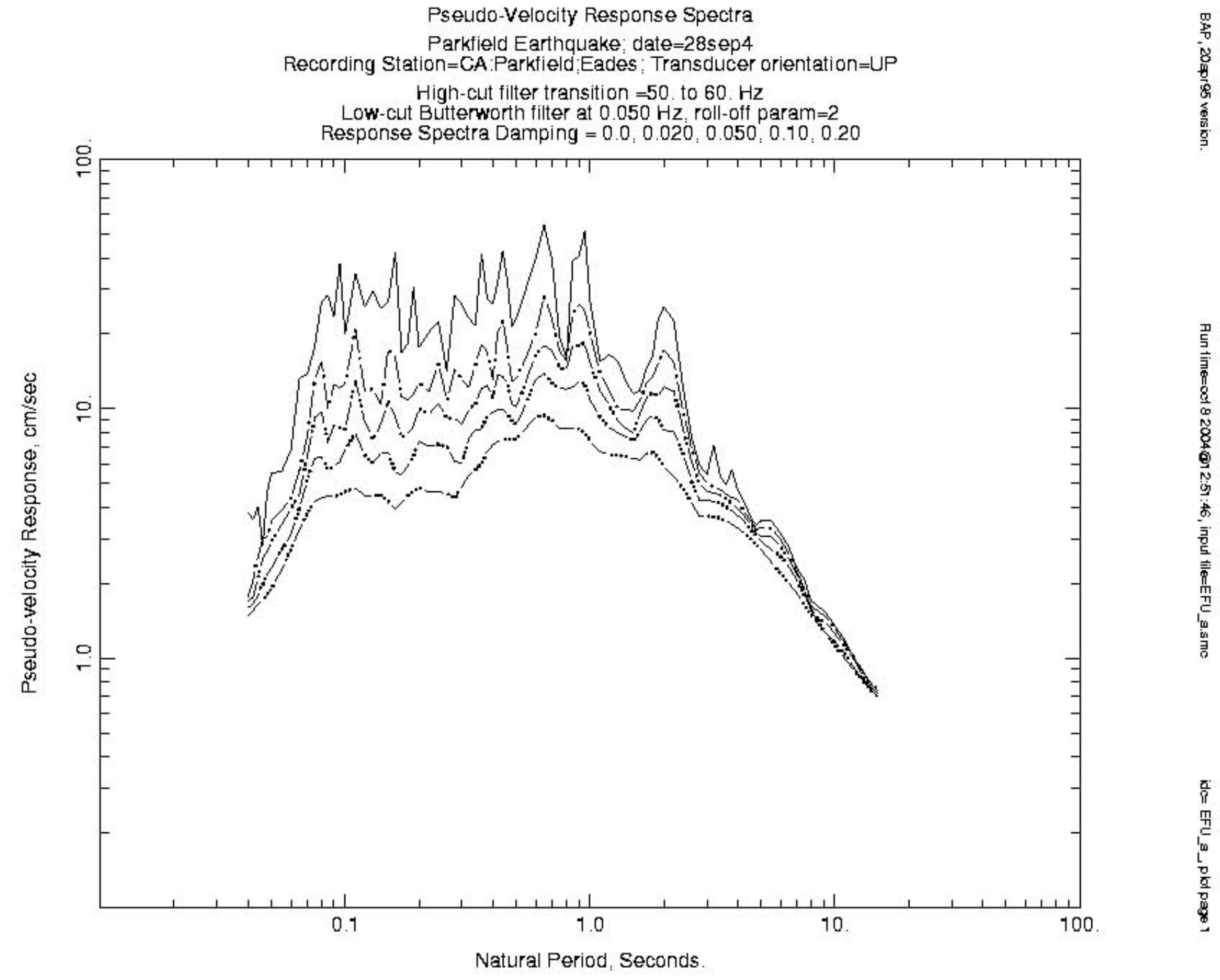

Figure 34. Pseudo velocity response spectra computed at the indicated levels of damping for the component of acceleration indicated and with the corresponding parameters indicated. 
Pseudo-Velocity Response Spectra

Parkfield Earthquake date $=28 \mathrm{sep} 4$

Recording Station=CA:Parkfield: Eades: Transducer orientation $=360$

High-cut filter transition $=50$. to $60 . \mathrm{Hz}$

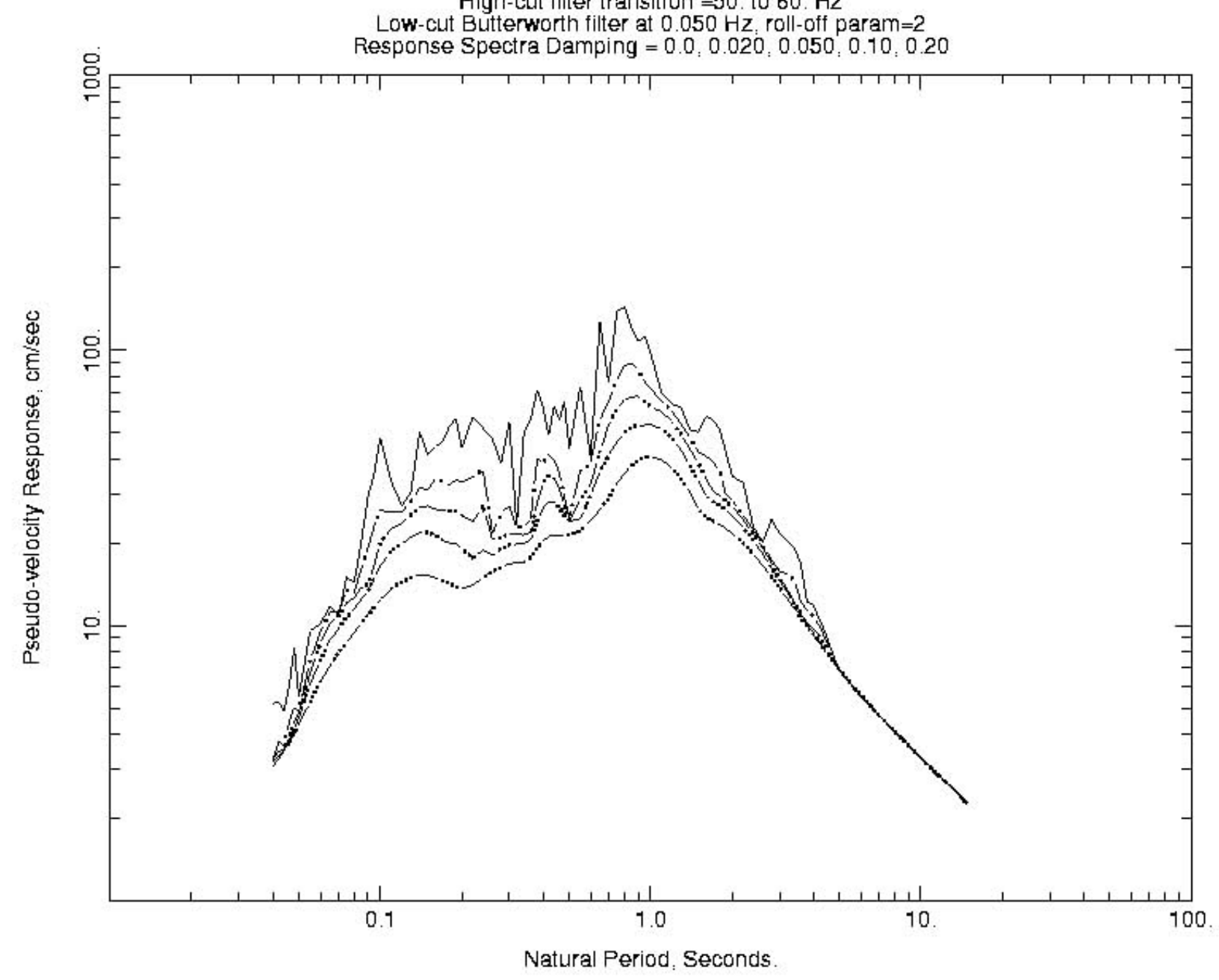

Figure 35. Pseudo velocity response spectra computed at the indicated levels of damping for the component of acceleration indicated and with the corresponding parameters indicated. 


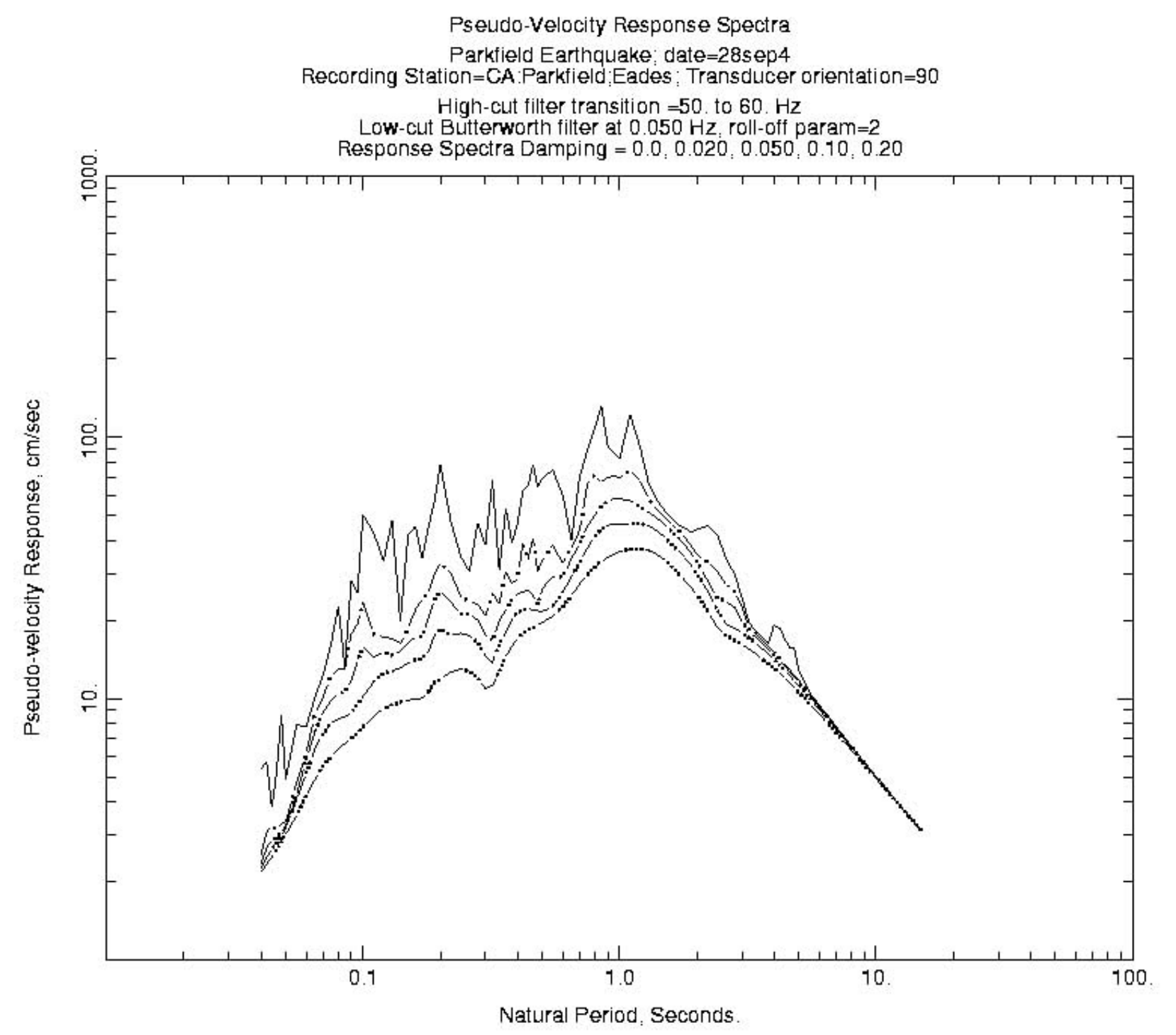

Figure 36. Pseudo velocity response spectra computed at the indicated levels of damping for the component of acceleration indicated and with the corresponding parameters indicated. 


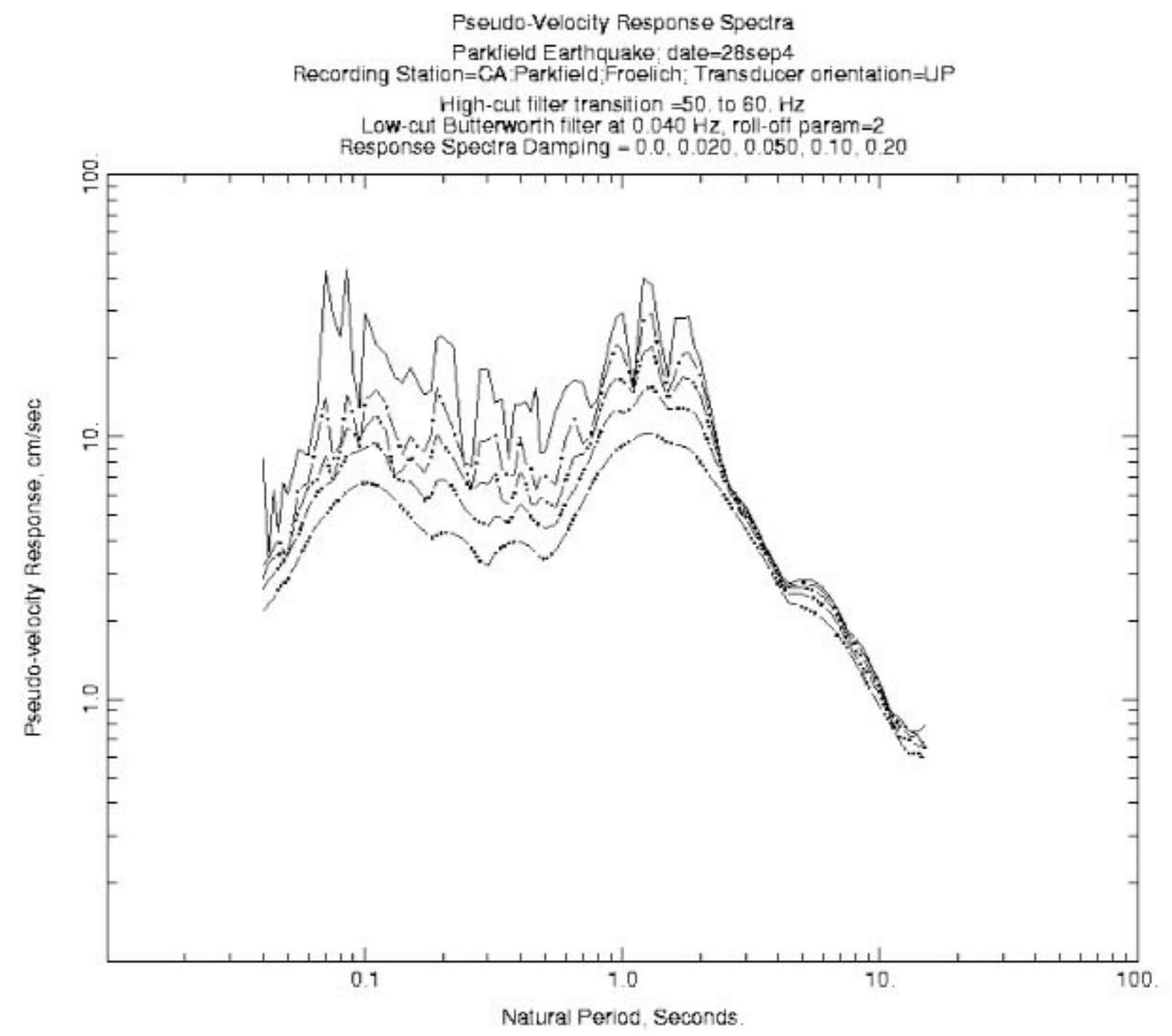

Figure 37. Pseudo velocity response spectra computed at the indicated levels of damping for the component of acceleration indicated and with the corresponding parameters indicated. 


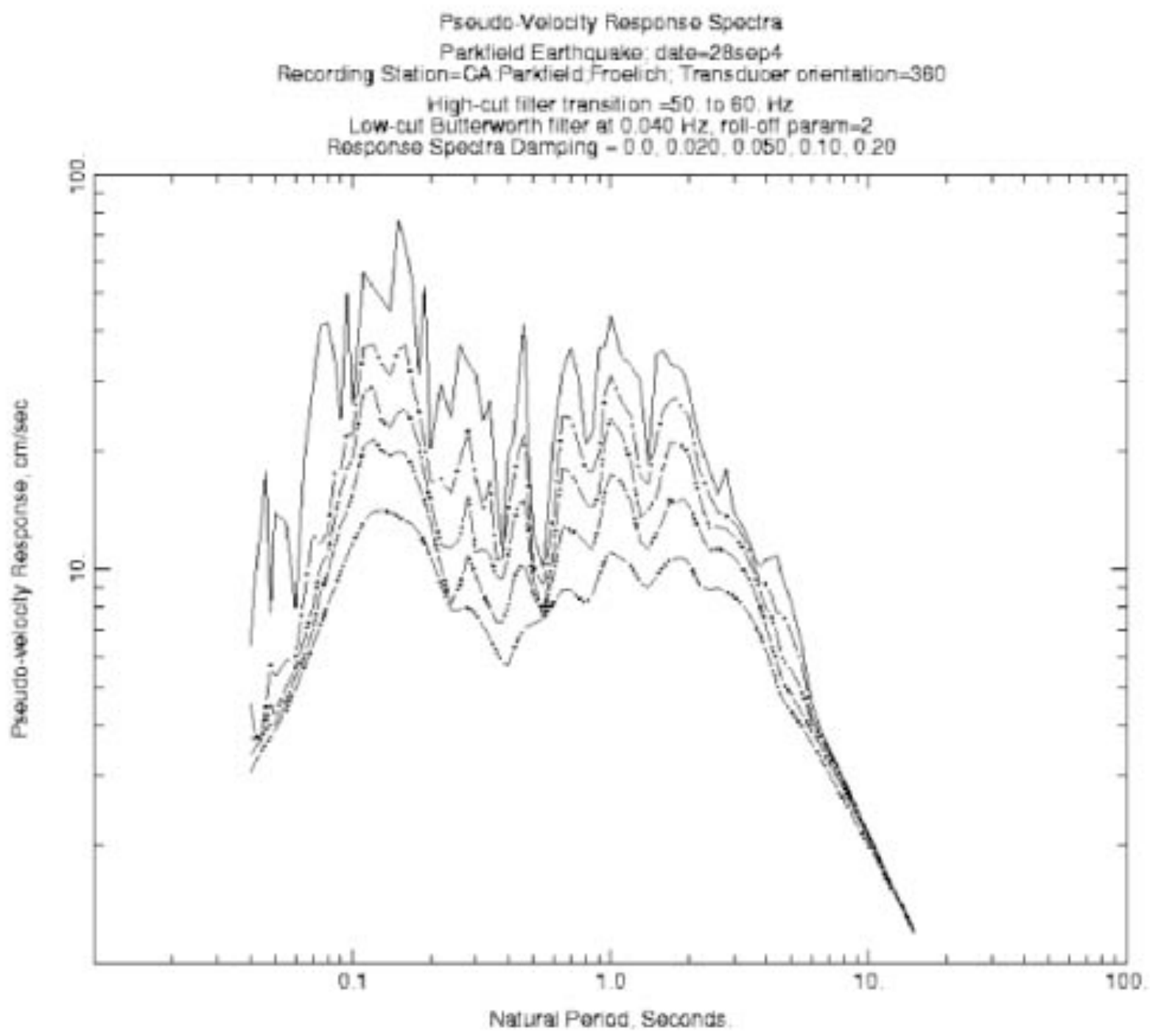

Figure 38. Pseudo velocity response spectra computed at the indicated levels of damping for the component of acceleration indicated and with the corresponding parameters indicated. 


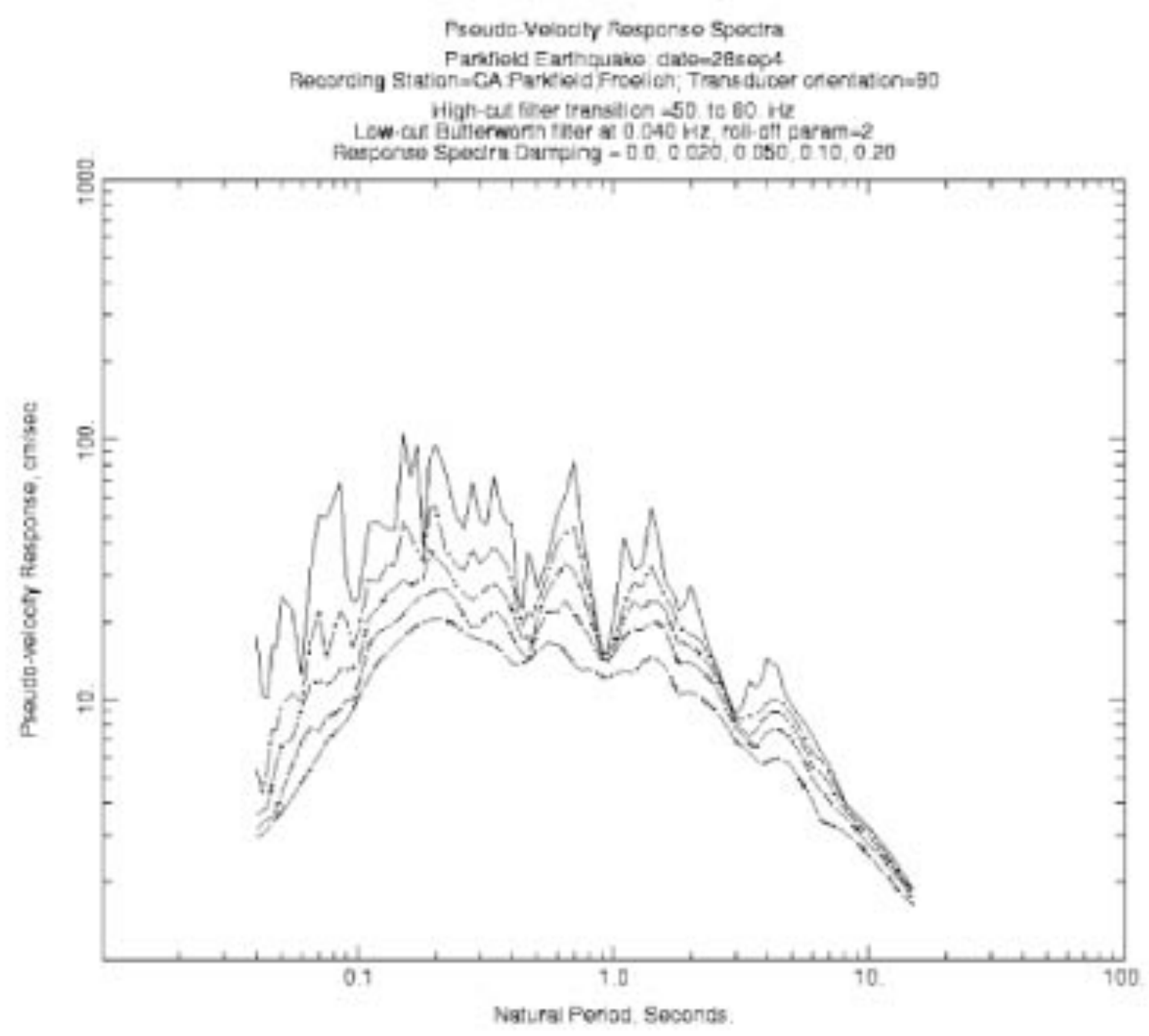

Figure 39. Pseudo velocity response spectra computed at the indicated levels of damping for the component of acceleration indicated and with the corresponding parameters indicated. 


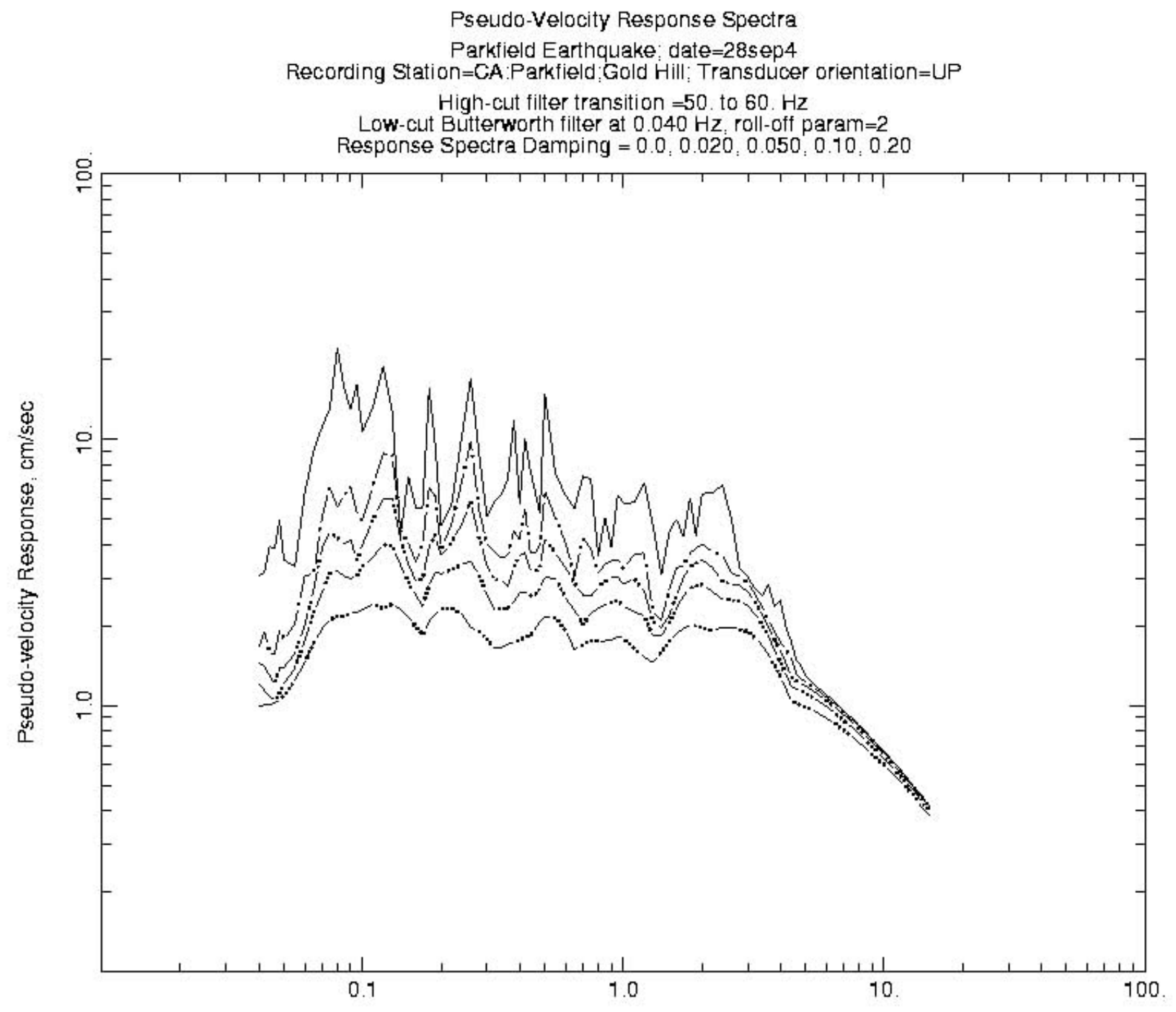

Figure 40. Pseudo velocity response spectra computed at the indicated levels of damping for the component of acceleration indicated and with the corresponding parameters indicated. 
Pseudo-Velocity Response Spectra

Parkfield Earthquake: date $=28 \mathrm{sep} 4$

Recording Station=CA:Parkfield: Gold Hill: Transducer orientation=360

High-cut filter transition $=50$. to $60 . \mathrm{Hz}$

Response Spectra Damping $=0.0,0.020,0.050,0.10,0.20$

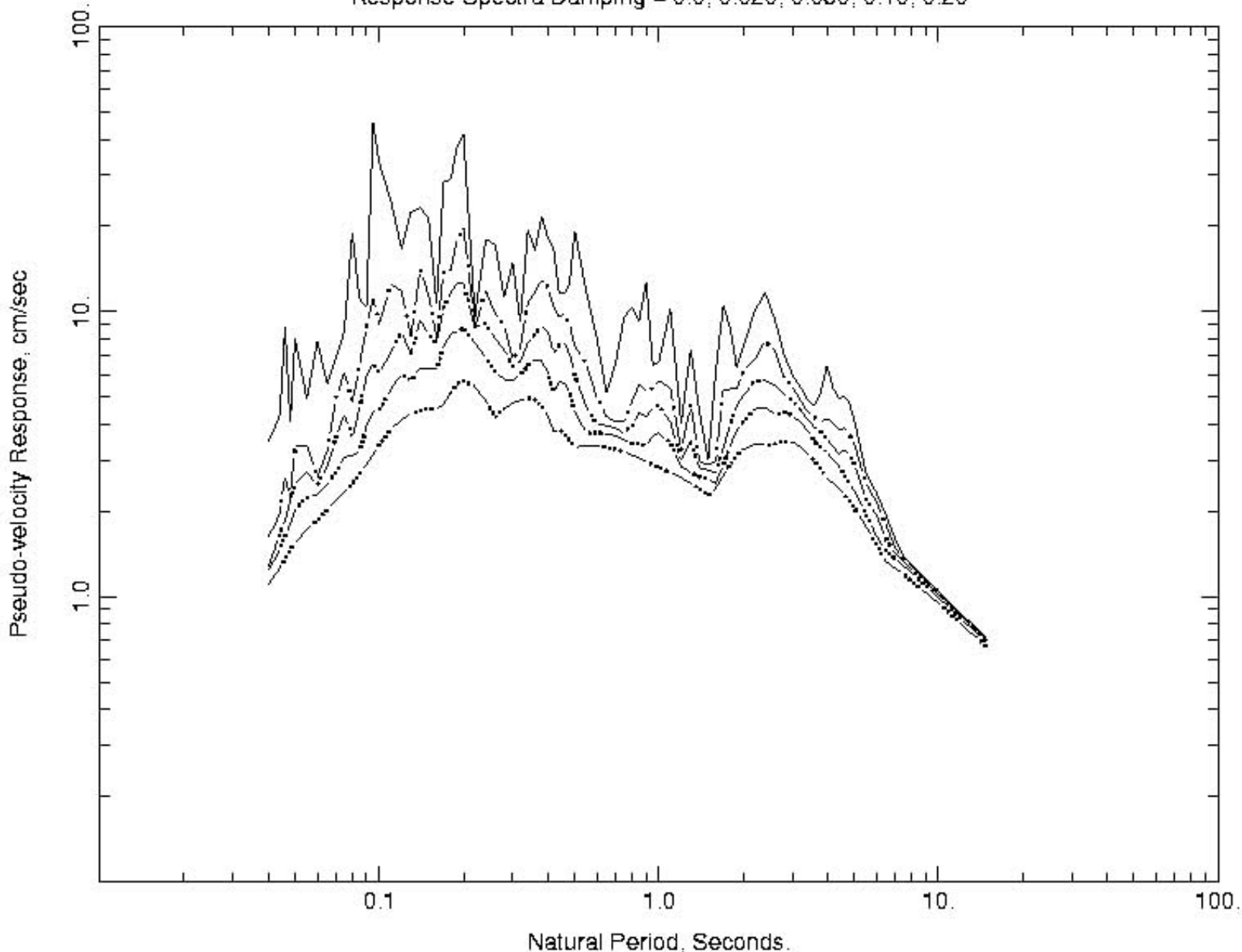

Figure 41. Pseudo velocity response spectra computed at the indicated levels of damping for the component of acceleration indicated and with the corresponding parameters indicated. 


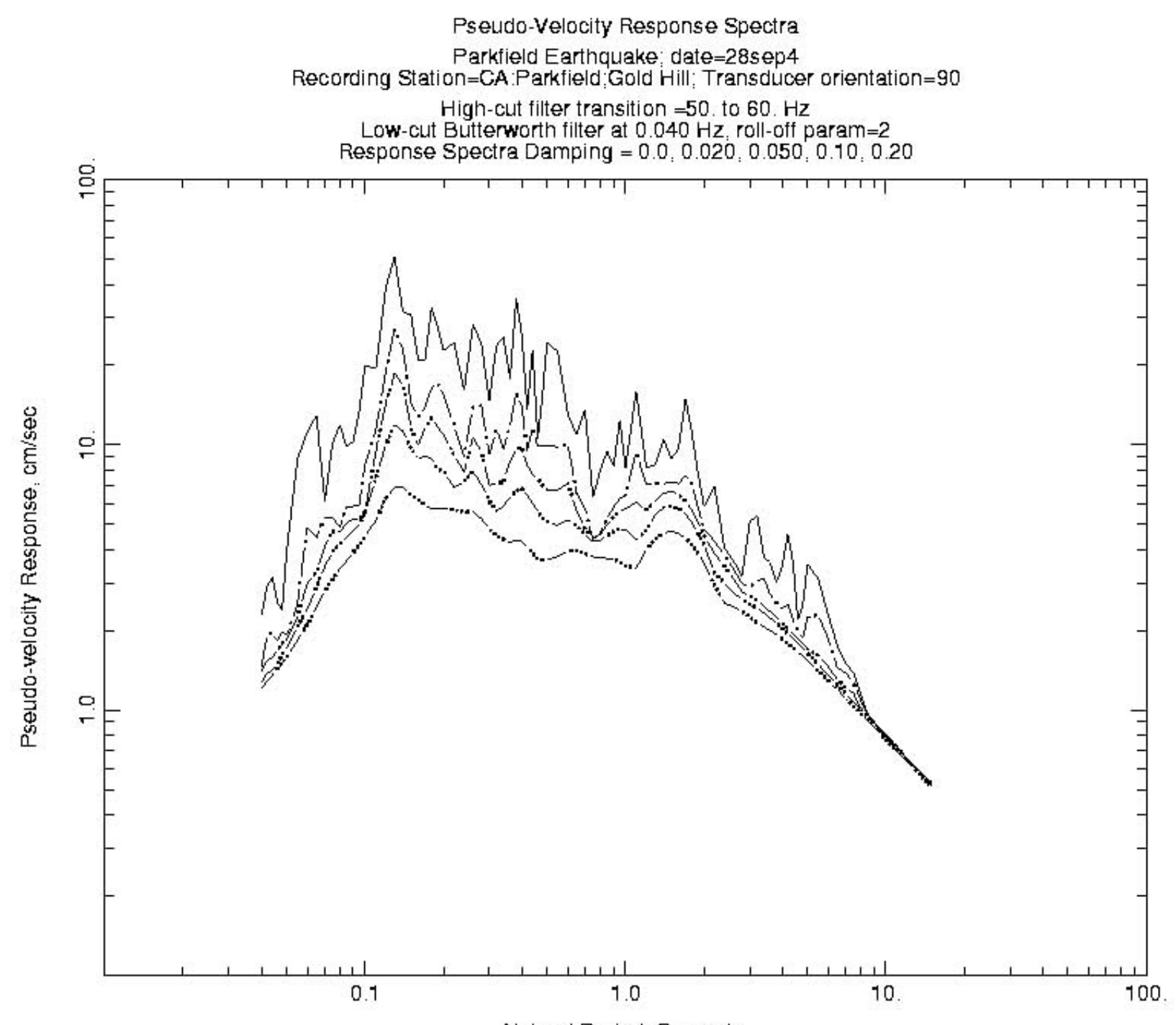

Figure 42. Pseudo velocity response spectra computed at the indicated levels of damping for the component of acceleration indicated and with the corresponding parameters indicated. 
Pseudo-Velocity Response Spectra

Parkfield Earthquake: date=28sep4
Recording Station=CA:Parkfield Joaquin Canyon: Transducer orientation=UP

High-cut filter transition $=50$. to $60 . \mathrm{Hz}$

Low-cut Butterworth filter at $0.040 \mathrm{~Hz}$, roll-off param $=2$

Response Spectra Damping $=0.0,0.020,0.050,0.10,0.20$

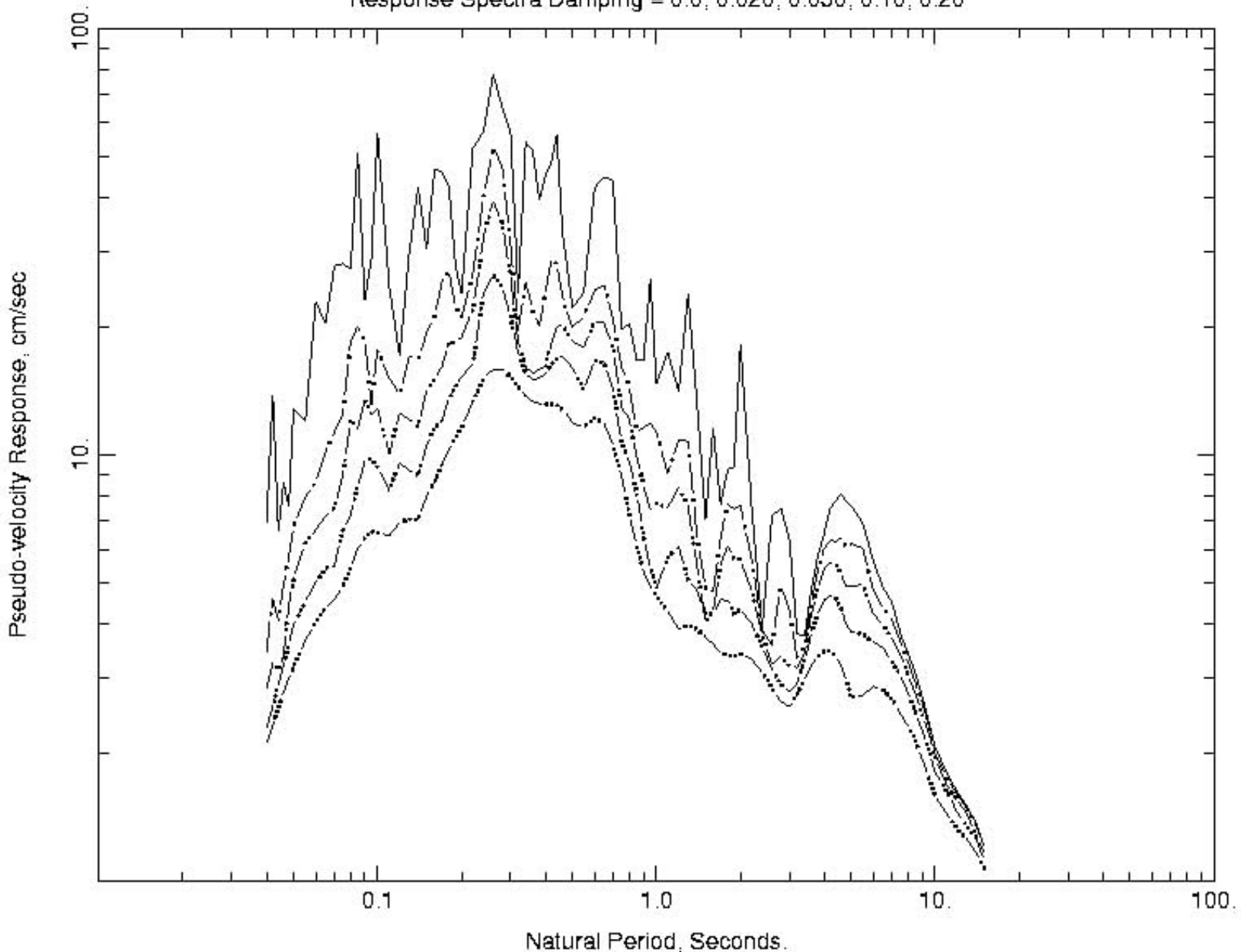

Figure 43. Pseudo velocity response spectra computed at the indicated levels of damping for the component of acceleration indicated and with the corresponding parameters indicated. 


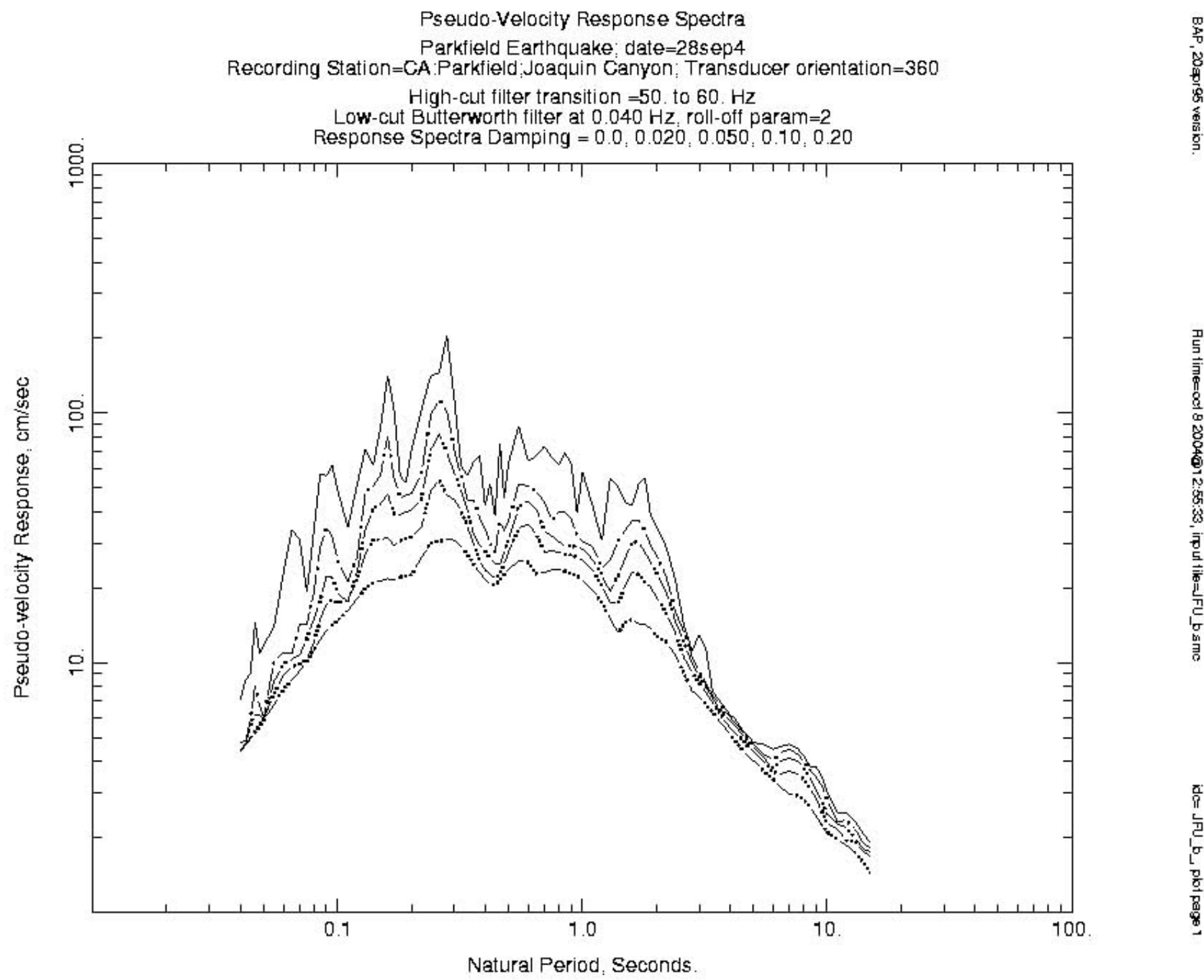

Figure 44. Pseudo velocity response spectra computed at the indicated levels of damping for the component of acceleration indicated and with the corresponding parameters indicated. 


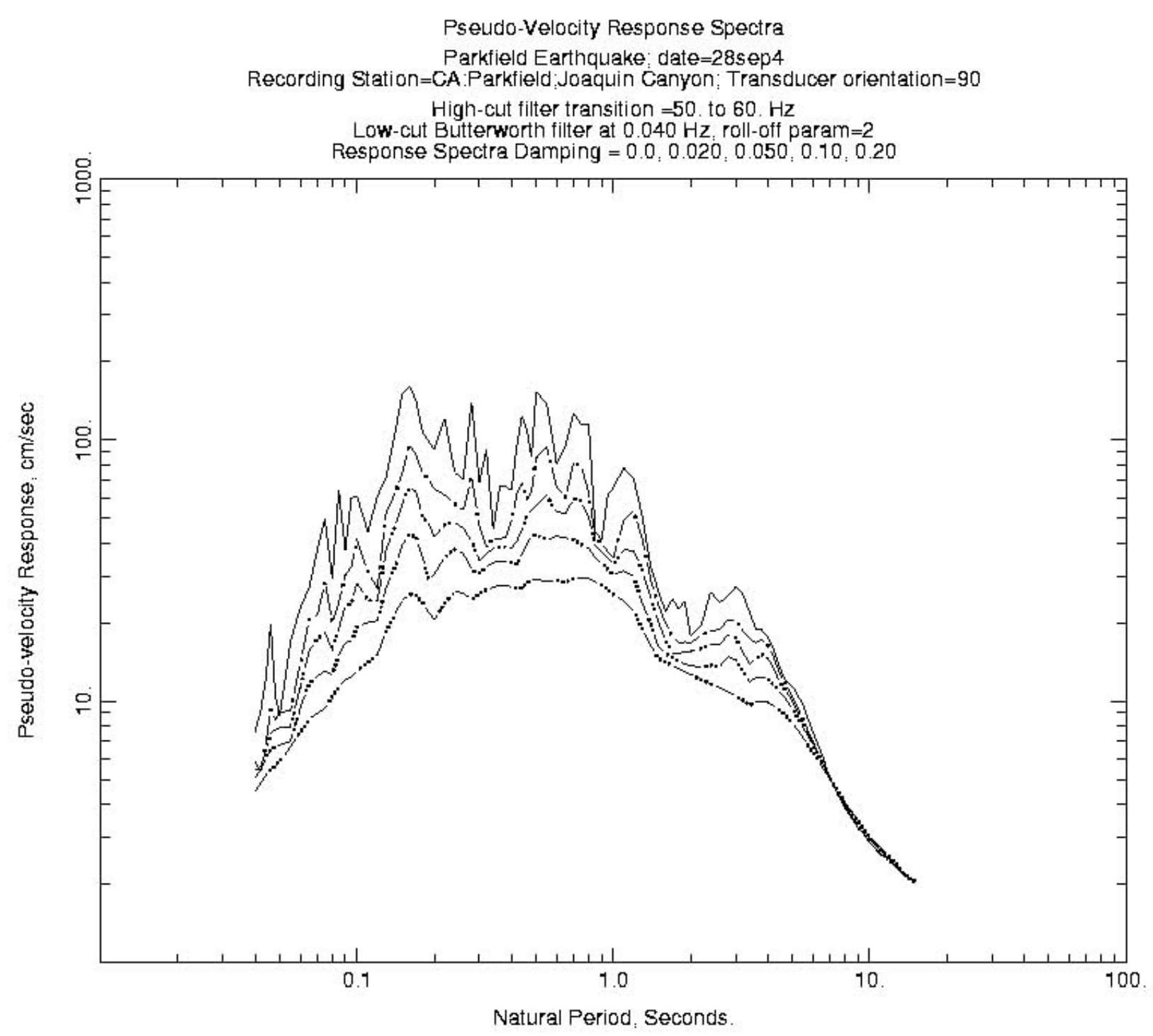

Figure 45. Pseudo velocity response spectra computed at the indicated levels of damping for the component of acceleration indicated and with the corresponding parameters indicated. 


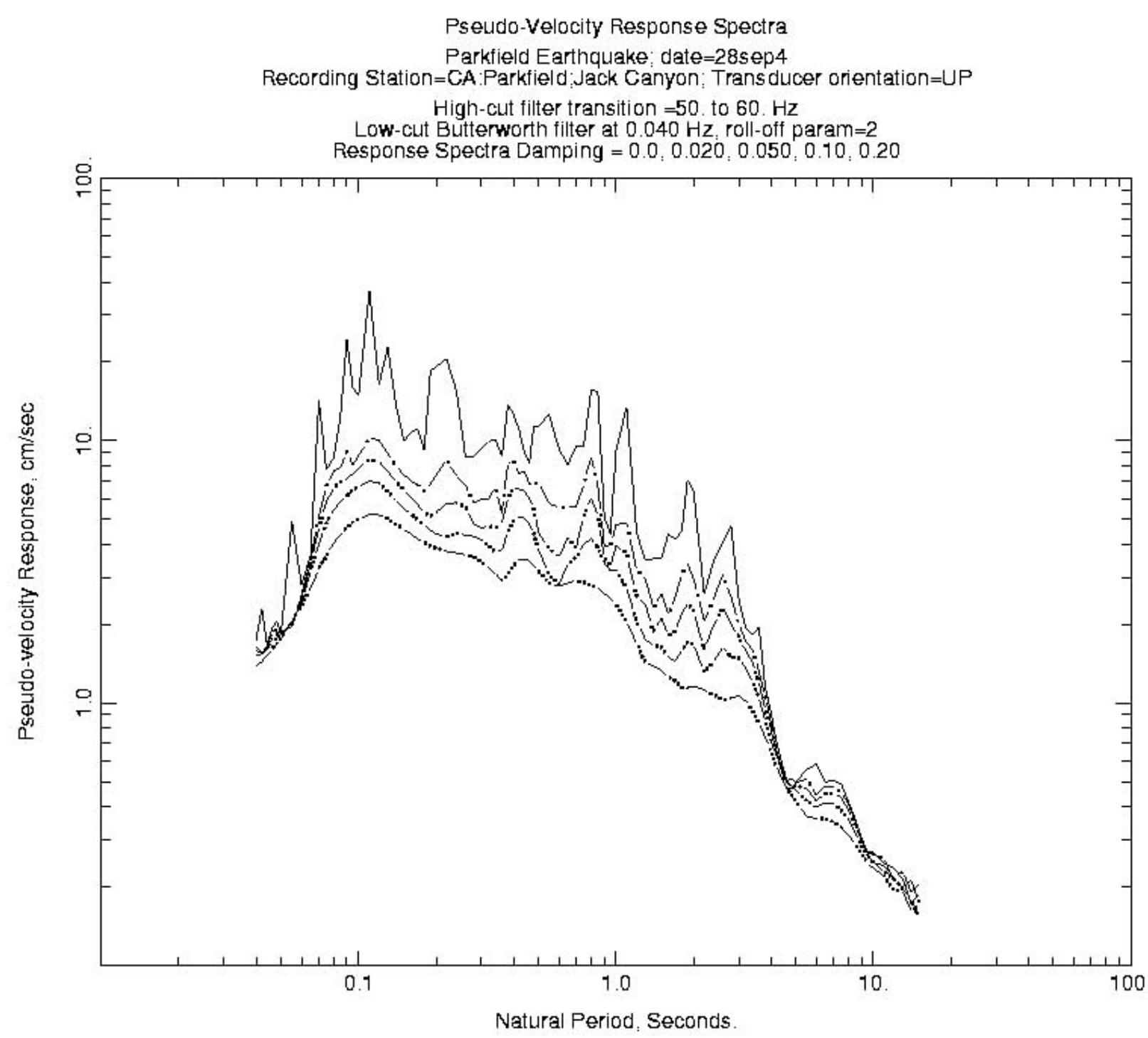

Figure 46. Pseudo velocity response spectra computed at the indicated levels of damping for the component of acceleration indicated and with the corresponding parameters indicated. 
Pseudo-Velocity Response Spectra

Parkfield Earthquake date $=28 \mathrm{sep} 4$

Recording Station=CA:Parkfield:Jack Canyon; Transducer orientation=360

High-cut filter transition $=50$. to 60 . $\mathrm{Hz}$

Low-cut Butterworth filter at $0.040 \mathrm{~Hz}$ roll-off param $=2$

Response Spectra Damping $=0.0,0.020,0.050,0.10,0.20$

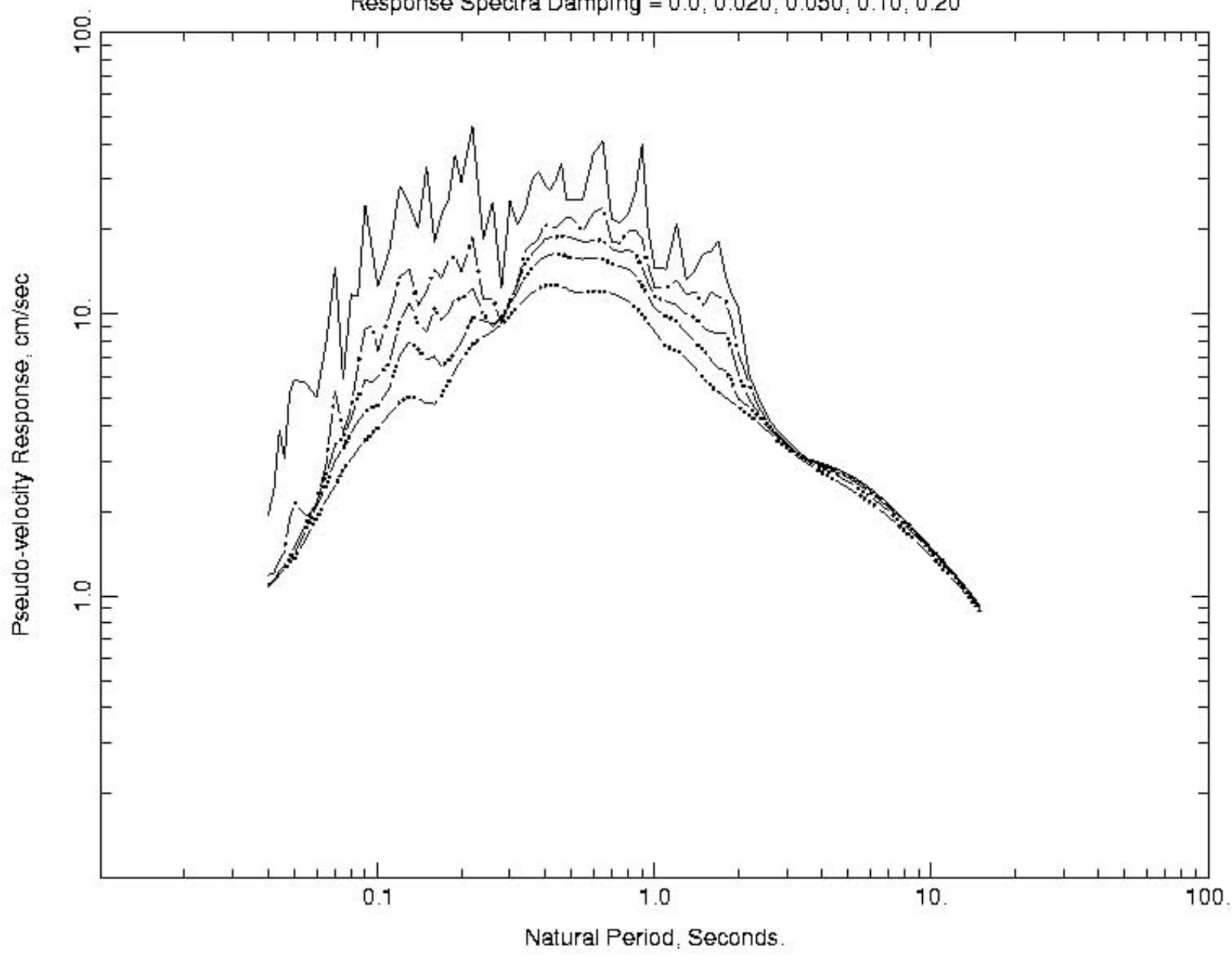

Figure 47. Pseudo velocity response spectra computed at the indicated levels of damping for the component of acceleration indicated and with the corresponding parameters indicated. 


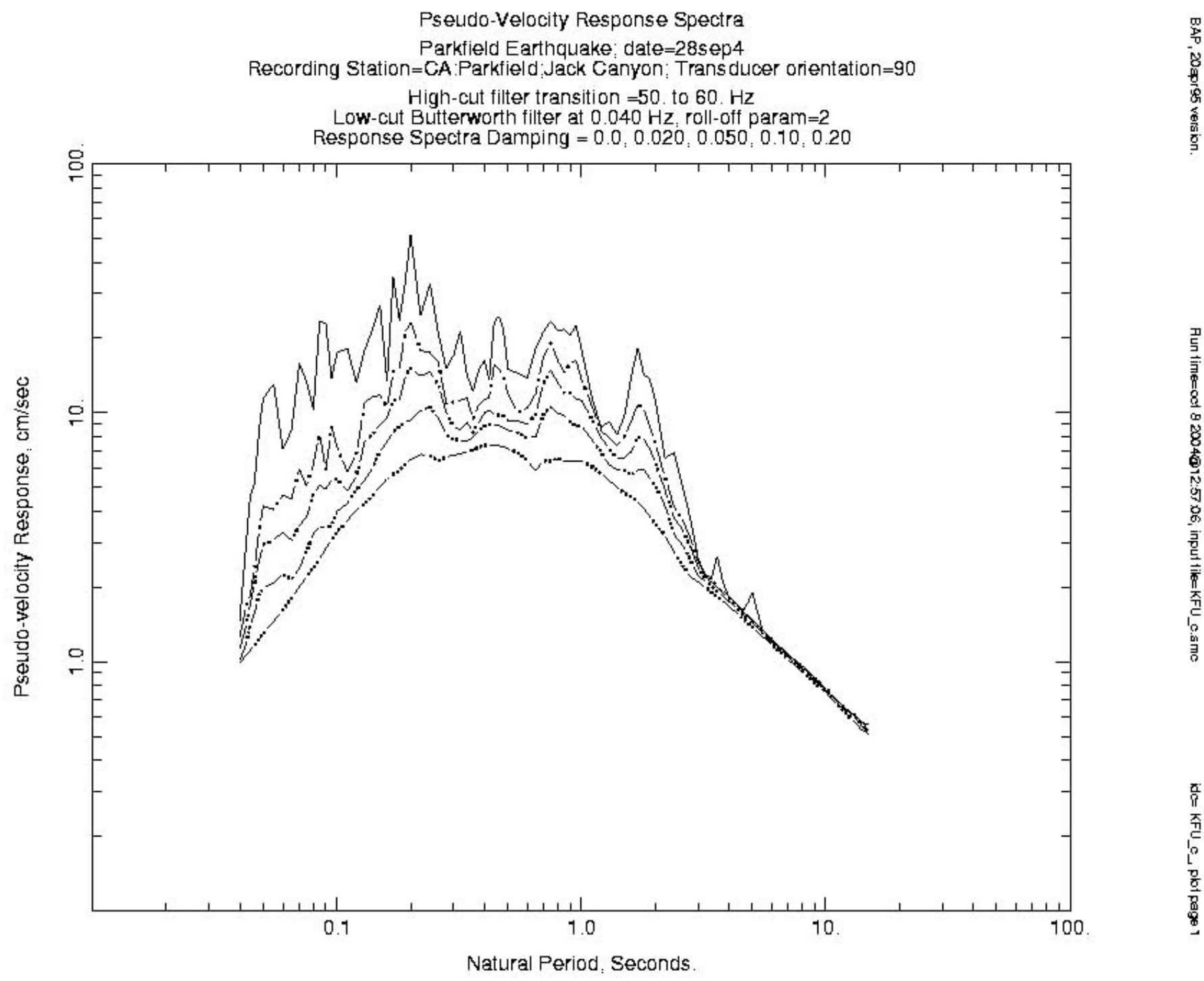

Figure 48. Pseudo velocity response spectra computed at the indicated levels of damping for the component of acceleration indicated and with the corresponding parameters indicated. 


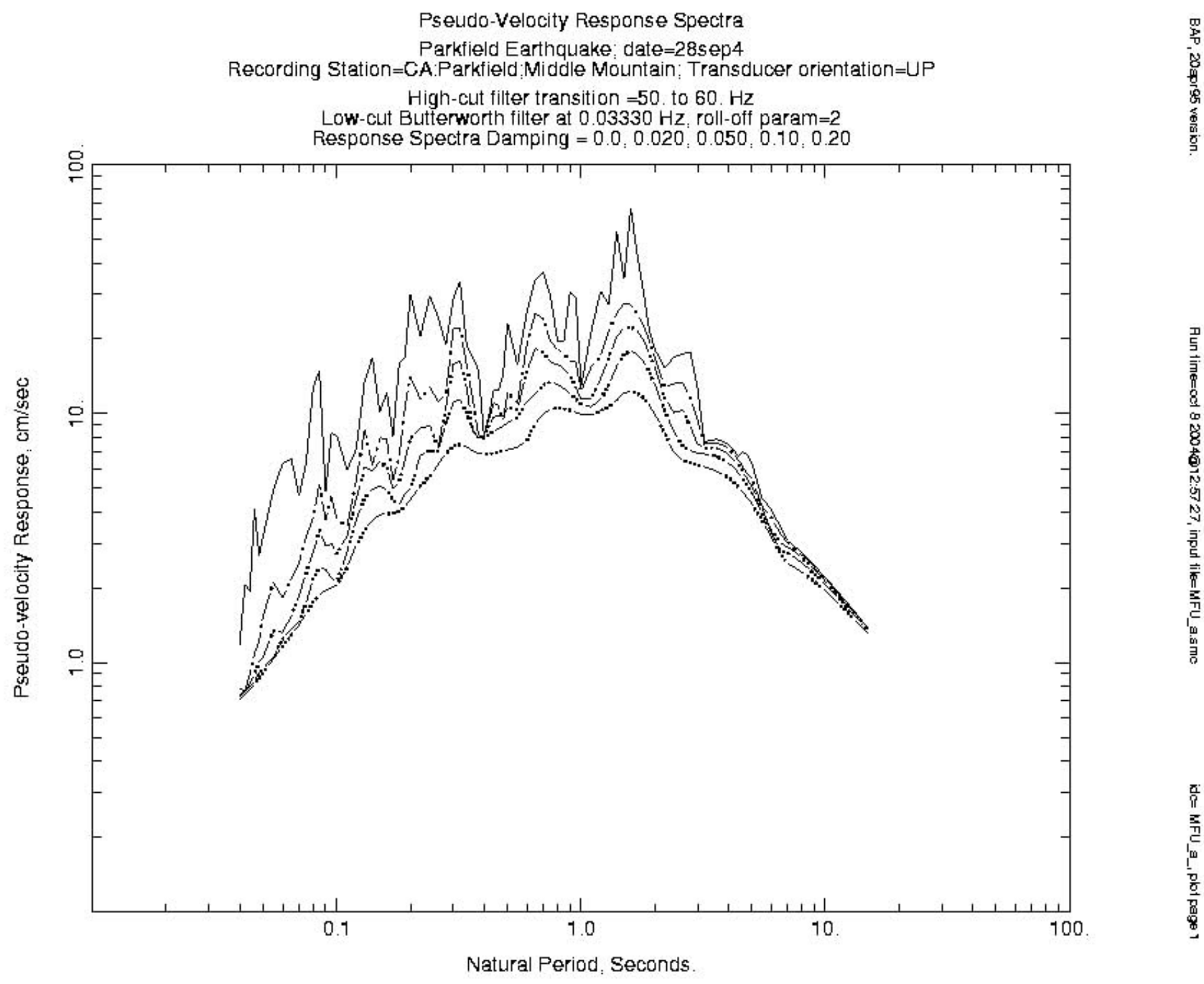

Figure 49. Pseudo velocity response spectra computed at the indicated levels of damping for the component of acceleration indicated and with the corresponding parameters indicated. 


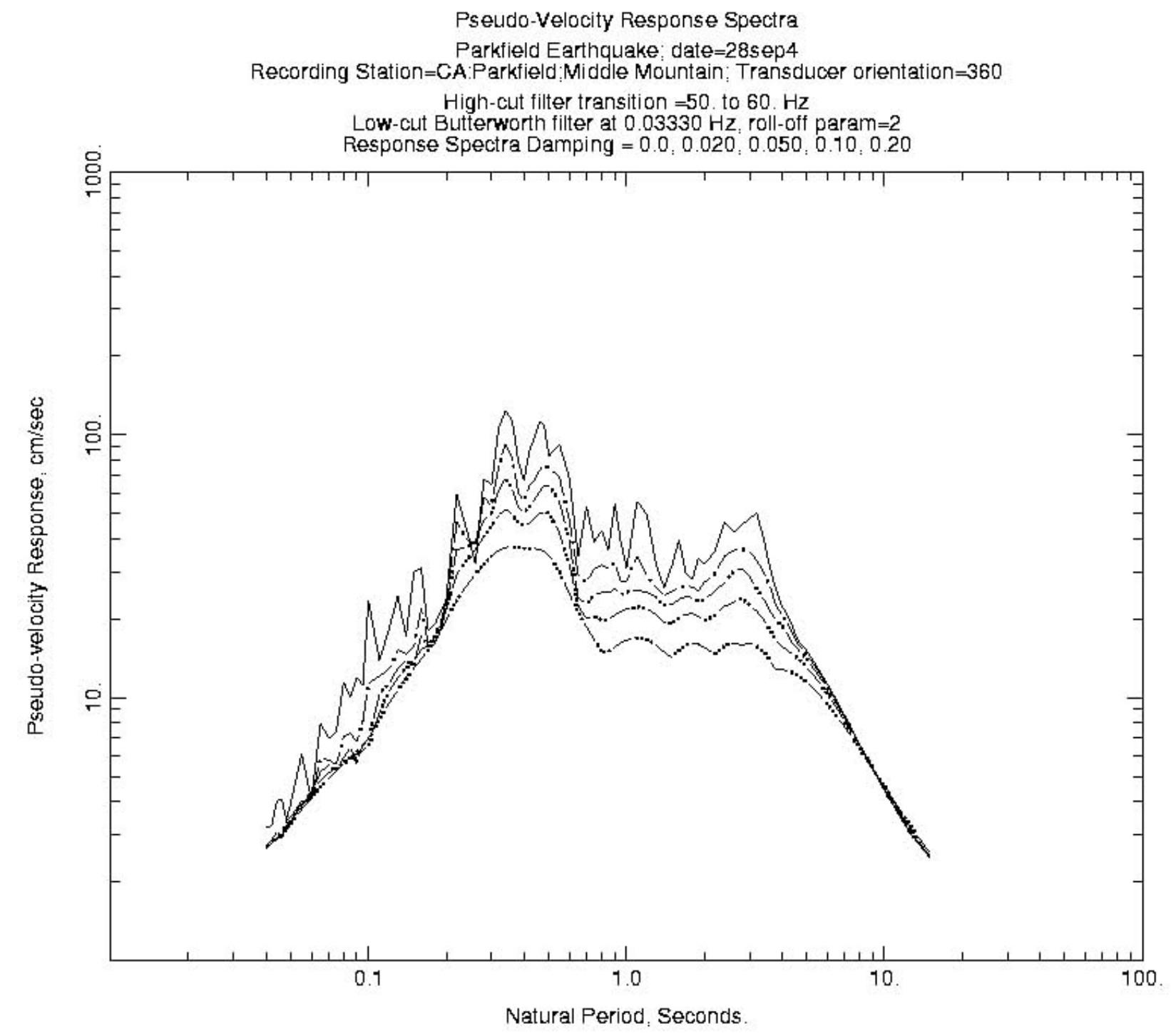

Figure 50. Pseudo velocity response spectra computed at the indicated levels of damping for the component of acceleration indicated and with the corresponding parameters indicated. 
Pseudo-Velocity Response Spectra

Parkfield Earthquake date $=28$ sep 4

Recording Station=CA:Parkfield: Middle Mountain: Transducer orientation $=90$

High-cut filter transition $=50$. to 60 . $\mathrm{Hz}$

Low-cut Butterworth filter at $0.03330 \mathrm{~Hz}$. roll-off param $=2$

Response Spectra Damping $=0.0,0.020,0.050,0.10,0.20$

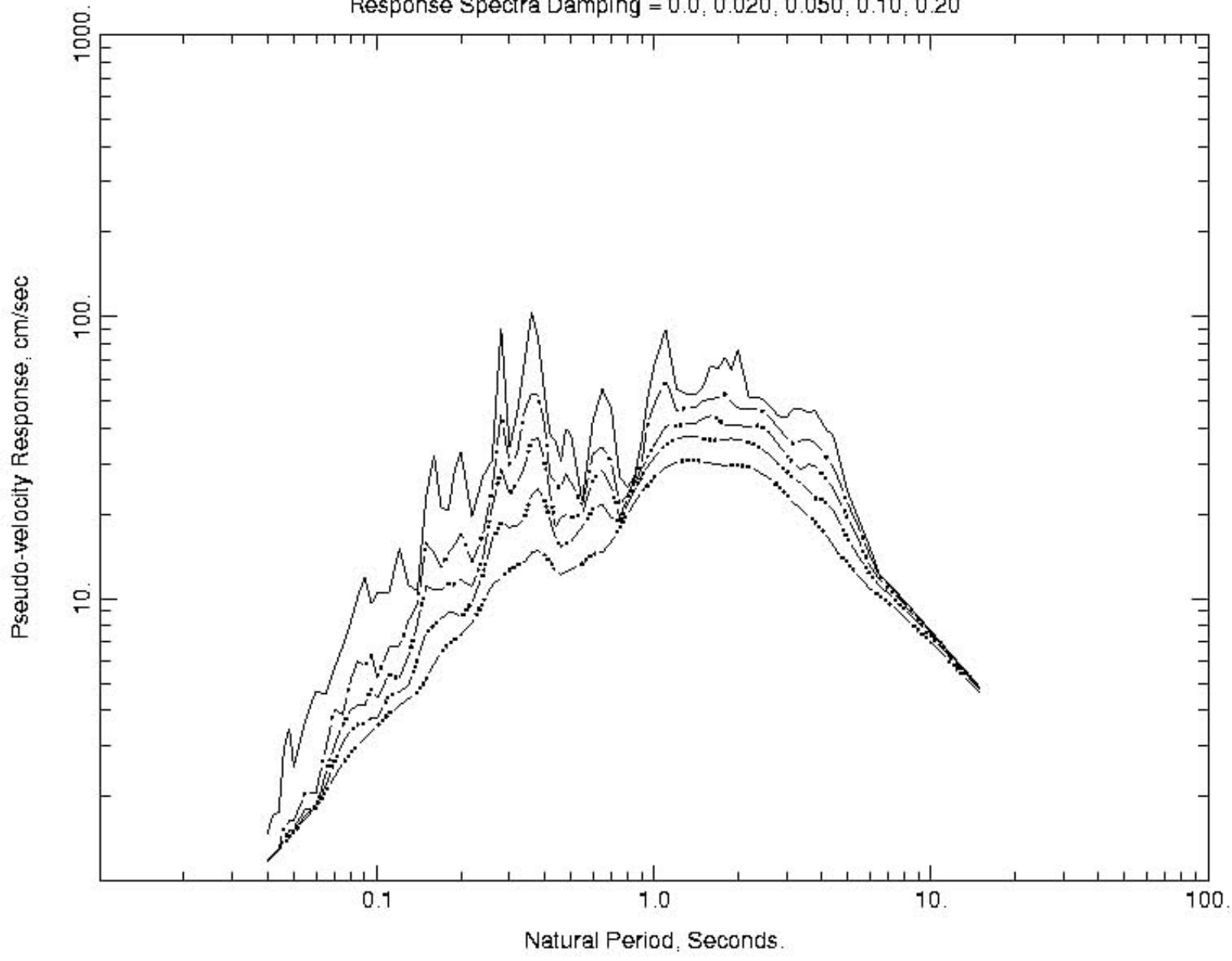

Figure 51. Pseudo velocity response spectra computed at the indicated levels of damping for the component of acceleration indicated and with the corresponding parameters indicated. 


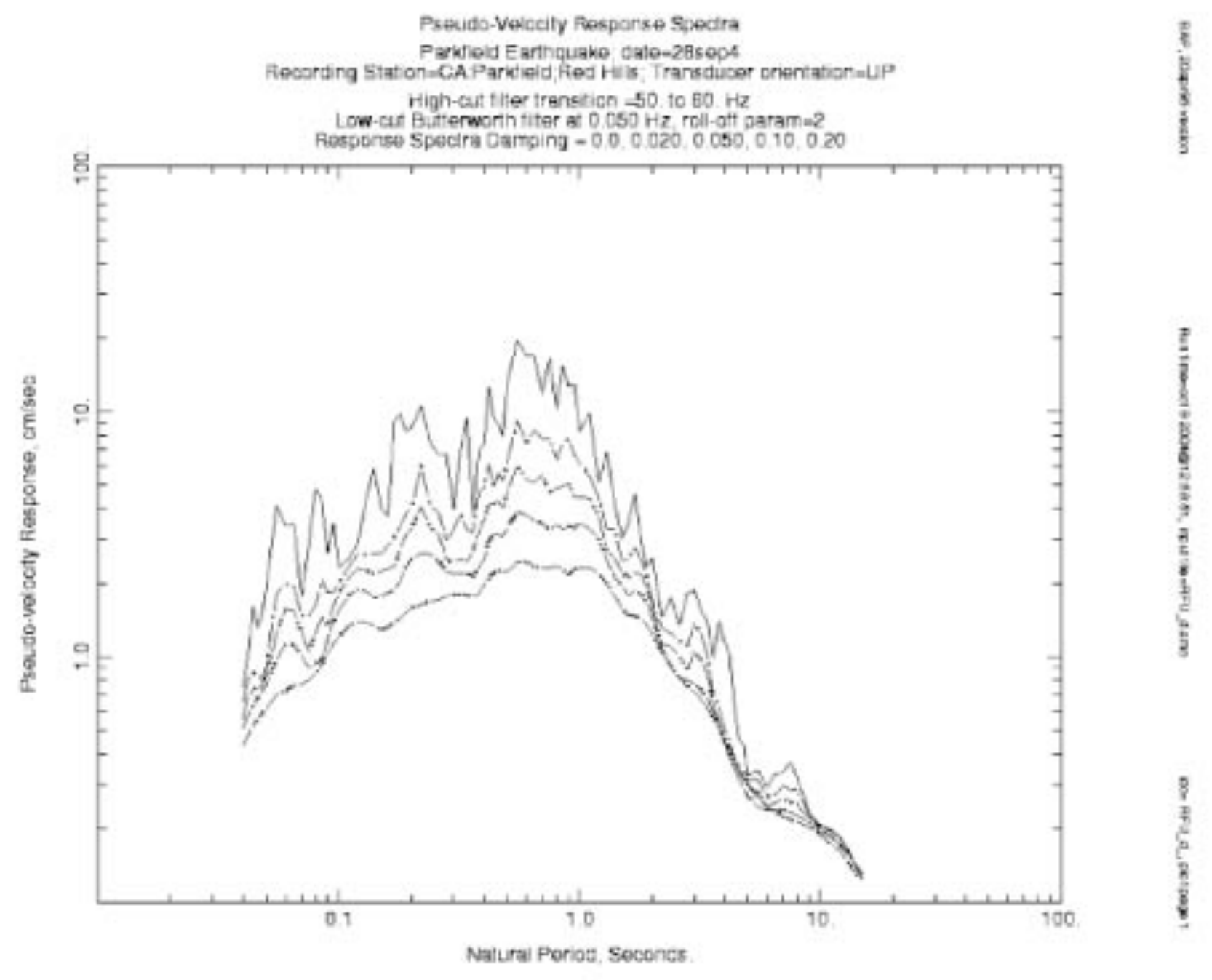

Figure 52. Pseudo velocity response spectra computed at the indicated levels of damping for the component of acceleration indicated and with the corresponding parameters indicated. 


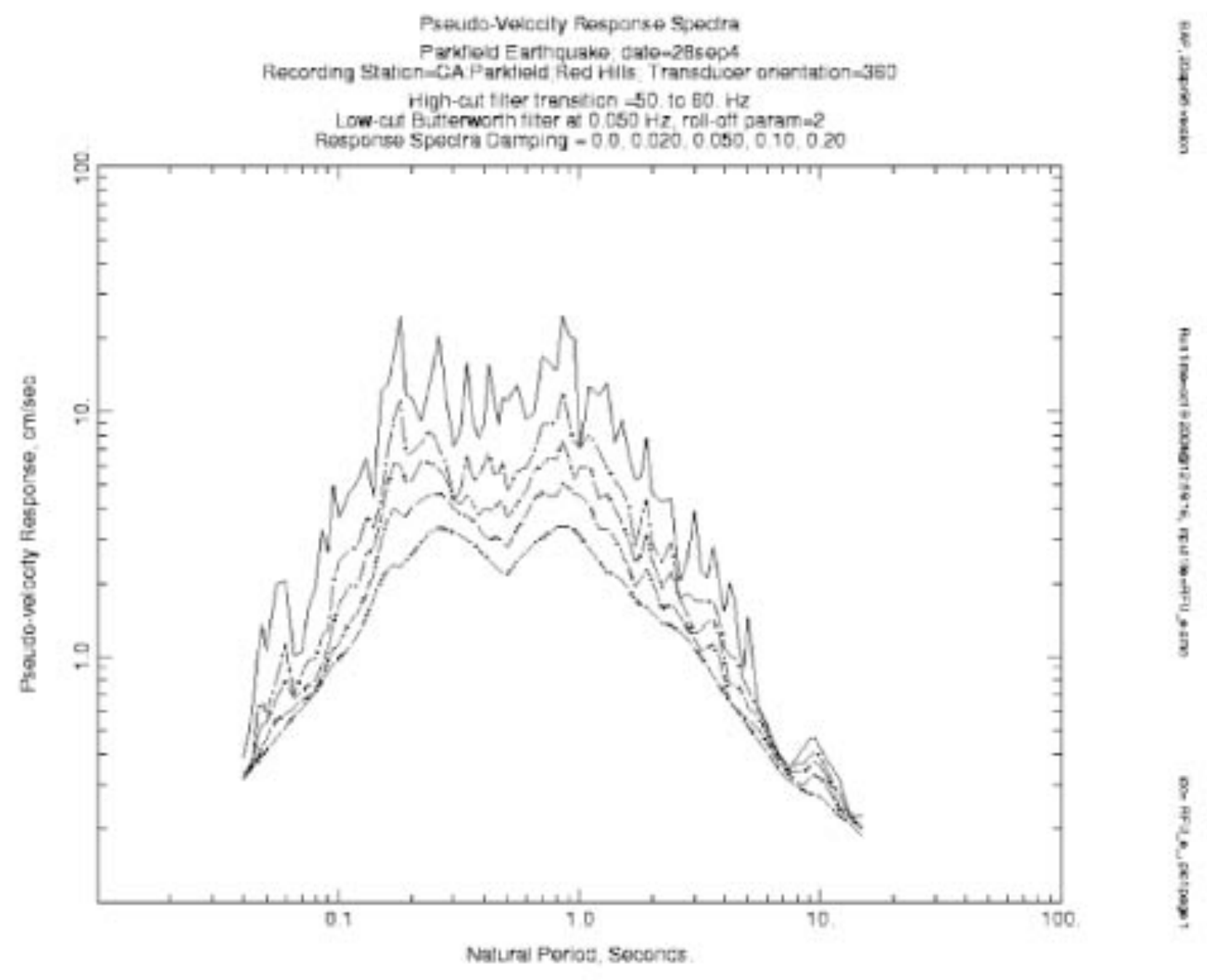

Figure 53. Pseudo velocity response spectra computed at the indicated levels of damping for the component of acceleration indicated and with the corresponding parameters indicated. 


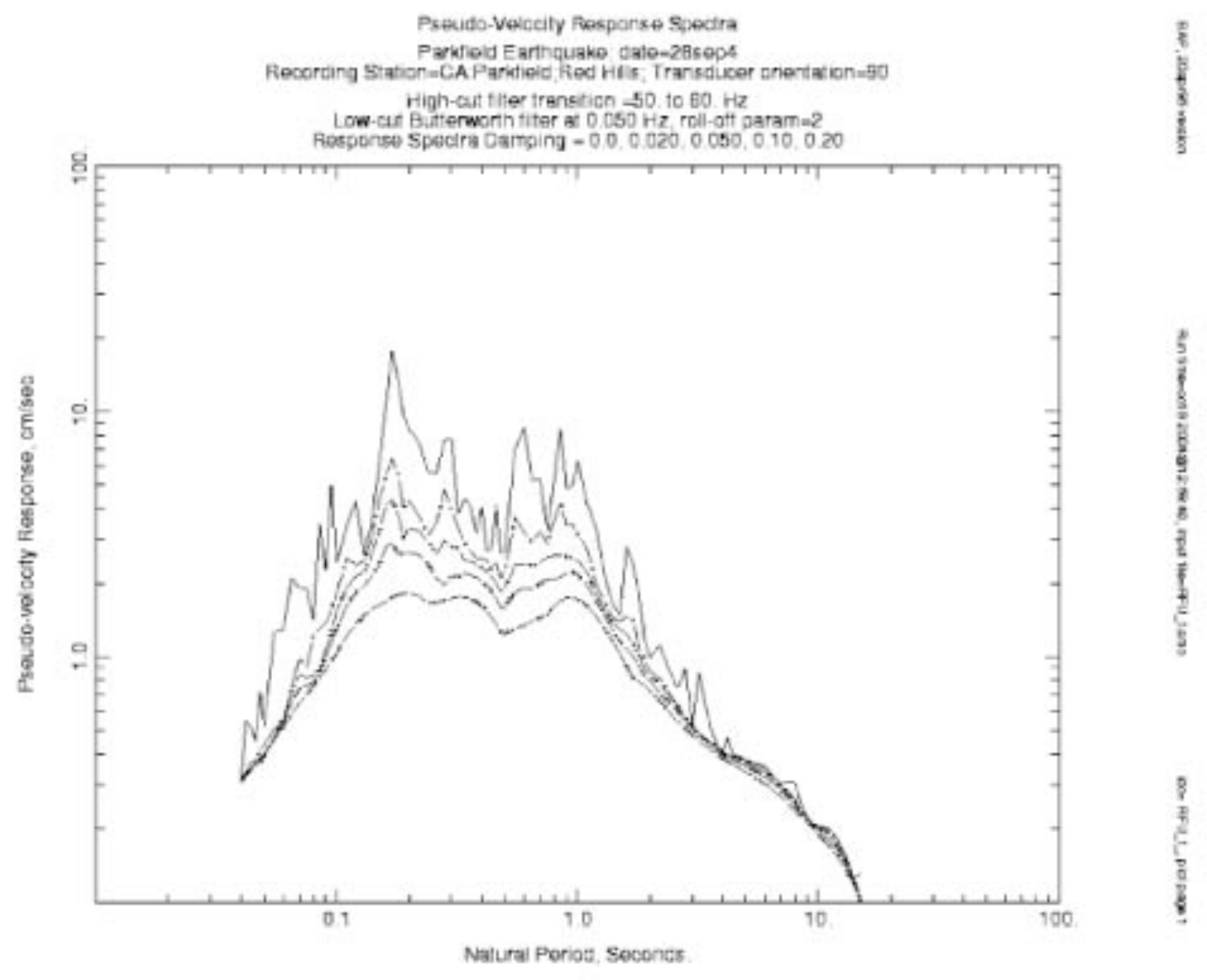

Figure 54. Pseudo velocity response spectra computed at the indicated levels of damping for the component of acceleration indicated and with the corresponding parameters indicated. 
High-cut filter transition $=50$. to $60 . \mathrm{Hz}$

Low-cut Butterworth filter at $0.040 \mathrm{~Hz}$, roll-off param $=2$

Response Spectra Damping $=0.0,0.020,0.050,0.10,0.20$

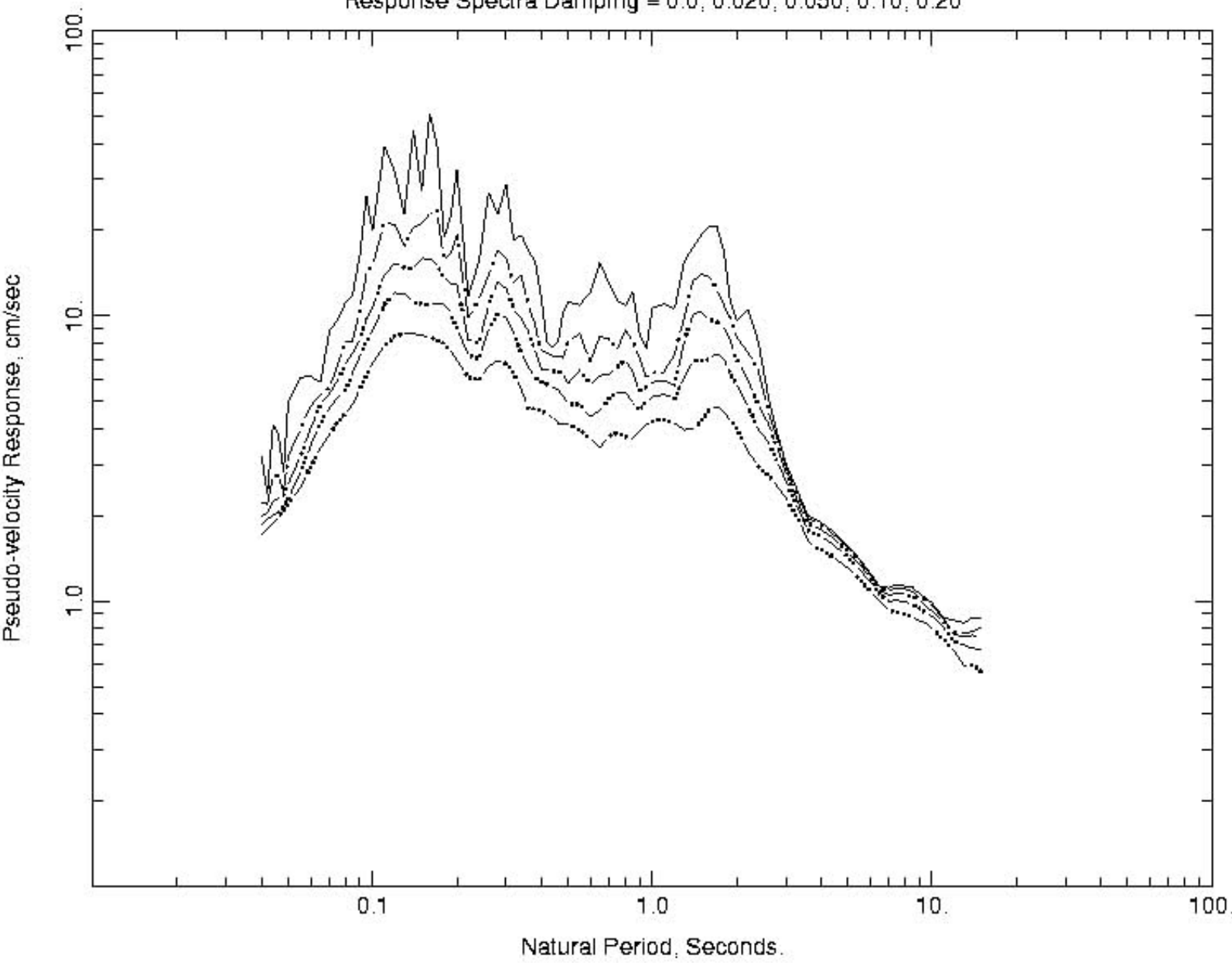

Figure 55. Pseudo velocity response spectra computed at the indicated levels of damping for the component of acceleration indicated and with the corresponding parameters indicated. 
Pseudo-Velocity Response Spectra

Parkfield Earthquake: date $=28 \mathrm{sep} 4$

Recording Station=CA:Parkfield :Stockdale Mtn; Transducer orientation=270

High-cut filter transition $=50$. to 60 . $\mathrm{Hz}$

ow-cut Butterworth filter at $0.040 \mathrm{~Hz}$ -

Response Spectra Damping $=0.0,0.020,0.050,0.10,0.20$

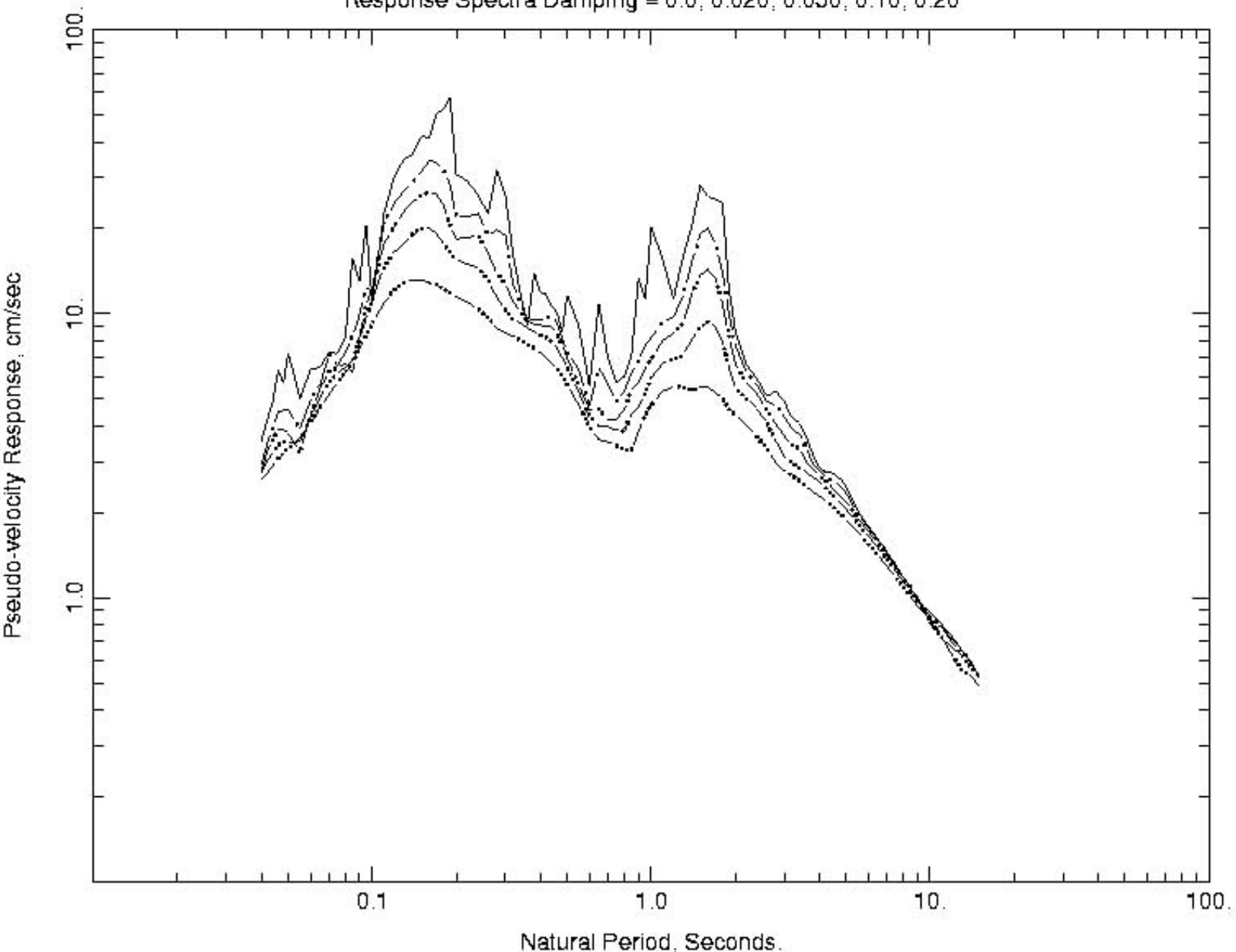

Figure 56. Pseudo velocity response spectra computed at the indicated levels of damping for the component of acceleration indicated and with the corresponding parameters indicated. 


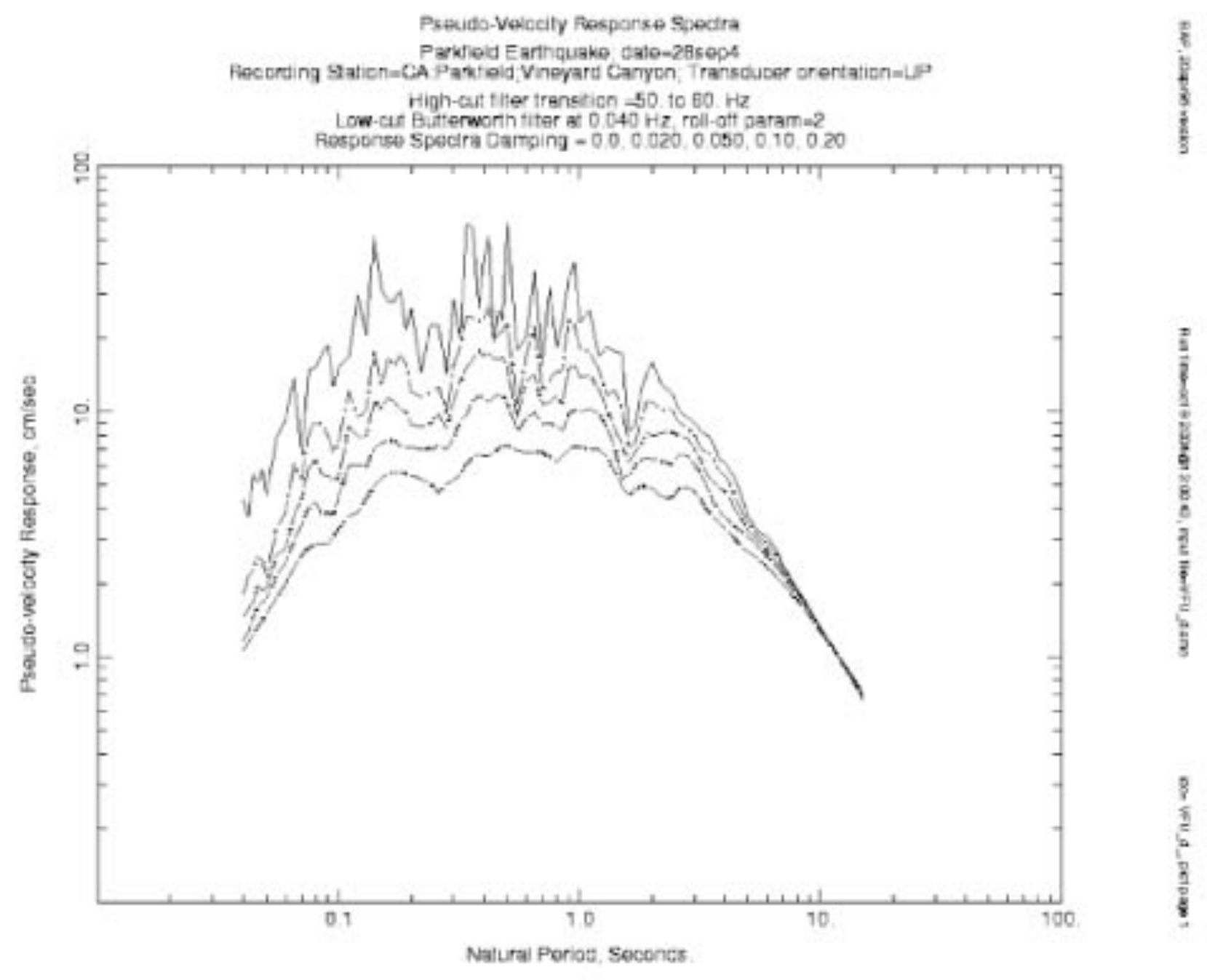

Figure 57. Pseudo velocity response spectra computed at the indicated levels of damping for the component of acceleration indicated and with the corresponding parameters indicated. 


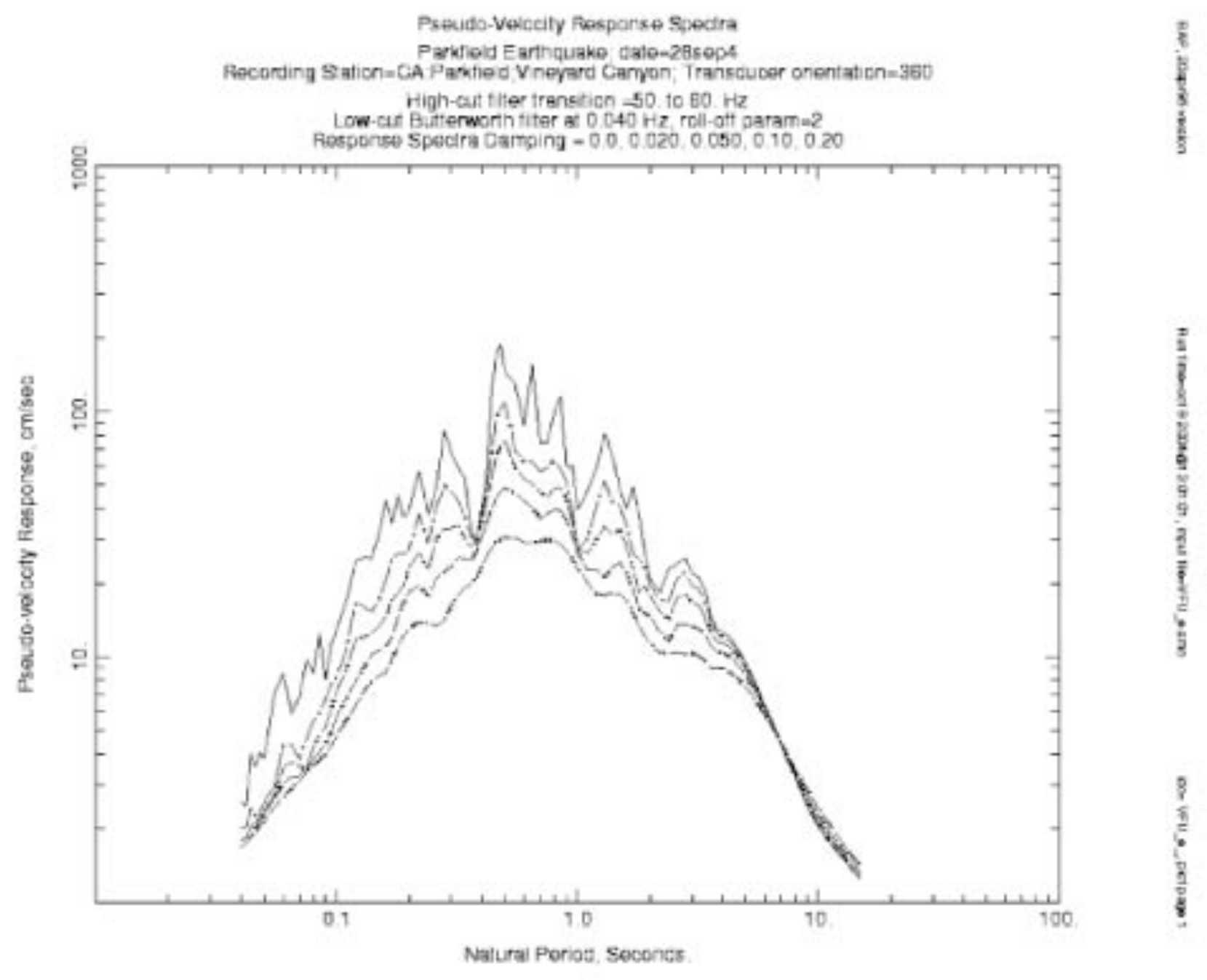

Figure 58. Pseudo velocity response spectra computed at the indicated levels of damping for the component of acceleration indicated and with the corresponding parameters indicated. 


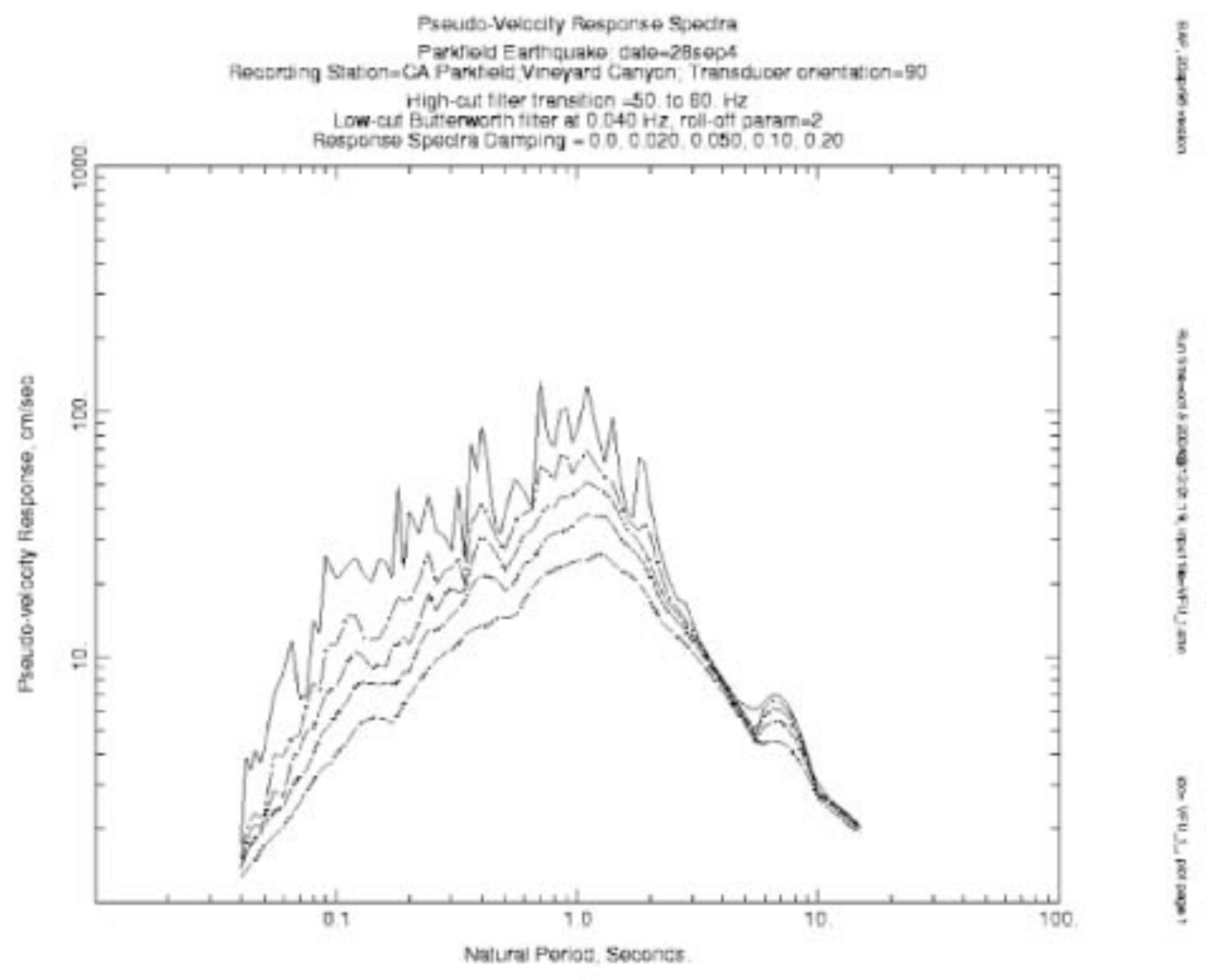

Figure 59. Pseudo velocity response spectra computed at the indicated levels of damping for the component of acceleration indicated and with the corresponding parameters indicated. 


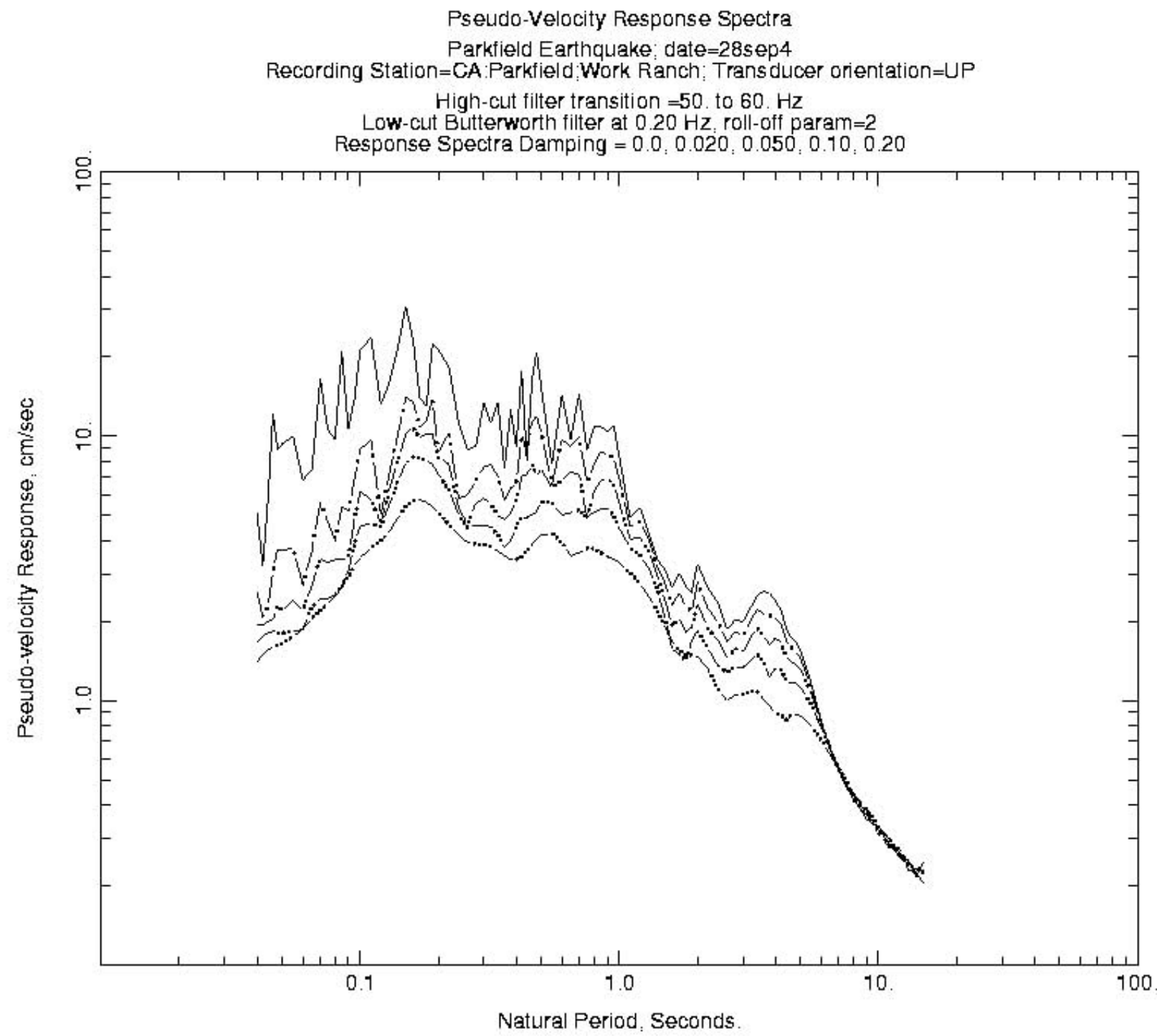

Figure 60. Pseudo velocity response spectra computed at the indicated levels of damping for the component of acceleration indicated and with the corresponding parameters indicated. 
Pseudo-Velocity Response Spectra

Parkfield Earthquake date $=28 \mathrm{sep} 4$

Recording Station=CA: Parkfield Work Ranch: Transducer orientation $=90$

High-cut filter transition $=50$. to $60 . \mathrm{Hz}$

Low-cut Butterworth filter at $0.20 \mathrm{~Hz}$, roll-off param $=2$

Response Spectra Damping $=0.0,0.020,0.050,0.10,0.20$

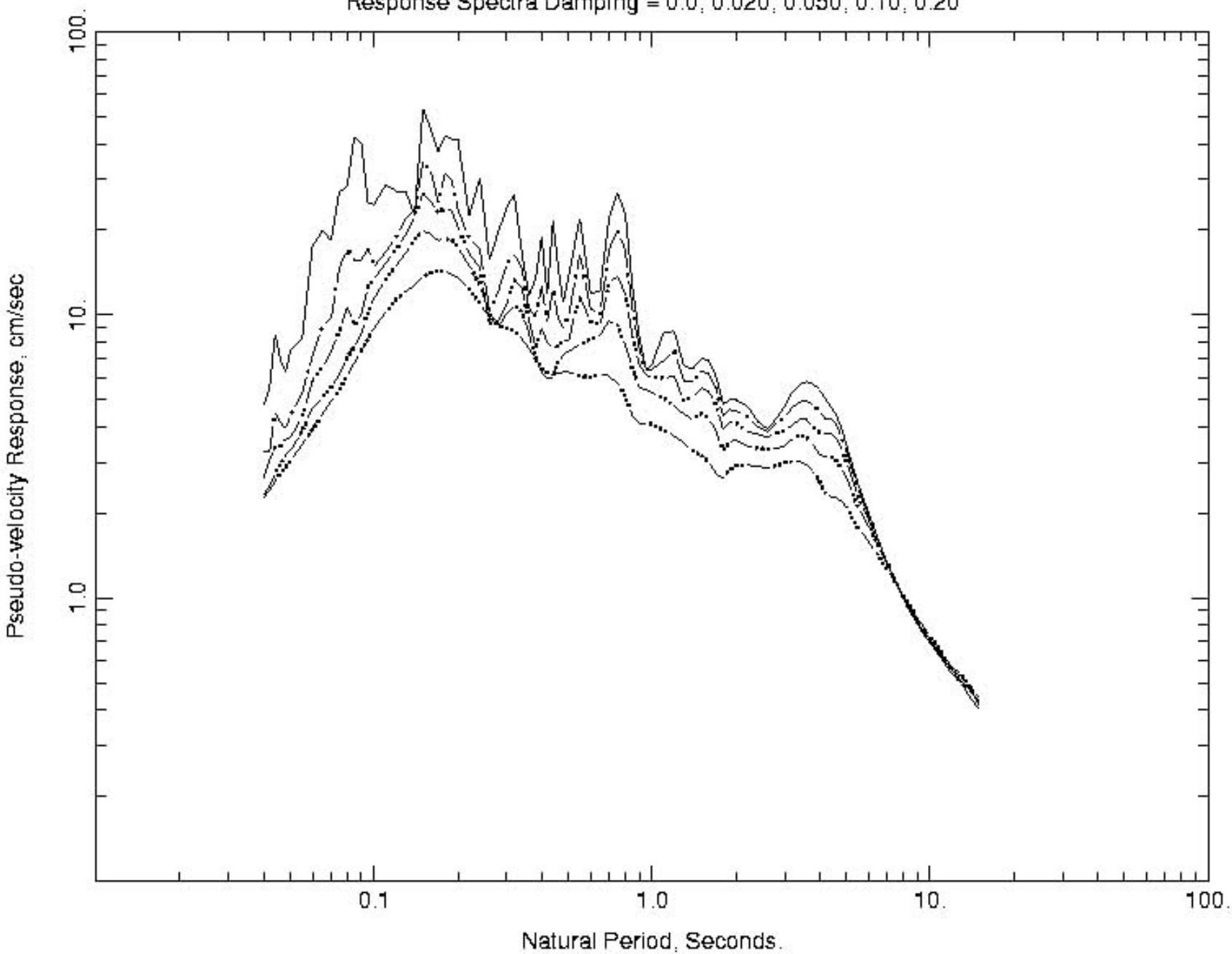

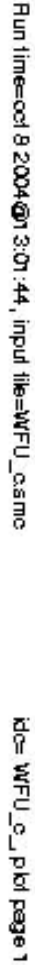

Figure 61. Pseudo velocity response spectra computed at the indicated levels of damping for the component of acceleration indicated and with the corresponding parameters indicated. 


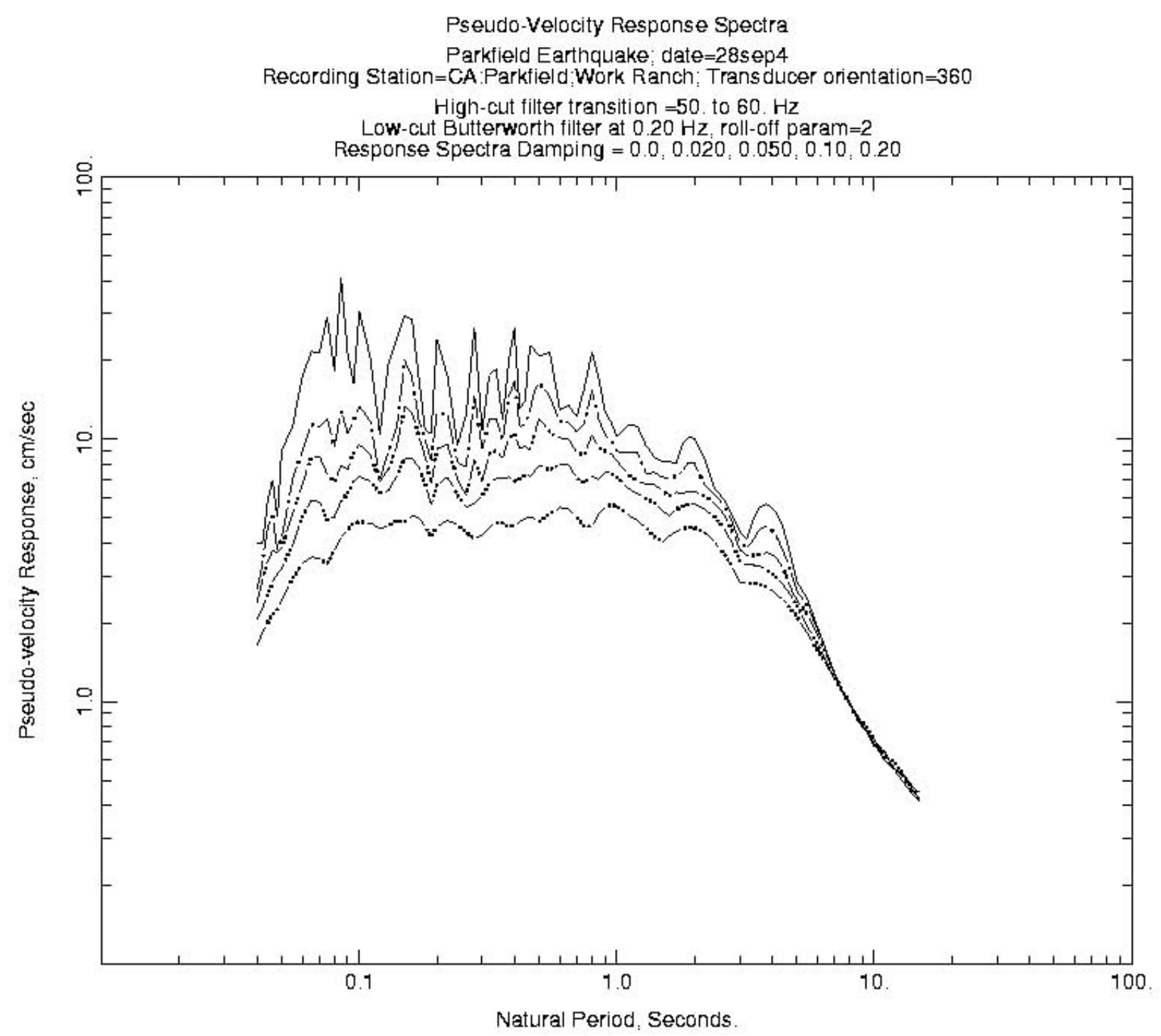

Figure 62. Pseudo velocity response spectra computed at the indicated levels of damping for the component of acceleration indicated and with the corresponding parameters indicated. 
PARKFIELD : CA EARTHQUAKE: date $=28 \mathrm{sep} 4$

Recording Station=CA:Parkfield: Donna Lee: Transducer orientation=UP

High-cut filter transition $=50$. to $60 . \mathrm{Hz}$

Low-cut Butterworth filter at $0.050 \mathrm{~Hz}$. roll-off param $=2$

Response Spectra Damping $=0.0,0.020,0.050,0.10,0.20$

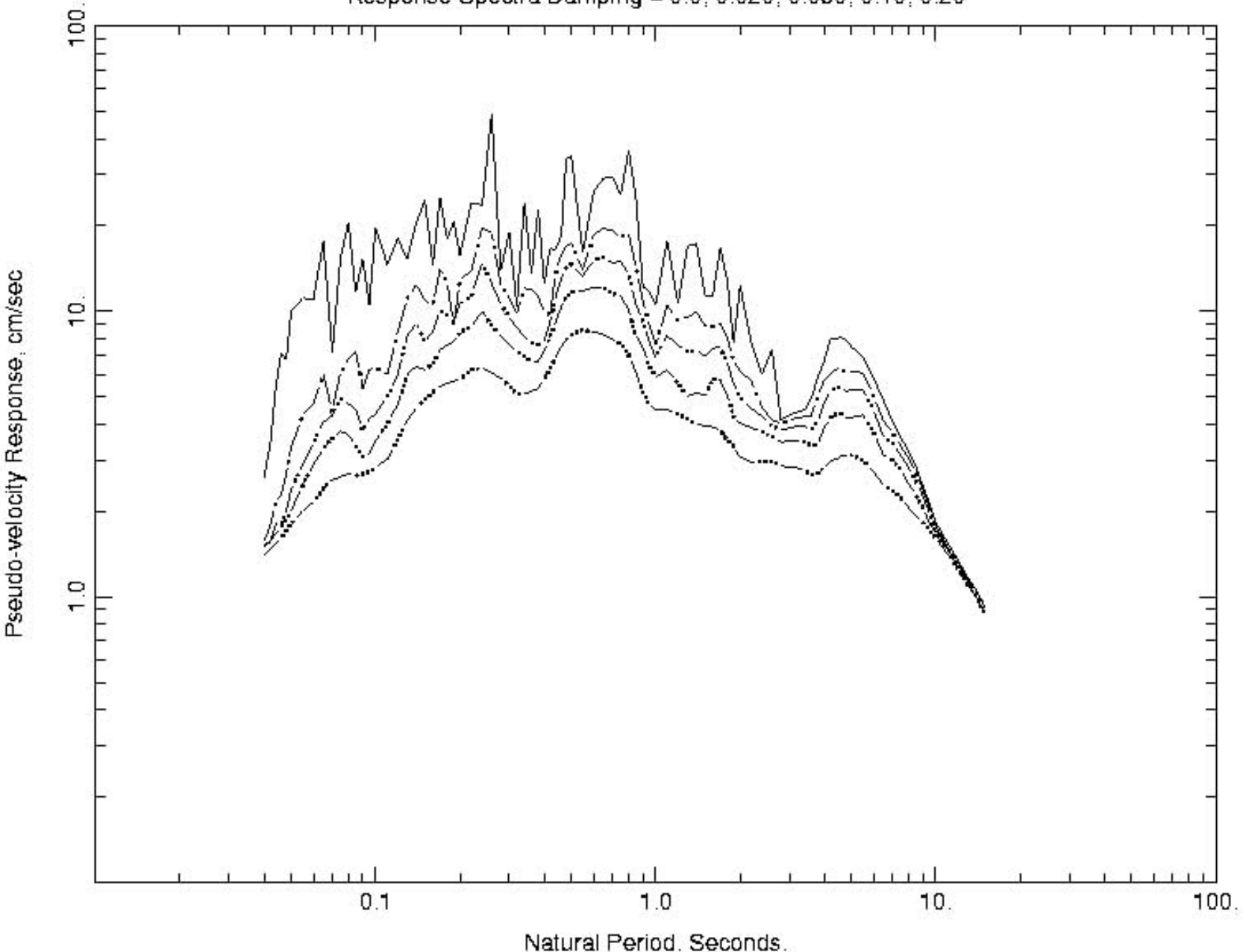

Figure 63. Pseudo velocity response spectra computed at the indicated levels of damping for the component of acceleration indicated and with the corresponding parameters indicated. 
Pseudo-Velocity Response Spectra

PARKFIELD CA EARTHQUAKE date $=28 \mathrm{sep} 4$

Recording Station=CA:Parkfield: Donna Lee Transducer orientation=360

High-cut filter transition $=50$. to $60 . \mathrm{Hz}$

Low-cut Butterworth filter at $0.050 \mathrm{~Hz}$, roll-off param $=2$

Response Spectra Damping $=0.0,0.020,0.050,0.10,0.20$

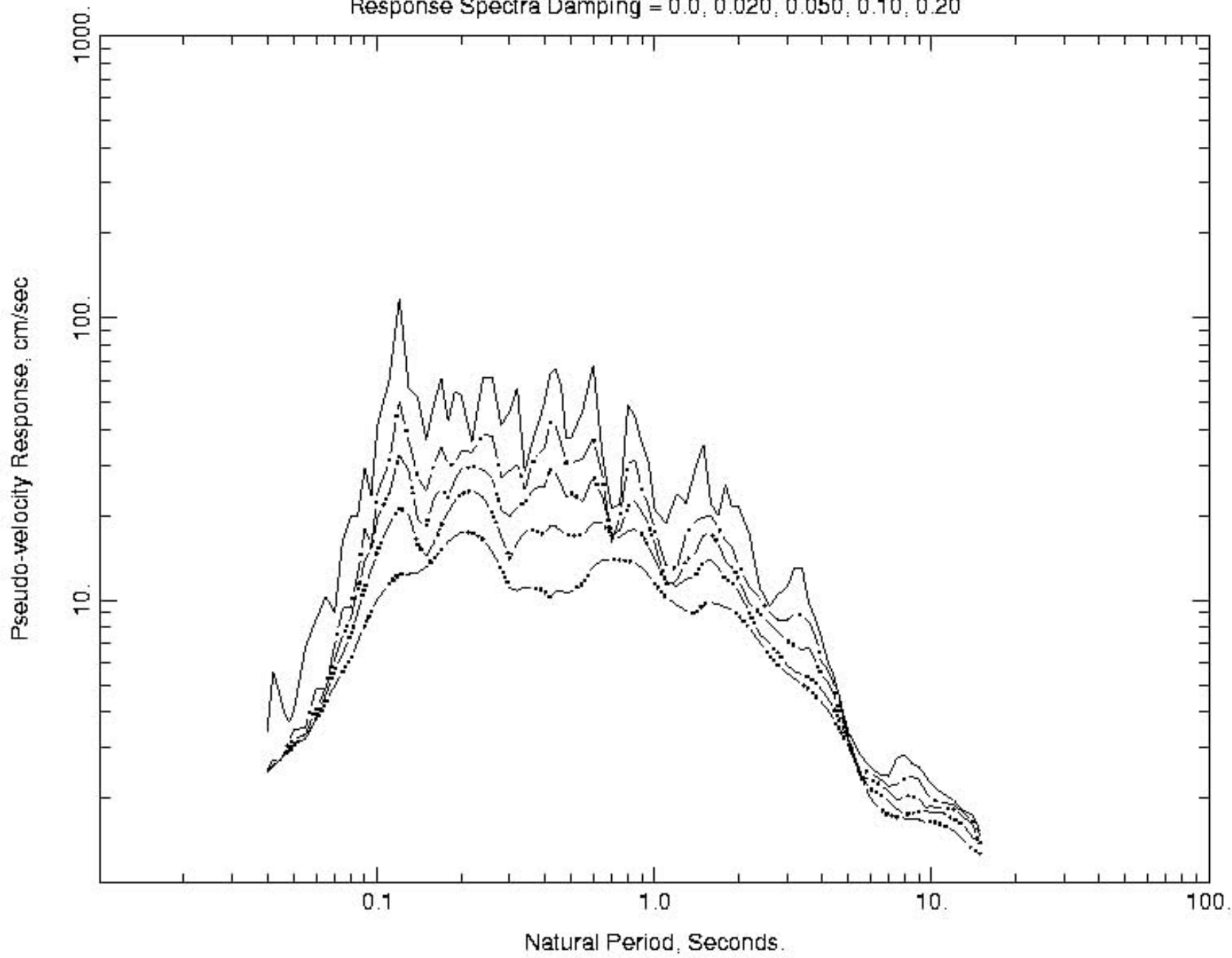

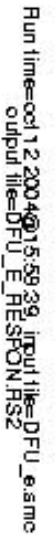

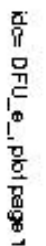

Figure 64. Pseudo velocity response spectra computed at the indicated levels of damping for the component of acceleration indicated and with the corresponding parameters indicated. 
PARKFIELD CA EARTHQUAKE: date $=28 \mathrm{sep} 4$

Recording Station=CA:Parkfield: Donna Lee Transducer orientation=90

High-cut filter transition $=50$. to $60 . \mathrm{Hz}$

Low-cut Butterworth filter at $0.050 \mathrm{~Hz}$, roll-off param $=2$

Response Spectra Damping $=0.0,0.020,0.050,0.10,0.20$

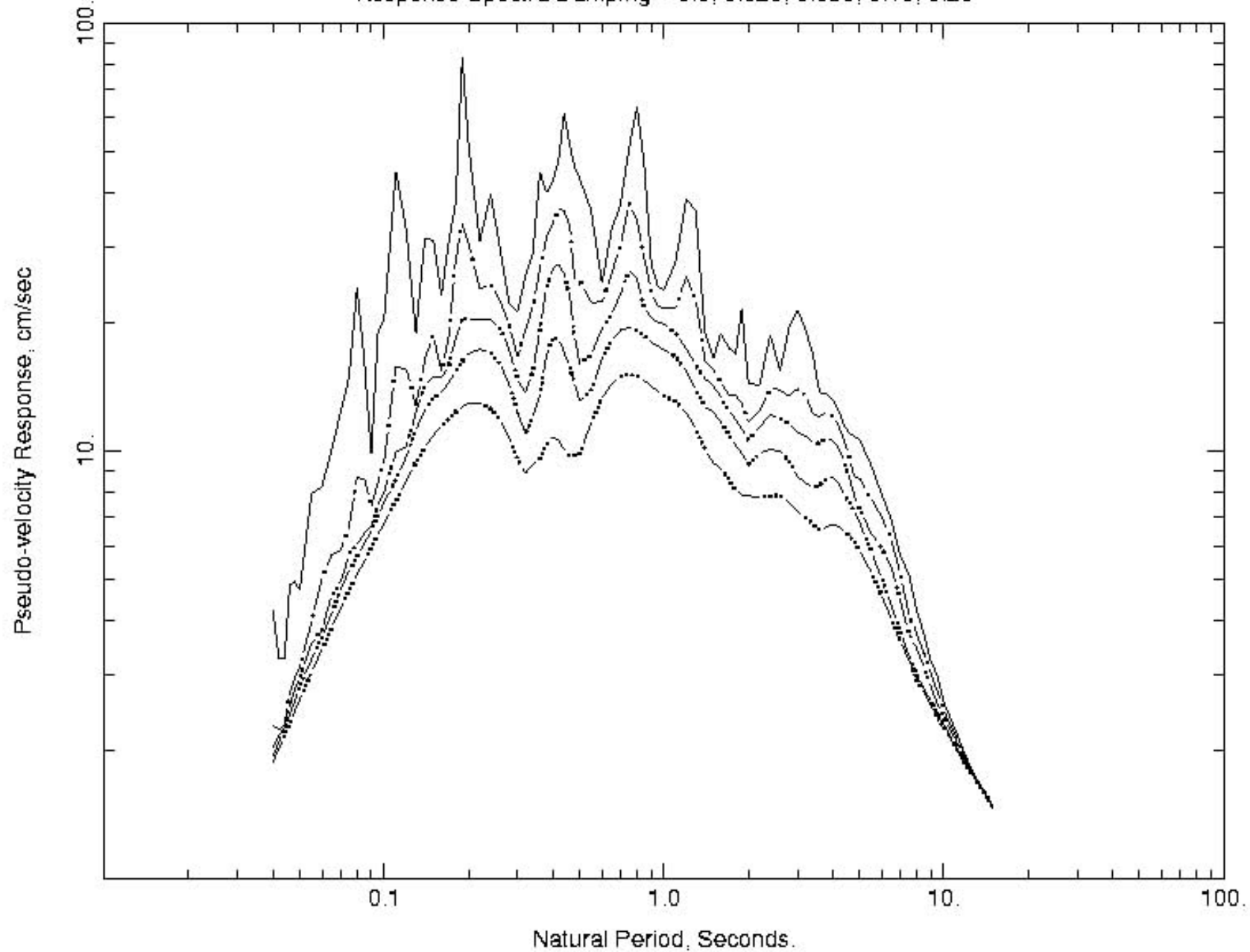

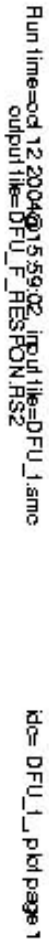

Figure 65. Pseudo velocity response spectra computed at the indicated levels of damping for the component of acceleration indicated and with the corresponding parameters indicated. 